\title{
ESTABILIDADE FOTOXIDATIVA DOS ÓLEOS DE SOJA, MILHO E CANOLA.
}

\author{
Fabiana Maria de Siqueira \\ Engenheiro Agrônomo
}

Orientadora: Profa. Dra. MARISA A. B. REGITANO D'ARCE

Dissertação apresentada à Escola Superior de Agricultura 'Luiz de Queiroz', Universidade de São Paulo, para obtenção do título de Mestre em Ciências, Área de Concentração: Ciência e Tecnologia de Alimentos.

\author{
PIRACICABA \\ Estado de São Paulo - Brasil \\ Fevereiro - 1998
}


Dados Internacionais de Catalogação na Publicação (CIP)

DIVISÃO DE BIBLIOTECA E D.OCUMENTAÇÃO - Campus "Luiz de Queiroz"/USP

Siqueira, Fabiana Maria de

Estabilidade fotoxidativa dos óleos de soja, milho e canola / Fabiana Maria de Siqueira. - Piracicaba, 1998.

$91 \mathrm{p}$.

Dissertaçăo (mestrado) - Escola Superior de Agricultura Luiz de Queiroz, 1998.

Bibliografia.

1. Fotoxidação 2. Óleo de colza 3. Óleo de milho 4. Óleo de soja 5. Óleo vegetal I. Título 


\section{.ESTABILIDADE FOTOXIDATIVA DOS ÓLEOS DE SOJA, MILHO E CANOLA.}

FABIANA MARIA DE SIQUEIRA

Aprovada em: 13. 04. 1998

Comissão julgadora:

Profa. Dra. Marisa A. B. Regitano d'Arce ESALQ/ USP

Prof. Dr. Luiz Eduardo Gutierrez ESALQ/ USP

Prof. Dr. Arnaldo Antonio Rodella ESALQ/ USP

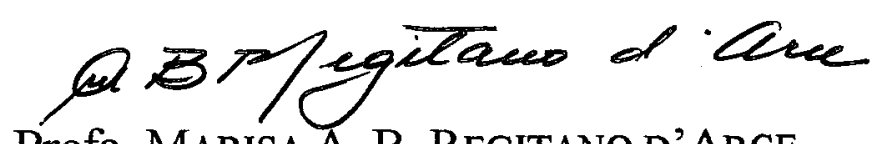

Profa. MARISA A. B. Regitano D'ARCE Orientadora 


\section{DEDICO}

Ao meu pai JOSÉ e à minha mãe MERCEDES pelo incentivo e apoio em todos os momentos e pelo esforço em minha educação

Ao SAMUEL pelo carinho e apoio durante toda esta etapa 


\section{AGRADECIMENTOS}

A Deus por mais esta realização na minha vida.

À Profa. Dra Marisa A. B. Regitano d'Arce pela amizade, orientação e incentivo à elaboração deste trabalho e oportunidade desta especialização profissional.

À Escola Superior de Agricultura "Luiz de Queiroz", em particular ao docentes e funcionários do Departamento de Ciência e Tecnologia Agroindustrial pela ajuda prestada para o desenvolvimento deste trabalho.

Ao Conselho Nacional de Desenvolvimento Científico e Tecnológico $(\mathrm{CNPq})$, pelo auxílio financeiro concedido através da bolsa de estudo.

Às indústrias de óleos Cargill Agrícola S.A. (Unidade de Mairinque), Refino de Óleos Brasil Ltda e a COCAMAR - Cooperativa de Cafeicultores e Agropecuária de Maringá Ltda pelo fornecimento dos óleos usados nesse trabalho e a Rhodia-Ster pelo fornecimento das embalagens.

Aos meus irmãos José Antonio, Almir e Amauri pelo carinho e amizade. 
À técnica Maria Fernanda de Almeida Prado pelo auxílio técnico e pela amizade.

Aos colegas Carlos Magno Evangelista, Érica M: Roel Gutierrez, Mariana Micotti da Glória, Sílvia M. Ferreira Carpi, Renata Franco de Almeida e Thaís M. Souza Vieira.

A todos que direta ou indiretamente contribuíram para a elaboração deste trabalho. 


\section{SUMÁRIO}

Página

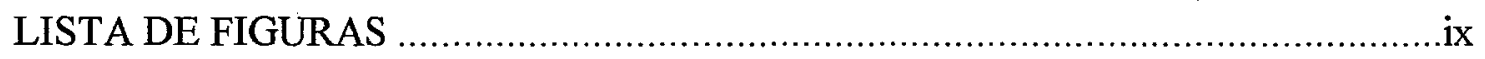

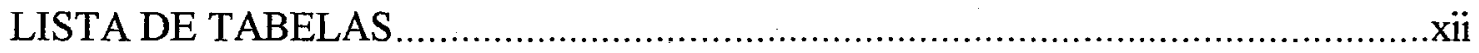

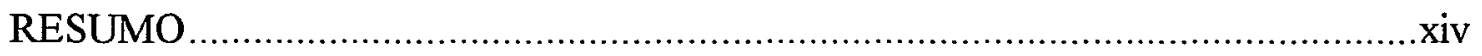

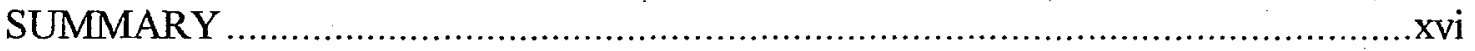

1 INTRODUÇÃO

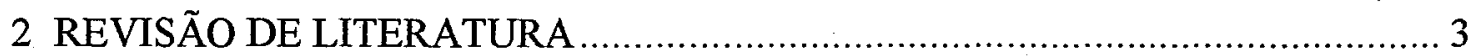

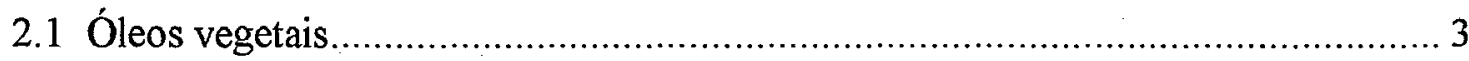

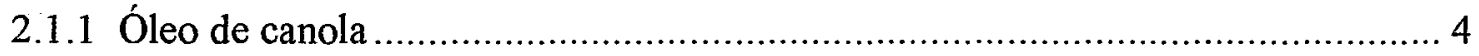

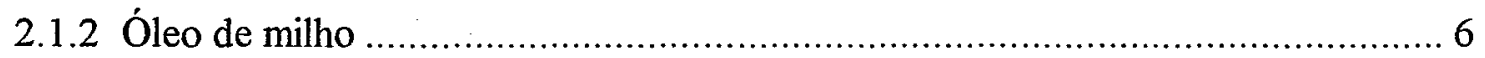

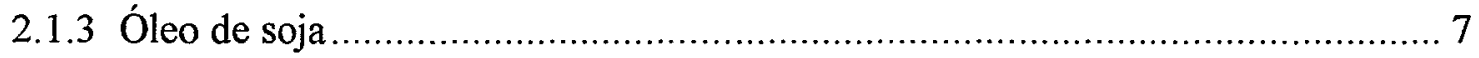

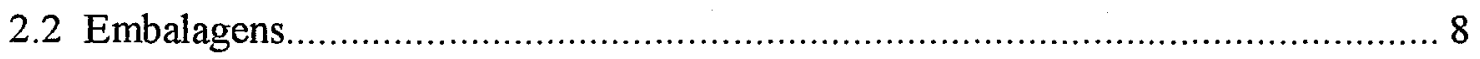

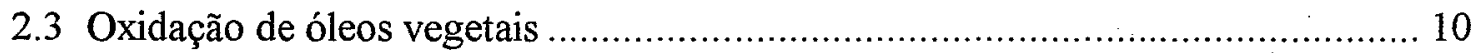

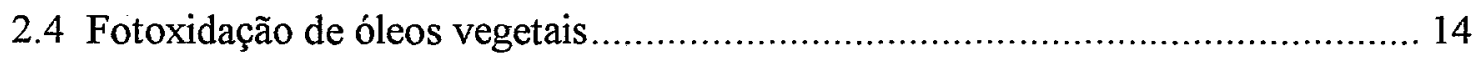

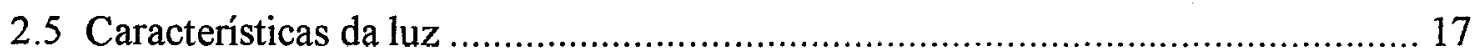

2.6 Testes acelerados para acompanhamento da fotoxidação ..................................... 19

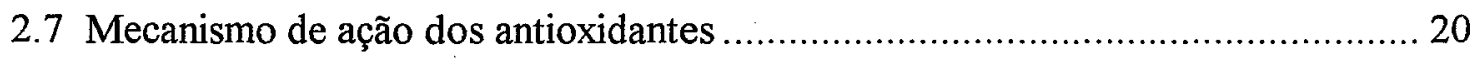

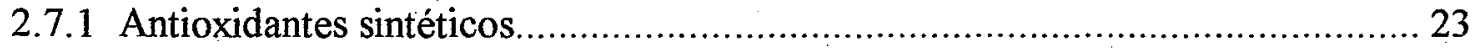

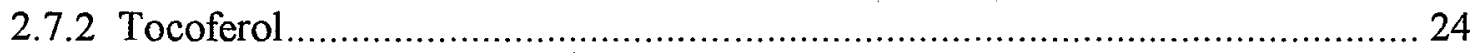

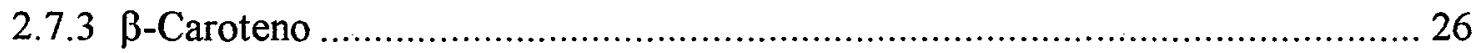

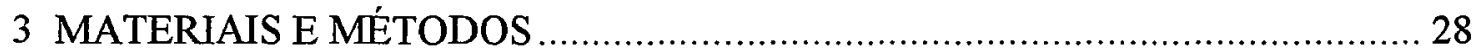

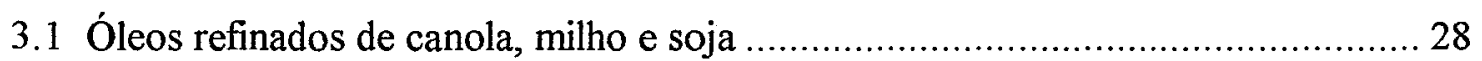

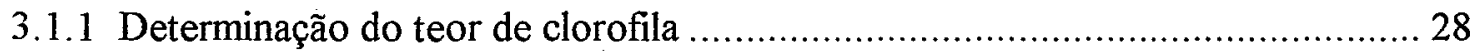

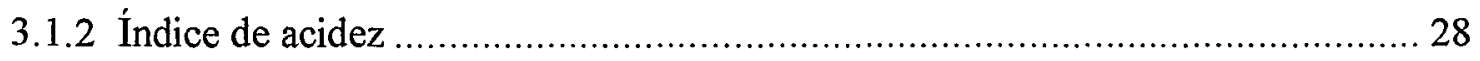

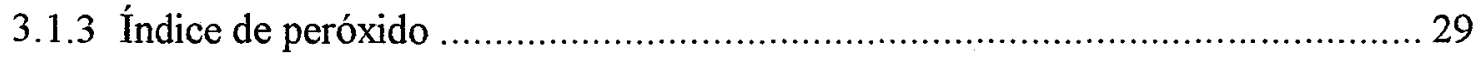

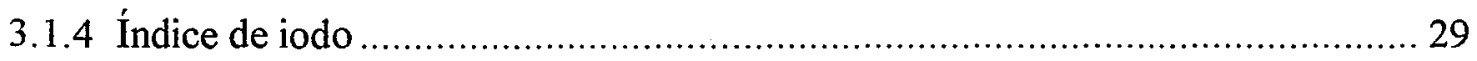

3.1.5 Exame espectrofotométrico sob luz ultravioleta......................................... 30

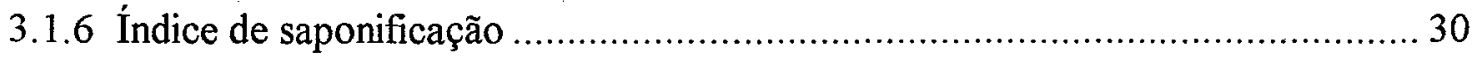




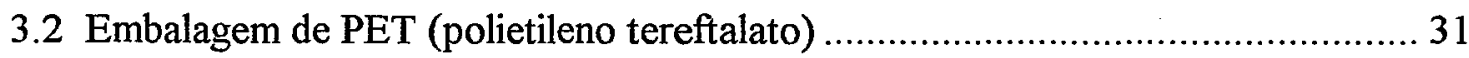

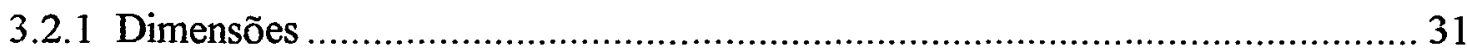

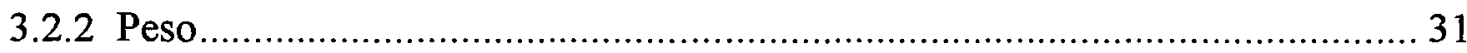

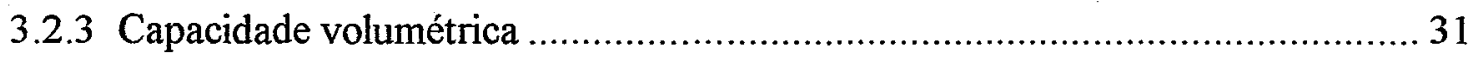

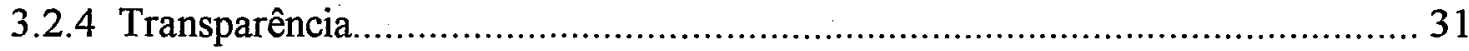

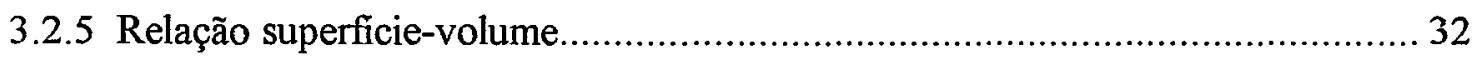

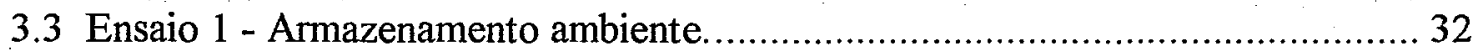

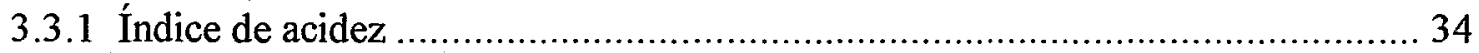

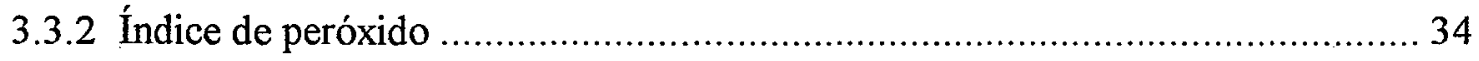

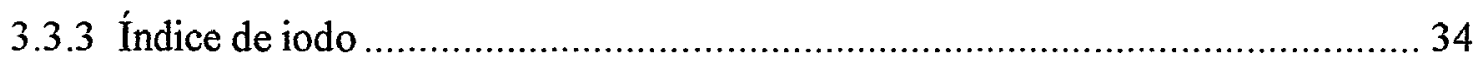

3.3.4 Exame espectrofotométrico sob luz ultravioleta......................................... 34

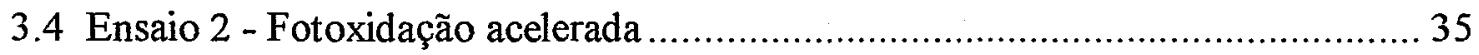

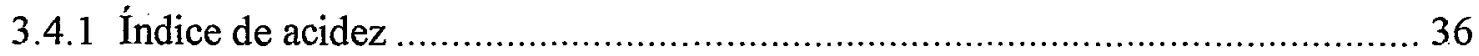

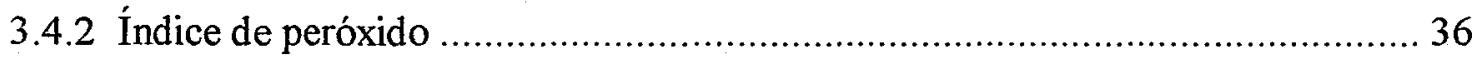

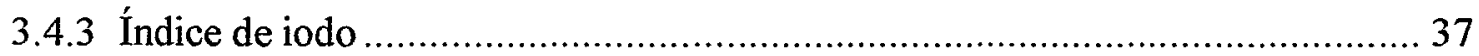

3.4.4 Exame espectrofotométrico sob luz ultravioleta........................................... 37

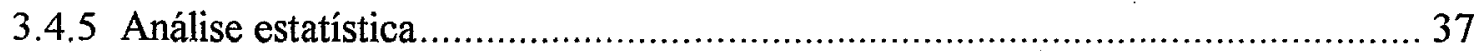

3.5 Ensaio 3 - Atividade antioxidante de $\beta$-caroteno, $\alpha$-tocoferol e TBHQ............... 37

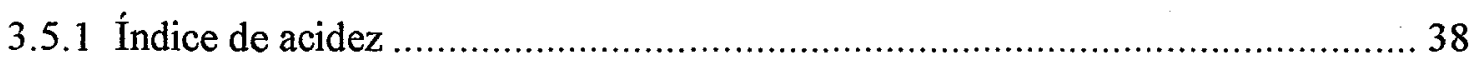

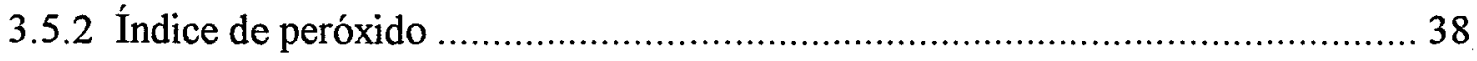

3.5.3 Exame espectrofotométrico sob luz ultravioleta........................................... 38

3.5.4 Absorbância dos óleos de canola, milho e soja no espectro visível .................. 38

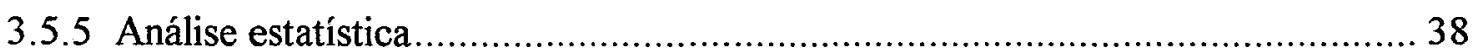

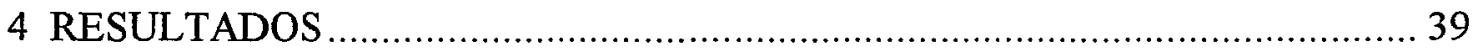

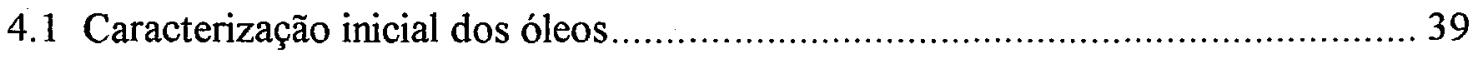

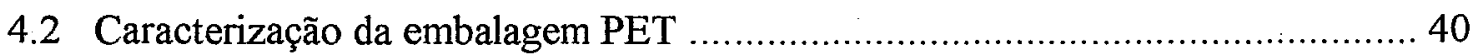

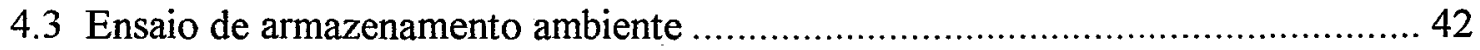

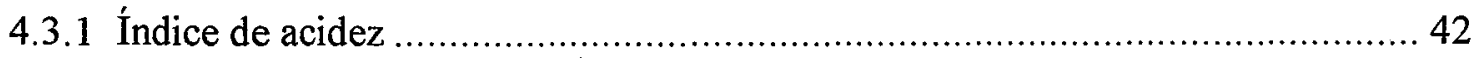

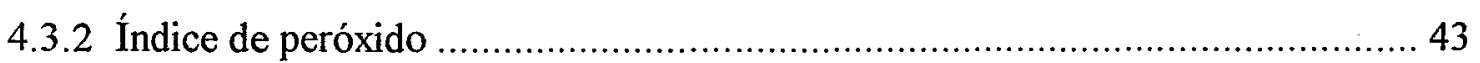

4.3.3 Exame espectrofotométrico sob luz ultravioleta........................................... 45 


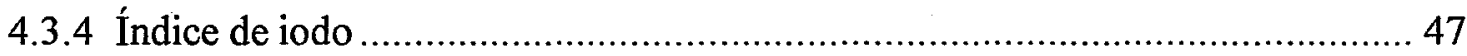

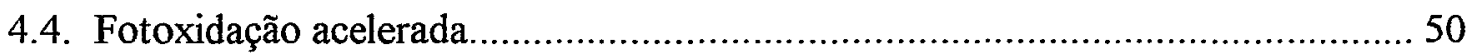

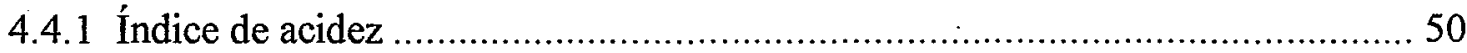

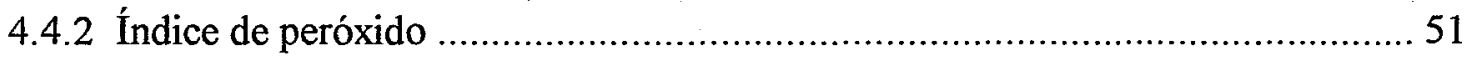

4.4.2.1 Comparação entre os óleos de canola, milho e soja sob luz sem a adição de

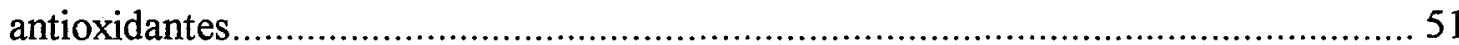

4.4.2.2 Comparação do índice de peróxido dos óleos de canola, milho e soja sob luz

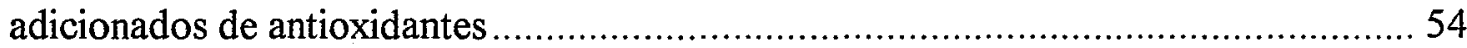

4.4.3. Exame espectrofotométrico sob luz ultravioleta......................................... 55

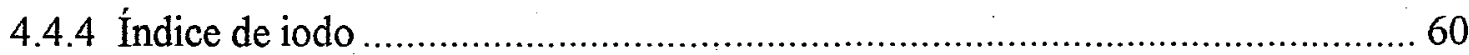

4.5 Correlação entre armazenamento ambiente e fotoxidação acelerada.................... 62

4.6 Atividade antioxidante de $\beta$-caroteno, $\alpha$-tocoferol e TBHQ............................... 64

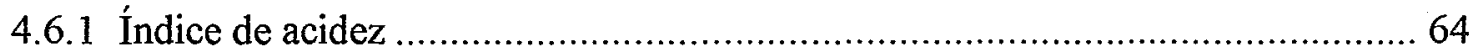

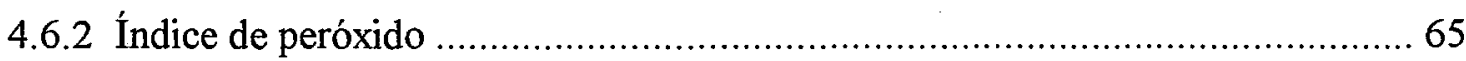

4.6.2.1 Comparação entre todos os tratamentos testados na fotoxidação acelerada... 69

4.6.3 Exame espectrofotométrico sob luz ultravioleta............................................ 71

4.6.4 Espectro de absorção dos óleos adicionados de $\beta$-caroteno ............................... 76

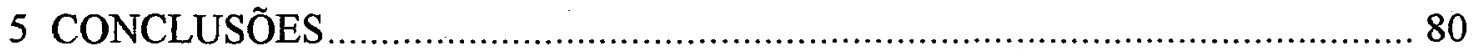

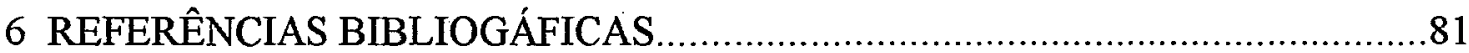




\section{LISTA DE FIGURAS}

Página

1 Esquema geral do mecanismo da oxidação lipídica. 12

2 Armazenamento dos óleos de canola, milho e soja embalados em frascos PET sob condições ambientes (Laboratório de Óleos e Gorduras -ESALQ/USP). 33

3 Curvas de Umidade Relativa (\%) e Temperaturas médias $\left({ }^{\circ} \mathrm{C}\right)$ ao longo dos meses de armazenamento ambiente. 33

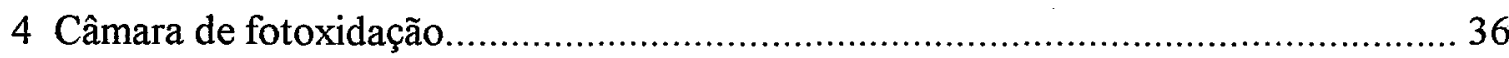

5 Variação da transmitância da embalagem de PET com a variação do comprimento... 41

6 Índice de iodo ( $\mathrm{mg}$ de iodo/ $100 \mathrm{mg}$ de óleo) do óleo de canola embalado em frascos PET e armazenado sob condições ambientes.

7 Índice de iodo ( $\mathrm{mg}$ de iodo/ $100 \mathrm{mg}$ de óleo) do óleo de milho embalado em frascos PET e armazenado sob condições ambientes. 49

8 Índice de iodo (mg de iodo/ $100 \mathrm{mg}$ de óleo) do óleo de soja embalado em frascos de PET e armazenado sob condições ambientes. 49

9 Comportamento dos óleos de canola, milho e soja em câmara de fotoxidação sem adição de antioxidantes após diferentes tempos de exposição à luz (índice de peróxido meq $\mathrm{O} 2 / \mathrm{kg}$ de óleo). 52

10 Correlação entre índice de peróxido e coeficiente de extinção em $232 \mathrm{~nm}$ do óleo de canola sob fotoxidação acelerada. 58

11 Correlação entre índice de peróxido e coeficiente de extinção em $232 \mathrm{~nm}$ do óleo de milho sob fotoxidação acelerada.

12 Correlação entre índice de peróxido e coeficiente de extinção em $232 \mathrm{~nm}$ do óleo de soja sob fotoxidação acelerada. 
13 Índice de iodo (mg de iodo/ $100 \mathrm{mg}$ ) do óleo de canola submetido à fotoxidação acelerada por 120 horas.

14 Índice de iodo (mg de iodo/ $100 \mathrm{mg}$ ) do óleo de milho submetido à fotoxidação acelerada por 120 horas.

15 Índice de iodo (mg de iodo/ $100 \mathrm{mg}$ ) do óleo de soja submetido à fotoxidação acelerada por 120 horas.

16 Correlação entre armazenamento ambiente e teste acelerado de fotoxidação dos óleos de canola, milho e soja adicionados de diferentes antioxidantes. 63

17 Variação do índice de peróxido (meq $\mathrm{O} 2 / \mathrm{kg}$ de óleo) para o óleo de canola adicionado de $500 \mathrm{ppm}$ de $\alpha$-tocoferol, $1 \mathrm{ppm}$ de $\beta$-caroteno e $200 \mathrm{ppm}$ de TBHQ e submetido à fotoxidação acelerada 66

18 Variação do índice de peróxido (meq $\mathrm{O} 2 / \mathrm{kg}$ de óleo) para o óleo de milho adicionado de $500 \mathrm{ppm}$ de $\alpha$-tocoferol, $1 \mathrm{ppm}$ de $\beta$-caroteno e $200 \mathrm{ppm}$ de TBHQ e submetido à fotoxidação acelerada 67

19 Variação do índice de peróxido (meq $\mathrm{O} 2 / \mathrm{kg}$ de óleo) para o óleo de soja adicionado de $500 \mathrm{ppm}$ de $\alpha$-tocoferol, $1 \mathrm{ppm}$ de $\beta$-caroteno e $200 \mathrm{ppm}$ de TBHQ e submetido à fotoxidação acelerada 68

20 Variação do coeficiente de extinção em $232 \mathrm{~nm}$ para o óleo de canola adicionado de $500 \mathrm{ppm}$ de $\alpha$-tocoferol, $1 \mathrm{ppm}$ de $\beta$-caroteno e $200 \mathrm{ppm}$ de TBHQ e submetido à fotoxidação acelerada. 72

21 Variação do coeficiente de extinção em $232 \mathrm{~nm}$ para o óleo de milho adicionado de $500 \mathrm{ppm}$ de $\alpha$-tocoferol, $1 \mathrm{ppm}$ de $\beta$-caroteno e $200 \mathrm{ppm}$ de TBHQ e submetido à fotoxidação acelerada. 73

22 Variação do coeficiente de extinção em $232 \mathrm{~nm}$ para o óleo de soja adicionado de $500 \mathrm{ppm}$ de $\alpha$-tocoferol, $1 \mathrm{ppm}$ de $\beta$-caroteno e $200 \mathrm{ppm}$ de TBHQ e submetido à fotoxidação acelerada. 
23 Absorbância do óleo de canola no espectro visível $(400-700 \mathrm{~nm})$ com e sem a adição de $\beta$-caroteno

24 Absorbância do óleo de milho no espectro visível (400 - $700 \mathrm{~nm})$. com e sem a adição de $\beta$-caroteno. 78

25 Absorbância do óleo de soja no espectro visível (400 - $700 \mathrm{~nm}$ ) com e sem a adição de $\beta$-caroteno. 78 


\section{LISTA DE TABELAS}

Página

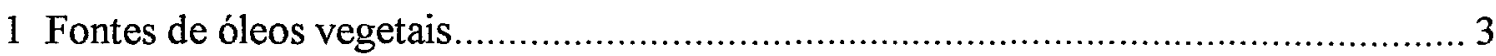

2 Composição em ácidos graxos (\%) do óleo de colza .............................................. 4

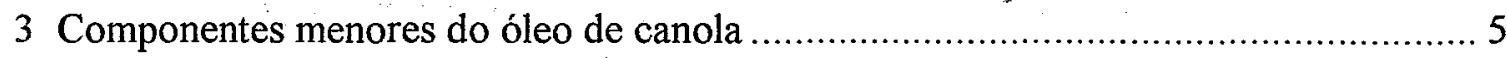

4 Composição em ácidos graxos (\%) do óleo de milho ................................................. 6

5 Composição em ácidos graxos do óleo de soja ………............................................. 7

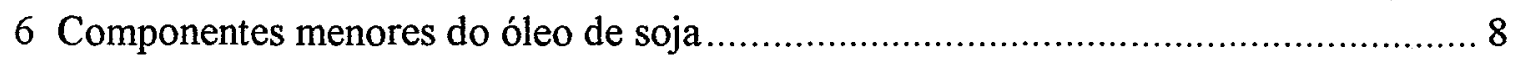

7 Concentração máxima de antioxidantes sintéticos permitida em óleos vegetais.......... 24

8 Caracterização inicial dos óleos de canola, milho e soja refinados ........................... 40

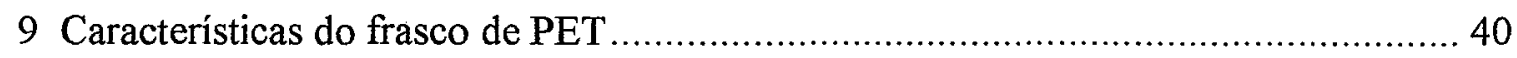

10 Índice de acidez ( $\mathrm{mg} \mathrm{KOH} / \mathrm{g}$ de óleo) de óleos de canola, milho e soja embalados em frascos PET e armazenados sob condições ambientes......................................... 42

11 Índice de peróxido (meq de $\mathrm{O}_{2} / \mathrm{kg}$ de óleo) de óleos de canola, milho e soja embalados em frascos PET e armazenados sob condições ambientes...................... 44

12 Coeficiente de extinção em $232 \mathrm{~nm}$ de óleos de canola, milho e soja em frascos PET e

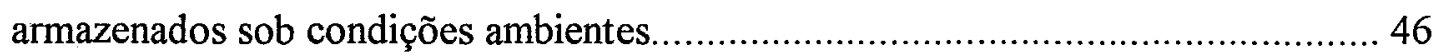

13 Coeficiente de extinção em $270 \mathrm{~nm}$ de óleos de canola, milho e soja embalados em frascos de PET e armazenados sob condições ambientes......................................... 47

14 Índice de acidez (mg de $\mathrm{KOH} / \mathrm{g}$ de óleo) dos óleos de canola, milho e soja submetidos à fotoxidação acelerada por 120 horas.

15 Equação da reta obtida por regressão linear, coeficientes de determinação $\left(R^{2}\right)$ e de correlação ( $r$ ) para os valores de índice de peróxido (IP) dos óleos de canola, milho e soja expostos à fotoxidação induzida por tempos diferentes (TL) 
16 Índice de peróxido (meq $\mathrm{O}_{2} / \mathrm{kg}$ de óleo) dos óleos de canola, milho e soja submetidos à fotoxidação acelerada por 120 horas.

17 Coeficiente de extinção em $232 \mathrm{~nm}$ dos óleos de canola, milho e soja 56

18 Coeficiente de extinção em $270 \mathrm{~nm}$ dos óleos de canola, milho e soja submetidos à fotoxidação acelerada por 120 horas.

19 Índice de acidez (mg KOH/g de óleo) dos óleos de canola, milho e soja adicionados de $\alpha$-tocoferol, $\beta$-caroteno e TBHQ e submetidos à fotoxidação acelerada por 120 horas. 65

20 Índice de peróxido (meq $\mathrm{O}_{2} / \mathrm{kg}$ de óleo) do óleo de canola adicionado de diferentes antioxidantes nos dois ensaios de fotoxidação acelerada.

21 Índice de peróxido (meq $\mathrm{O}_{2} / \mathrm{kg}$ de óleo) do óleo de milho adicionado de diferentes antioxidantes nos dois ensaios de fotoxidação acelerada.

22 Índice de peróxido (meq $\mathrm{O}_{2} / \mathrm{kg}$ de óleo) do óleo de soja adicionado de diferentes antioxidantes nos dois ensaios de fotoxidação acelerada.

23 Coeficiente de extinção em $270 \mathrm{~nm}$ dos óleos de canola, milho e soja adicionados de $\alpha$-tocoferol, $\beta$-caroteno e TBHQ e submetidos à fotoxidação acelerada por 120 horas. 


\title{
ESTABחIDADE FOTOXIDATIVA DOS ÓLEOS DE SOJA, MILHO E CANOLA.
}

\author{
Autora: FABIANA MARIA DE SIQUEIRA \\ Orientadora: Profa Dra MARISA A. B. REGITANO D'ARCE
}

\section{RESUMO}

Com o objetivo de verificar as condições para o desenvolvimento e aplicação do teste acelerado de fotoxidação para óleos vegetais e compará-lo com o que ocorre no armazenamento ambiente, óleos refinados de canola, milho e soja adicionados dos antioxidantes butileno hidroxitilueno (BHT) + butileno hidroxianisol (BHA) (200 ppm), butileno hidroxitilueno (BHT) + butileno hidroxianisol (BHA) (200 ppm)+ ácido cítrico (100 ppm), ácido cítrico (100 ppm) além do controle foram em béqueres de $50 \mathrm{ml}$ colocados em câmara de luz de dimensões $80 \times 35 \times 60 \mathrm{~cm}$, provida de 6 lâmpadas fluorescentes de $20 \mathrm{~W}$ e intensidade luminosa de 8.370 lux à temperatura de $30^{\circ} \mathrm{C}$. Paralelamente foi conduzido um ensaio à temperatura ambiente com os óleos embalados em frascos de PET (polietileno tereftalato) transparentes com os mesmos tratamentos avaliados no teste acelerado. As análises de índice de peróxido, índice de acidez, índice de iodo, coeficiente de extinção a 232 e $270 \mathrm{~nm}$ foram realizadas para o acompanhamento.

Os tratamentos não apresentaram comportamento diferenciado no ensaio ambiente nem no teste acelerado em relação ao controle. O melhor parâmetro analítico para acompanhamento da qualidade do óleo foi o índice de peróxido. Observou-se uma correlação ótima $(r=0,94)$ entre o teste acelerado e o ambiente.

Outro ensaio foi desenvolvido com o objetivo de avaliar o comportamento de 1 ppm de $\beta$-caroteno, $500 \mathrm{ppm}$ de $\alpha$-tocoferol e $200 \mathrm{ppm}$ de tertio-butileno hidroquinona 
(TBHQ) na fotoxidação dos óleos refinados de canola, milho e soja. Esse experimento foi realizado em câmara de luz, descrita anteriormente, e para acompanhamento foram realizadas as análises de índice de acidez, índice de peróxido e coeficientes de extinção a 232 e $270 \mathrm{~nm}$.

Dos tratamentos realizados, a adição de $200 \mathrm{ppm}$ de TBHQ mostrou ser o melhor, nos três óleos analisados. As adições de $1 \mathrm{ppm}$ de $\beta$-caroteno e $500 \mathrm{ppm}$ de $\alpha$ tocoferol não tiveram efeito protetor em prevenir a fotoxidação dos óleos.

Os antioxidantes BHA, BHT e ácido cítrico também não foram eficientes em retardar a fotoxidação dos óleos vegetais tanto no armazenamento sob condições ambientes como no teste acelerado.

$\mathrm{O}$ uso do teste acelerado de fotoxidação nas condições propostas nesse trabalho mostrou-se viável, pois num curto intervalo de tempo foram obtidos resultados de estabilidade fotoxidativa de óleos vegetais de diferentes composições que se correlacionaram positivamente com o que ocorre no armazenamento ambiente. 


\section{PHOTOOXIDATIVE STABILITY OF SOYBEAN, CORN AND RAPESEED \\ OILS.}

Author: FABIANA MARIA DE SIQUEIRA

Adviser: Profa Dra MARISA A. B. REGITANO D'ARCE

\section{SUMMARY}

The objective of the present work was to evaluate the application of an accelerated photooxidation test in a light chamber and compare it with ambient storage of rapeseed, corn and soybean refined oils added of antioxidants butylated hydroxyanisole(BHA) + butylated hydroxytoluene (BHT) (200 ppm), BHA + BHT (200 $\mathrm{ppm})+$ citric acid $(100 \mathrm{ppm})$, citric acid $(100 \mathrm{ppm})$ and control. Oil in $50 \mathrm{ml}$ beakers was placed in a $80 \times 35 \times 60 \mathrm{~cm}$ chamber with six $20 \mathrm{~W}$ fluorescents lamps, light intensity of 8.370 lux and temperature of $30^{\circ} \mathrm{C}$. An ambient temperature essay was conducted with rapeseed, corn and soybean oils bottled in $500 \mathrm{ml}$ PET flasks and stored for six months, with the same antioxidants of the accelerated test. The analysis of peroxide, acid and iodine values and UV spectrophotometry at 232 and $270 \mathrm{~nm}$ were performed to monitor the storage.

The treatments showed no different behavior in the ambient essay nor in the accelerated test when compared with the control. The better analytic parameter to accompany the oils quality was the peroxide value, whose values showed an excellent correlation $(r=0,93)$ between the accelerated test and ambient storage.

Another essay was developed with the objective to evaluate the behavior of $1 \mathrm{ppm}$ $\beta$-carotene, $500 \mathrm{ppm} \alpha$-tocoferol and $200 \mathrm{ppm}$ TBHQ (tertiary butylhydroquinone) in the 
photooxidation of rapeseed, corn and soybean refined oils. This experiment was performed in the light chamber, described previously and the same the analysis employed.

The best treatment was TBHQ 200 ppm in three analysed oils. Addition of 1 ppm $\beta$-carotene and $500 \mathrm{ppm} \alpha$-tocopherol did not have any protective effect to prevent the photooxidation of rapeseed, corn and soybean oils.

The antioxidants BHA, BHT and citric acid did not show to be efficient in retarding oil photooxidation.

The use of accelerated photooxidation test, under the conditions present in this work, showed to be feasible, because it was possible to obtain oil photoxidative stability data that correlated positively with ambient storage. 


\section{INTRODUÇÃo}

Os óleos vegetais são suscetíveis à reação de oxidação, que uma vez iniciada é dificil de ser controlada, causando alterações deteriorativas que modificam as suas características de qualidade ou dos alimentos que os contém, reduzindo assim o tempo de comercialização por torná-los inadequados ou inaceitáveis para o consumo.

O controle do processo oxidativo é alcançado através da manipulação dos aceleradores, sendo que, dentre eles, a luz exerce papel preponderante (Gunstone \& Norris, 1983 e Schaich, 1980).

A deterioração de óleos vegetais pela luz não envolve radicais livres, mas resulta na geração do oxigênio singlete $\left({ }^{1} \mathrm{O}_{2}\right)$ pela ação de agentes sensibilizadores, como a clorofila, presente em pequenas quantidades nos óleos refinados, e que absorvem a energia luminosa e a transferem para o oxigênio do meio, que passa para o estado ativo (singlete) (Carlsson et al., 1976).

A adição de substâncias antioxidantes em óleos é o recurso mais utilizado pelas indústrias para retardar o processo oxidativo em óleos, aumentando com isso o tempo de conservação desses produtos (Guinones, 1995). Para a comercialização de óleos vegetais em embalagens transparentes de polietileno tereftalato (PET) faz-se necessária a utilização de antioxidantes que ajam, sobretudo retardando a fotoxidação. Estudos tem demonstrado que a utilização de compostos antioxidantes, como tocoferóis e $\beta$-caroteno, naturalmente presentes nos óleos e perdidos durante o processo de refino, são antioxidantes eficazes, agindo como desativadores de oxigênio singlete no processo fotoxidativo (Carlsson et al., 1976; Jung \& Min, 1990; Lee \& Min, 1988 e St Angelo, 1996). 
Para a avaliação da suscetibilidade fotoxidativa dos óleos existem métodos acelerados, desenvolvidos normalmente em cabines de luz, através dos quais provoca-se um aumento da intensidade luminosa sobre as amostras de óleos, com controle da temperatura, objetivando-se que num curto intervalo de tempo possa ser determinada a estabilidade dessas amostras (Moser et al., 1965). Entretanto, a comparação dos resultados da estabilidade oxidativa das amostras de óleos obtidos no teste acelerado de fotoxidação com a estabilidade dessas mesmas amostras sob condições ambientes de armazenamento em embalagens transparentes (PET) se faz necessária para o estabelecimento das aplicações e dos limites desse teste.

Os objetivos desse trabalho foram verificar a aplicação do teste acelerado em câmara de luz nas condições propostas para a construção da câmara e encontrar a correlação existente entre a fotoxidação dos óleos refinados, em embalagem PET, armazenados sob condições ambientes e sob condições de aceleração, em câmara de luz. Avaliou-se também a adição dos antioxidantes BHA, BHT e ácido cítrico em diferentes misturas, bem como adições de $\beta$-caroteno, $\alpha$-tocoferol e TBHQ, no aumento da estabilidade fotoxidativa dos óleos de canola, milho e soja. 


\section{REVISÃO DE LITERATURA}

\section{1 Óleos vegetais}

Óleos e gorduras são matérias-primas com larga faixa de aplicação. São um dos principais componentes dos alimentos e desempenham um importante papel nutricional como a maior fonte de energia calórica e de ácidos graxos essenciais na dieta. Atuam também como transportadores de nutrientes essenciais, incluindo as vitaminas lipossolúveis A, D, E e K e são fontes de precursores metabólicos, de hormônios e prostaglandinas.

Segundo Nawar (1985), lipídios constituem um largo grupo de compostos que são geralmente solúveis em solventes orgânicos e moderadamente solúveis em água. Eles são os maiores componentes dos tecidos adiposos, e junto com proteínas e carboidratos constituem o componente estrutural de todas as células vivas. Ésteres de glicerol e ácidos graxos, que perfazem $99 \%$ dos lipídios de plantas e animais, são tradicionalmente chamados de óleos e gorduras. A distinção entre os termos óleos e gorduras é feita basicamente pelo estado fisico, sólido ou líquido, à temperatura ambiente, sendo muitas vezes usados indistintamente.

Os óleos vegetais podem ser obtidos de várias fontes, como mostra a Tabela 1 , variando quanto ao teor de óleo de seus grãos ou frutos.

Tabela 1. Fontes de óleos vegetais

\begin{tabular}{cccccccccc}
\hline Fonte & babaçu & copra & milho & algodão & oliva & dendê & canola & soja & girassol \\
$\%$ de óleo & $60-65$ & $65-68$ & 5 & $18-20$ & $25-30$ & $45-50$ & $40-45$ & $18-20$ & $34-45$ \\
\hline
\end{tabular}

Fonte: Gunstone \& Norris (1983) 
No Brasil, o óleo vegetal mais usado na alimentação é o de soja, tendo seu consumo largamente ampliado tanto para uso residencial como para uso industrial, para o qual é parcialmente hidrogenado, diminuindo o seu potencial de oxidação pela redução da insaturação. Já os óleos de milho e canola são de consumo menos popular e fazem parte dos "óleos especiais" cujo mercado vem crescendo nos últimos anos.

\subsection{1 Óleo de canola}

As sementes de canola (Brassica napus, B. rapa, B. campestris), variedade melhorada geneticamente a partir da colza, isenta de ácido erúcico, são pequenas, redondas $(0,1-0,2 \mathrm{~mm}$ de diâmetro) e podem ser de coloração amarela, marrom ou preta. O seu conteúdo de óleo é de $40-60 \%$. O óleo pode ser obtido por prensagem ou por extração com solvente ou uma combinação dos dois métodos. O óleo bruto é de coloração âmbar escura e contém alto nível de fosfatídeos $(3,5 \%)$, pigmentos, especialmente clorofila, provenientes de sementes não amadurecidas e compostos sulfurados (Mag, 1983). O óleo refinado é amarelo claro e livre de cera, de fósforo e de enxofre (Padley et al., 1994).

O óleo de colza apresenta composição média em ácidos graxos diferente para as variedades com alto e baixo teor de ácido erúcico (Tabela 2).

Tabela 2. Composição em ácidos graxos (\%) do óleo de colza

\begin{tabular}{|c|c|c|c|c|c|c|c|c|c|}
\hline Variedade & $\mathrm{C} 16: 0$ & C18:0 & $\mathrm{C} 20: 0$ & C22:0 & $\mathrm{C} 18: 1$ & C18:2 & $\mathrm{C} 18: 3$ & C20:1 & C22:1 \\
\hline $\begin{array}{l}\text { Alto teor de ác. } \\
\text { erúcico }\end{array}$ & 3 & 1 & 1 & $\mathrm{tr}$ & 16 & 14 & 10 & 6 & 49 \\
\hline $\begin{array}{c}\text { Baixo teor de ác. } \\
\text { erúcico }\end{array}$ & 4 & 2 & $\operatorname{tr}$ & $\operatorname{tr}$ & 56 & 26 & 10 & 2 & $\operatorname{tr}$ \\
\hline
\end{tabular}

Fonte: Padley et al., 1994.

Testes biológicos em animais revelaram o potencial de dano ao coração de humanos pelo consumo de óleo com alto conteúdo de ácido erúcico (óleo de colza). Foram então desenvolvidas variedades com mais baixos teores de ácido erúcico e 
glucosinolatos. A FAO/ WHO (Food and Agriculture Organization/ World Health Organization) recomenda somente o uso de variedades com baixo conteúdo de ácido erúcico (canola) para fins alimentares. O óleo de canola é usado como óleo de salada, fritura e em margarinas e "shortenings" (Padley et al., 1994).

Os pigmentos predominantes do óleo de canola são as clorofilas $a$ e $b$ e seus produtos de decomposição as feofitinas $a$ e $b$ (Usuki et al., 1984b).

De acordo com Tkachuk et al. (1988), óleos brutos extraídos de sementes imaturas de canola são de coloração verde escura devido à presença de clorofila e feofitinas. A clorofila presente nesses óleos produz uma coloração indesejável, acelera a oxidação e afeta a taxa de hidrogenação. Os pigmentos clorofila são dificeis de serem removidos durante o processamento e sua remoção aumenta o custo do refino.

O óleo degomado contém $10-300$ ppm de fósforo dependendo do tipo de degomagem feita, com ácido ou água (Mag, 1983). A Tabela 3 apresenta os teores dos componentes menores do óleo de canola.

Tabela 3. Componentes menores do óleo de canola

\begin{tabular}{cccc}
\hline Componentes & $\begin{array}{c}\text { Óleo bruto } \\
\text { degomado com água }\end{array}$ & Neutralizado & $\begin{array}{c}\text { Clarificado e } \\
\text { desodorizado }\end{array}$ \\
\hline Ácidos graxos livres (\%) & $0,1-1$ & 0,05 & 0,05 \\
Fósforo (ppm) & $150-250$ & $0-5$ & 5 \\
Enxofre (ppm) & $3-15$ & $2-7$ & - \\
Clorofila (ppm) & $5-25$ & $1-25$ & não coloração verde \\
Sabão (ppm) & - & $0-50$ & tr \\
Umidade & 0,05 & 0,05 & - \\
Fe (ppm) & $1-3$ & 0,1 & 0,1 \\
Cu (ppm) & - & 0,1 & 0,01 \\
\hline
\end{tabular}

Fonte : Mag (1983).

A composição em tocoferóis totais $(67 \mathrm{mg} / \mathrm{kg}$ de óleo) encontrada no óleo de colza, com alto conteúdo de ácido erúcico é a seguinte: $\alpha$-tocoferol $(8-24 \mathrm{mg} / \mathrm{kg}$ de 
óleo), $\gamma$-tocoferol (38-42 mg/ kg de óleo) e $\delta$-tocoferol (1,1-1,2 mg/ kg de óleo) (Padley et al., 1994).

\subsection{2 Óleo de milho}

O conteúdo de óleo no grão de milho (Zea mays) é de aproximadamente $5 \%$, sendo que $80 \%$ desse total está concentrado no germe. (Padley et al., 1994). Na Tabela 4 pode-se encontrar a composição média de ácidos graxos do óleo de milho.

Tabela 4. Composição em ácidos graxos (\%) do óleo de milho

\begin{tabular}{ccccccccc}
\hline C12:0 & C14:0 & C16:0 & C18:0 & C20:0 & C18:1 & C18:2 & C18:3 & C20:1 \\
0,1 & 0,2 & 13,0 & 2,5 & 0,5 & 30,5 & 52,0 & 1,0 & 0,2 \\
\hline
\end{tabular}

Fonte: Padley et al. (1994)

O óleo de milho é obtido do germe após ele ter sido separado do grão por moagem úmida ou seca. $\mathrm{O}$ germe é obtido como subproduto das indústrias do milho. Na indústria de amido, o germe é obtido por moagem úmida e na indústria de farinha de milho, por moagem seca. A extração do óleo de milho a partir do germe da moagem úmida ou seca não envolve problemas especiais de processamento (Leibovitz \& Ruckenstein, 1983).

O óleo bruto é isolado do germe pela combinação das extrações por solvente e prensagem. O óleo bruto normalmente contém menos de 3\% de ácidos graxos livres e 1 $3 \%$ de fosfatídeos, removidos durante o refino comercial. Traços de ceras $(0,05 \%)$ podem ser removidos durante a "winterização". O óleo refinado é usado para saladas e frituras, e como componente de margarinas (Padley et al., 1994).

As condições ambientais podem afetar a composição em ácidos graxos do óleo de milho, que é considerado uma excelente fonte de ácidos graxos essenciais. A alta estabilidade do óleo de milho, apesar do seu nível de insaturação, é parcialmente atribuída à distribuição não casualizada dos ácidos graxos nas moléculas dos triglicerídeos, onde 
98\% dos ácidos graxos esterificados na posição 2 do triglicerídeo são insaturados, enquanto as posições 1 e 3 são ocupadas por todos os saturados e insaturados remanescentes. $\mathrm{O}$ óleo de milho é conhecido pela sua excelente estabilidade oxidativa em várias aplicações, incluindo fritura. Uma outra razão da excelente estabilidade do óleo de milho é o seu alto nivel de antioxidantes naturais como tocoferóis e ácido ferrúlico. É também considerado boa fonte de vitamina $\mathrm{E}$ (Ferrari, 1994).

O $\gamma$-tocoferol predomina no óleo de milho. Concentrações usuais no óleo de milho de $\alpha$-tocoferol são $150 \mathrm{mg} / \mathrm{kg}$, de $\beta$-tocoferol, $10 \mathrm{mg} / \mathrm{kg}$, de $\gamma$-tocoferol, 400 $900 \mathrm{mg} / \mathrm{kg}$ e de $\delta$-tocoferol, $40 \mathrm{mg} / \mathrm{kg}$ (Muller-Mulot, 1976).

\subsection{3 Óleo de soja}

A soja (Glycine max) é uma das culturas cultivadas há mais tempo no mundo e em maiores quantidades. O grão de soja apresenta de 18 - 22\% de óleo e é armazenado por tempo relativamente longo com umidade de $12 \%$. O óleo para fins alimentares é extraído por solvente, comumente o hexano, degomado e refinado (Padley et al., 1994).

O óleo de soja é composto de $85 \%$ de ácidos graxos insaturados e pertence ao grupo do ácido linolênico, ácido graxo que possui três duplas ligações em sua molécula, portanto bastante suscetível à degradação oxidativa. $\mathrm{O}$ óleo de soja apresenta uma ampla variação na sua composição, de acordo com a variedade de soja usada no plantio, época de colheita e fatores climáticos. $\mathrm{O}$ óleo de soja apresenta a seguinte composição média em ácidos graxos (Tabela 5):

Tabela 5. Composição em ácidos graxos do óleo de soja

\begin{tabular}{cccccccc}
\hline $\mathrm{C} 16: 0$ & $\mathrm{C} 18: 0$ & $\mathrm{C} 20: 0$ & $\mathrm{C} 16: 1$ & $\mathrm{C} 18: 1$ & $\mathrm{C} 18: 2$ & $\mathrm{C} 18: 3$ & $\mathrm{C} 20: 1$ \\
$11 \%$ & $4 \%$ & $1 \%$ & $0,5 \%$ & $22 \%$ & $53 \%$ & $7,5 \%$ & $1 \%$ \\
\hline
\end{tabular}

Fonte: Graef et al., 1985. 
O óleo de soja bruto é normalmente de coloração escura (alaranjado), devido à presença de pigmentos carotenóides. Dentre os pigmentos presentes no óleo, grande atenção é dada à clorofila. A clorofila, além de conferir ao óleo uma cor indesejada, pode afetar a taxa de hidrogenação e acelerar a oxidação, resultando em produtos rancificados prematuramente (Borghi \& Barrera-Arellano, 1994). A composição em componentes menores do óleo de soja é apresentada na Tabela 6.

Tabela 6. Componentes menores do óleo de soja

\begin{tabular}{cc}
\hline Componentes & Concentração \\
\hline Tocoferol (total) & $530-1500 \mathrm{mg} / \mathrm{kg}$ \\
$\alpha$-Tocoferol & $90-120 \mathrm{mg} / \mathrm{kg}$ \\
$\gamma$ - Tocoferol & $740-1020 \mathrm{mg} / \mathrm{kg}$ \\
$\delta$ - Tocoferol & $240-300 \mathrm{mg} / \mathrm{kg}$ \\
Clorofila & $1500 \mu \mathrm{g} / \mathrm{kg}$ \\
Hidrocarbonetos & $300 \mathrm{mg} / \mathrm{kg}(\mathrm{esqualeno} 150 \mathrm{mg} / \mathrm{kg}$ ) \\
Esteróis & $1000-3500 \mathrm{mg} / \mathrm{kg}$ \\
Álcoois triterpenos & $600 \mathrm{mg} / \mathrm{kg}$ \\
\hline
\end{tabular}

Fonte: Padley et al. (1994)

De acordo com Neumann (1991), a tendência à fotoxidação é bem maior no óleo de soja do que no de girassol e amendoim, não somente devido à presença de alta insaturação dos ácidos graxos, mas também devido à ausência de constituintes naturais, capazes de promover um efeito antioxidante protetor.

\subsection{Embalagens}

De acordo com Cabral et al. (1988), a definição de embalagem pode ser dada como sendo a estrutura projetada para conter um alimento de modo a facilitar o transporte e ao mesmo tempo, torná-lo mais seguro, proteger o produto contra 
contaminações, danos ou deteriorações e facilitar o consumo. A impressão externa tem as seguintes finalidades: identificar o conteúdo em termos de tipo e quantidade, identificar o fabricante, atrair o consumidor, induzi-lo à compra e instruir o consumidor quanto ao uso.

No mercado brasileiro de óleos vegetais a embalagem que foi desenvolvida para atender as exigências citadas acima foi a lata. No entanto, há alguns anos começou a chegar ao mercado de óleos vegetais a embalagem de PVC (policloreto de vinila) e mais recentemente a embalagem de PET (polietileno tereftalato). De acordo com o artigo Mercado de embalagens para óleos comestíveis...(1996), no Brasil, inicialmente, as embalagens de PET foram destinadas aos óleos designados como especiais (milho, canola, girassol), atualmente essas embalagens começaram a participar também do segmento de óleos comuns (soja).

O acondicionamento de óleos vegetais em frascos transparentes de $900 \mathrm{ml} \mathrm{de}$ polietileno tereftalato (PET) surgiu para atender a uma fatia de mercado composta por consumidores que se preocupavam com a qualidade dos produtos que consumiam, exigindo, na hora da compra, a sua visualização. Os óleos vegetais, que até então eram encontrados somente em latas de $900 \mathrm{ml}$, passaram a ser também comercializados em frascos de PET.

As embalagens de PVC e PET apresentam, dentre outras características, a transparência que, não impede a passagem de luz visível, tornando o óleo mais suscetível à fotoxidação, acarretando a diminuição no tempo de comercialização do produto.

Em experimento realizado em laboratório observou-se a influência da coloração das embalagens de PVC na fotoxidação do óleo de soja. Foram empregados frascos de PVC transparentes e nas cores amarela, verde e vermelha. O teste acelerado conduzido em câmara de fotoxidação $\left(2500 \mathrm{lux}, 35^{\circ} \mathrm{C}\right)$, usando-se placas de Petri cobertas com discos do material dos frascos, demonstrou que a ordem quanto ao grau de proteção luminosa foi a seguinte: transparente $<$ amarela $<$ verde $<$ vermelha $<$ controle (placa coberta com alumínio). Concluiu-se que a taxa de fotoxidação depende das características de transmissão, absorção e reflectância da embalagem e do produto (óleo), e que além do efeito da fonte de radiação, a intensidade de luz, a área da embalagem e o tempo de 
exposição são fatores importantes a serem considerados (Faria \& Espinoza-Atencia, 1993).

O grau de proteção direta oferecida pelas embalagens depende das características de transmissão da luz. Os materiais de embalagem de diferentes composições químicas ou estrutura molecular, tem diferentes características de transmissão de luz e isto deve ser considerado. A transmissão da luz UV é bastante intensa através dos filmes de polietileno (PE), polipropileno (PP) e cloreto de polivinila (PVC), os filmes de polietileno tereftalato (PET) absorvem os raios UV abaixo de $300 \mathrm{~nm}$ na ordem de $80 \%$, não transmitindo esses raios para os produtos contidos nas embalagens (Espinoza-Atencia \& Faria 1994).

As embalagens de PET transparentes se destacam entre as embalagens plásticas por oferecerem resistência química a ácidos, bases e vários solventes, porém não oferecem barreira à passagem da luz, fazendo-se necessária a adição de antioxidantes nos óleos para retardar a oxidação dos mesmos (Albuquerque \& Anjos, 1991).

\subsection{Oxidação de óleos vegetais}

As características de qualidade de óleos e gorduras ou materiais que os contém sempre estão relacionadas com o fenômeno da rancidez, que é sem dúvida nenhuma o fator de deterioração mais importante neste tipo de produto. Rancidez é definida como "alteração de óleos e gorduras organolepticamente detectável", e entre outras consequências, ocasiona a deterioração de sabor e odor, deprecia o produto e reduz seu valor nutritivo. Existem dois tipos de rancidez, a hidrolítica e a oxidativa. A reação de hidrólise é catalisada por lipases presentes em sementes oleaginosas e alimentos, ou produzidas por microrganismos. Ocorre também de forma não enzimática, como nos processos de fritura, em que a hidrólise se dá em altas temperaturas, produzindo ácidos graxos livres (Barrera-Arellano, 1993).

A rancidez oxidativa, também chamada de autoxidação, é do ponto de vista da qualidade, a mais importante em óleos e gorduras. É de grande interesse econômico para a indústria de alimentos porque tal deterioração produz "off-flavors" e odores desagradáveis em óleos comestíveis e em alimentos contendo gorduras. É de consenso 
que a autoxidação é a reação com oxigênio molecular. $O$ estudo das reações de oxidação não é recente. Almeida (1950) já relatava que bastava $0,1 \%$ dos ácidos graxos decompostos em substâncias voláteis, de baixo peso molecular, para que a gordura adquirisse o gosto e o cheiro de ranço.

As frações lipídicas dos alimentos são bastante suscetíveis à peroxidação, principalmente aquelas que contém quantidades elevadas de ácidos graxos insaturados (Foote \& Denny, 1968). Segundo Simic et al. (1992) a degradação de lipídios em alimentos pode ser iniciada por espécies endógenas $\left(\mathrm{H}_{2} \mathrm{O}_{2}, \mathrm{ROOH}\right)$ e radicais $\left(\mathrm{O}_{2}^{-}, \mathrm{ROO}\right.$, $\left.\mathrm{OH}, \mathrm{GS}^{\circ}\right)$ ou por espécies exógenas $\left({ }^{1} \mathrm{O}_{2}, \mathrm{O}_{3}\right)$, radicais $\left(\mathrm{NOx}, \mathrm{SO}_{3}{ }^{-}\right)$, e agentes externos (UV, radiação ionizante, calor). $\mathrm{O}$ alvo de ataque desses agentes são diversos e específicos para alguns agentes e condições.

$\mathrm{O}$ aumento do grau de insaturação aumenta a suscetibilidade e a intensidade de oxidação dos ácidos graxos. Estima-se que a velocidade de oxidação do metil linoleato seja 10 vezes superior à do metil oleato, e a do linolenato de 20 a 30 vezes superior à do linoleato a $100^{\circ} \mathrm{C}$ (Gray, 1978).

Segundo Robards et al. (1988), foram Farmer e colaboradores, em 1946, os primeiros a propor a sequência de reações que compõem o processo de autoxidação dos lipídios (Figura 1). A autoxidação é um processo em cadeia de radicais livres consistindo das etapas de iniciação, propagação e terminação. As reações de iniciação são de fundamental importância no processo de oxidação lipídica. A autoxidação inicia-se com a retirada do átomo de hidrogênio adjacente à dupla ligação do ácido graxo pela ação catalítica, mesmo que de traços, de peróxidos, metais pesados com duas valências (ferro, cobre, níquel), radiações ultravioleta e ionizante. Assim sendo, os primeiros radicais necessários para começar a reação de propagação, normalmente são formados por algum meio catalítico. Uma vez iniciada, a reação continua em série, envolvendo radicais livres que reagem diretamente com o oxigênio para formar radicais peróxidos, os quais podem iniciar novas séries de reações pela abstração de um átomo de hidrogênio de outra molécula, convertendo-se em hidroperóxidos. Estes últimos compostos decompõem sob 
determinadas condições, gerando novos radicais que iniciam outras reações ou formam polímeros (Nawar, 1985).

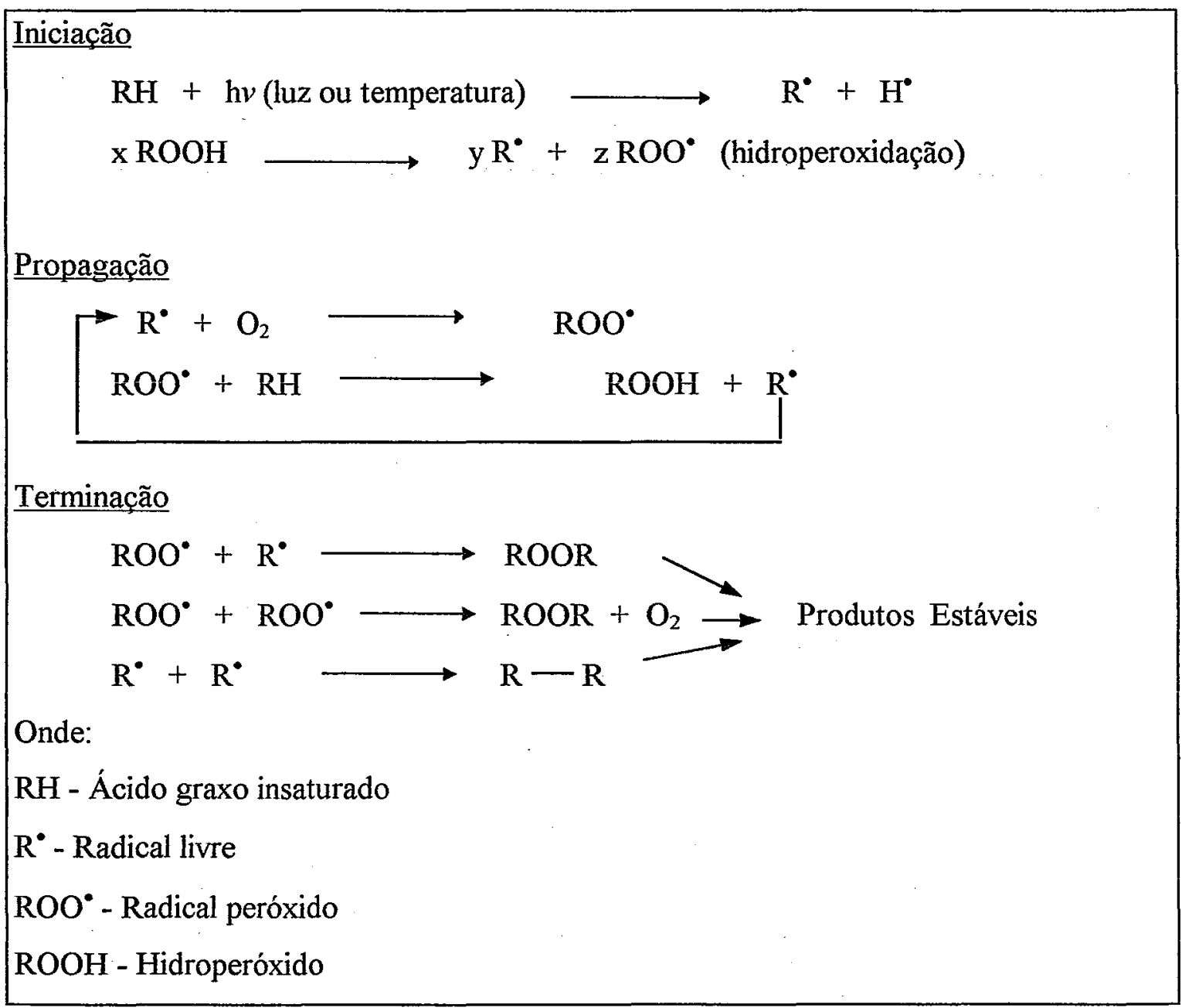

Figura 1 - Esquema geral do mecanismo da oxidação lipídica.

Visto que a reação, $\mathrm{RH}+\mathrm{O}_{2} \rightarrow$ Radicais livres, é dificil de ocorrer em bases da termodinâmica (energia de ativação 30 - $45 \mathrm{Kcal} / \mathrm{mol}$ ), a produção do primeiro radical necessário para o início da reação de propagação, normalmente precisa ocorrer por mecanismos outros. 
Existe a proposta de iniciação através da decomposição do hidroperóxido, por metais catalíticos ou por exposição à luz. Foi proposto também que o oxigênio singlete era a espécie ativa envolvida (Korycka-Dahl \& Richardson, 1978 e Nawar, 1985).

De acordo com St. Angelo (1996) acredita-se que a autoxidação das gorduras proceda via reações em cadeia envolvendo radical peróxido $\left(\mathrm{RO}_{2}{ }^{\circ}\right)$. Entretanto, a exata origem dos radicais livres iniciais é ainda desconhecida. Pode ser um radical de ácido graxo, ou pode ser um radical completamente diferente. Segundo o mesmo autor, o que é conhecido sobre as reações de iniciação da autoxidação é que são desencadeadas por certos fatores.

De acordo com Sherwin (1978) dentre os principais fatores desencadeadores da oxidação, pode-se citar:

- Enzimas: São catalisadores orgânicos (lipases e lipoxigenases), naturalmente presentes em tecidos animais e vegetais. Sob certas condições de temperatura e umidade, as enzimas catalisam a decomposição hidrolítica e oxidativa de óleos e gorduras;

- Metais: Em quantidades traço é reconhecido como o material prooxidante predominantemente encontrado em óleos e gorduras comerciais. O cobre ou o ferro em concentrações menores que $1 \mathrm{ppm}$ pode causar severas reduções na estabilidade de óleos e gorduras. Esse problema é aumentado pela presença de ácidos graxos livres, os quais agem como solubilizadores de metais em óleos;

- Temperatura: É um dos principais fatores da oxidação, em temperaturas maiores que $60^{\circ} \mathrm{C}$ estima-se que para cada aumento de $15^{\circ} \mathrm{C}$, duplique a velocidade de oxidação;

- Luz: A faixa próxima ou a do ultravioleta acelera fortemente a oxidação de óleos e gorduras;

- Aeração: O oxigênio em contato direto com gorduras e óleos acelera o processo de oxidação.

A reação de radicais livres pode ser acelerada e propagada (etapa de propagação) via ramificação de cadeia dos hidroperóxidos formados para gerar mais radicais livres. Os radicais livres formados podem iniciar ou promover a oxidação de ácidos graxos em velocidades mais rápidas. Assim, uma vez iniciada, a reação de formação de radicais 
livres é auto-sustentável e capaz de oxidar grandes quantidades de lipídios. Os produtos da oxidação de óleos e gorduras podem ser quebrados para formar compostos orgânicos menores tais como aldeídos, álcoois e ácidos (etapa de terminação) (Patterson, 1989).

Considerando-se que a quantidade de oxigênio necessária para alterar as características de um óleo é relativamente baixa $(<100 \mathrm{ppm})$, tornam-se mais relevantes todos os esforços que visam reduzir a velocidade da autoxidação na fase de indução do processo. O hexanal, um dos produtos resultantes da degradação de hidroperóxidos, já é perceptível nos testes de avaliação sensorial em concentrações de 50 ppb (Faria, 1994).

Não é possivel evitar a reação de autoxidação, porém é possivel retardá-la. Esta reação é iniciada por metais ou energia (térmica ou luminosa), produzindo os primeiros radicais livres $\left(\mathrm{R}^{*}\right)$, portanto a eliminação ou redução dos metais por agentes quelantes como ácido cítrico e a produção e armazenamento a baixas temperaturas protegidos da luz, retardariam o aparecimento da rancidez, aumentando a estabilidade ou vida de prateleira dos produtos. A redução ou eliminação do oxigênio também retardaria a reação. $\mathrm{O}$ uso de sequestrantes de oxigênio como ácido ascórbico, ou de sachês contendo compostos absorvedores de oxigênio, são práticas de fabricação que prolongam a vida útil dos alimentos.

\subsection{Fotoxidação de óleos vegetais}

A exposição à luz provoca a deterioração de óleos e alimentos contendo gordura. Muitos estudos tem mostrado que óleos vegetais são suscetiveis à fotoxidação (Gunstone \& Norris, 1983; Patterson, 1989 e Schaich, 1980).

A absorção de energia radiante é um processo fotoquímico primário e resulta numa molécula ativa (Sattar $\&$ deMan, 1975):

Segundo Sattar \& deMan (1975) existem outros dois tipos de reações induzidas pela luz, as quais são mais importantes em sistemas naturais do que nas clássicas reações fotoquímicas:

a) reação fotossensibilizada (espécies que absorvem a luz mas não sofrem alteração química permanente); 
b) reação fotoinduzida (a energia radiante produz espécies reativas, iniciando uma nova reação).

A oxidação dos lipídios por efeito da luz é uma das alterações mais significativas em óleos e gorduras. A luz pode agir de forma direta ou indireta sobre os ácidos graxos insaturados. A luz pode atuar diretamente sobre os ácidos graxos e formar radicais livres na etapa de iniciação da autoxidação. A formação de radicais livres ocorre quando um hidrogênio é removido do carbono $\alpha$-metilênico pela ação da luz. A fotoxidação direta pela absorção de luz pelos ácidos graxos não é importante, pois luz de comprimento de onda inferior a $300 \mathrm{~nm}$ não reage com lipídios em condições normais de armazenagem sob luz solar direta sem uma proteção exterior ou embalagem (Nawar, 1985).

O efeito fotoquímico indireto da luz nos ácidos graxos ocorre com a participação de fotossensibilizadores que são substâncias cromóforas presentes no óleo, como corantes e pigmentos naturais (clorofilas, feofitinas, mioglobinas, porfirinas e outros) que absorvem intensamente a luz visível próxima ao UV, acumulando energia e a transferindo para o oxigênio do meio que passa para o estado reativo singlete (Carlsson et al., 1976 e Clements et al., 1973).

$O$ oxigênio existe em dois estados na natureza, triplete e singlete. No estado triplete, mais estável, não é tão reativo com compostos insaturados. Sua ativação para o estado singlete, mais reativo, envolve a excitação fotoquímica de um elétron para um nível mais alto de energia, requerendo um fotossensibilizador intermediário (riboflavina, compostos heme, clorofila, feofitinas) (Korycka-Dahl \& Richardson, 1978). Estes fotossensibilizadores, principalmente a clorofila, podem estar presentes nos óleos brutos de canola, soja e oliva e permanecerem após o refino e durante o armazenamento destes óleos. Os fotossensibilizadores são prejudiciais aos óleos por absorverem energia luminosa de comprimento de onda na faixa do visível e transferirem para o oxigênio triplete, gerando o estado singlete (Usuki et al., 1984a).

O oxigênio singlete produzido reage com os ácidos graxos dos óleos vegetais aproximadamente 1450 vezes mais rápido que o oxigênio triplete (Rawls \& VanSanten, 1970). De acordo com Jung \& Min (1991), mais de $99 \%$ do índice de peróxido do óleo de soja contendo clorofila, estocado sob luz, foi devido à oxidação pela ação do oxigênio 
singlete fotossensibilizado pela clorofila $e$, menos de $1 \%$ foi devido ao oxigênio triplete na autoxidação. A seguir é apresentado o esquema da fotoxidação lipídica (Chan, 1977).

$$
\begin{aligned}
& \text { Sens }+\mathrm{h} v \text { - Sens }{ }^{*}-{ }^{3}{ }^{3} \mathrm{Sens}^{*}+{ }^{3} \mathrm{O}_{2}-{ }^{3} \text { Sens* } \\
& { }^{1} \mathrm{O}_{2}{ }^{*}+\mathrm{Sens} \\
& \mathrm{O}^{*}+\mathrm{RH}+\mathrm{RH} \text { - } \mathrm{RO}^{*}+\mathrm{HO}^{*}
\end{aligned}
$$

Onde:

Sens - sensibilizador no estado triplete

hv - energia da luz no comprimento de onda visivel

Sens* - sensibilizador no estado singlete excitado

${ }^{3}$ Sens* - sensibilizador no estado triplete excitado

${ }^{3} \mathrm{O}_{2}$ - oxigênio no estado triplete

${ }^{1} \mathrm{O}_{2} *$ - oxigênio no estado singlete

$\mathrm{Na}$ fotoxidação o oxigênio singlete reage com os ácidos graxos insaturados, produzindo uma mistura de hidroperóxidos conjugados e não conjugados que rapidamente se decompõem originando compostos indesejáveis de "flavor" (Frankel et al., 1982 e Gunstone, 1984).

A reação de fotoxidação não ocorre em cadeia e não há período de indução, sendo que os hidroperóxidos são formados pelo mecanismo de ciclo-adição. Esta reação é chamada "ene", sendo que o oxigênio molecular é ligado ao final de uma dupla ligação, abstraindo um próton alílico e uma nova ligação é formada entre o carbono da posição alilica e o outro da dupla ligação (Gunstone, 1994).

De acordo com Sattar \& deMan (1975) o mecanismo de ação fotoquímica é diferente do que envolve a autoxidação. No caso da fotoxidação, a quantidade de hidroperóxidos formada é proporcional ao total da quantidade de luz absorvida. Foi observado que quantidades apreciáveis de hidroperóxidos não conjugados são formadas 
na fotoxidação, ao passo que na autoxidação todos os hidroperóxidos formados são conjugados.

Sattar \& deMan (1976) mensuraram a estabilidade de óleos comestíveis na luz fluorescente. Os óleos de milho, coco, canola e soja foram expostos à luz fluorescente ( $500 \mathrm{ft}-\mathrm{c}=5000 \mathrm{lux})$ em condições variáveis de tempo-temperatura. Observou-se que o aumento da temperatura em ausência de luz teve um efeito mínimo na oxidação das amostras; entretanto na presença de luz a velocidade de oxidação aumentou consideravelmente com um correspondente descrécimo nos conteúdos de vitamina $A$ e $\beta$ caroteno. A velocidade de oxidação diminuiu sob iluminação com altos comprimentos de onda $(500-750 \mathrm{~nm})$. $O \beta$-caroteno serviu como um filtro para a luz de comprimento de onda menor.

Lugasi et al. (1995) verificaram que a irradiação de luz ultravioleta afetou a peroxidação de óleos vegetais e que a velocidade da oxidação dependeu da composição de ácidos graxos e do nível de tocoferol ou outros antioxidantes dos óleos e do tempo de exposição à fonte luminosa.

\subsection{Características da luz}

A luz é uma forma de energia radiante, que se propaga no espaço com um movimento ondulatório transversal, produzido em um campo eletromagnético, à velocidade de $3 \times 10^{10} \mathrm{~cm} / \mathrm{seg}$. A energia luminosa é a energia emitida por uma fonte de luz (Weigel, 1952).

A energia radiante é classificada de acordo com seu comprimento de onda. As radiações de comprimento de onda mais curtos são chamados de raios cósmicos, seguidos pelos raios gama, raios $\mathrm{X}$, raios ultravioleta, raios visiveis, raios infravermelho, ondas de rádio e, finalmente, radiações de potência linear, com comprimentos de ondas quilométricos (Shaum \& Van Der Merwe, 1973). 
De acordo com a teoria quântica, a radiação é emitida descontinuamente em unidades chamadas fótons. Cada fóton contém um "quantum" de energia cujo valor depende do comprimento de onda da radiação, conforme a expressão:

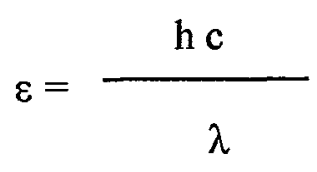

Onde:

$\varepsilon$ - energia do fóton em ergs

h - constante de Planck $\left(6,63 \times 10^{-27}\right.$ erg.s)

c - velocidade da luz $\left(3 \times 10^{10} \mathrm{~cm} / \mathrm{s}\right)$

$\lambda$ - comprimento de onda $(\mathrm{cm})$

$v$ - frequência da radiação $\left(\mathrm{s}^{-1}\right)$

A energia radiante apresenta propriedades ondulatórias e propriedades corpusculares. A relação entre a energia cinética, que é propriedade da partícula e a frequência, que é propriedade da onda, indica que o conteúdo de energia dos fótons de luz varia inversamente com o comprimento de onda. Quanto menor é o comprimento, mais alta é a energia do fóton de luz e maior, o efeito sobre as reações químicas (Sattar \& deMan, 1975).

A faixa do espectro eletromagnético percebida pelos olhos, de $400-750 \mathrm{~nm}$, denomina-se luz visivel. As fontes de luz visível podem ser natural (luz solar) e artificial (lâmpadas fluorescente e incandescente), contendo espectros com teores de radiação UV que induzirão à fotoxidação dos alimentos fotossensíveis (Lugasi et al., 1995).

De acordo com Shaum \& Van Der Merwe (1973) o grau de iluminação (E) sobre uma superficie plana é o produto da relação do fluxo que incide normalmente por unidade de área:

$$
E\left(\text { lx ou } 1 \mathrm{~m} / \mathrm{m}^{2}\right)=\frac{F(\mathrm{~lm})}{A\left(\mathrm{~m}^{2}\right)}
$$


A unidade de iluminação é o lux $(\mathrm{lx})$ igual ao lúmen por metro quadrado $\left(\mathrm{lm} / \mathrm{m}^{2}\right)$, de maneira que $1 \mathrm{~lx}=1 \mathrm{~lm} / \mathrm{m}^{2}$.

A luz artificial obtida com lâmpadas fluorescentes para iluminação nos pontos de venda tem alta eficiência luminosa (75 - 80 lumes/ watt), sendo econômicas e de pouca dissipação de calor. Em adição à luz, muitas outras formas de energia são emitidas pelas lâmpadas fluorescentes: a radiação do ultravioleta próximo ocupa pequena parte da radiação da lâmpada (0,5\%); aproximadamente $1 / 3(35,7 \%)$ é emitido como energia infravermelha devido à baixa temperatura da parede da lâmpada. Essa baixa temperatura e o longo comprimento de onda caracteriza uma forma de energia que contrasta com o comprimento de onda curto da energia do infravermelho próximo produzida pela alta temperatura dos filamentos de tungstênio nas lâmpadas incandescentes. A energia remanescente $(41,8 \%)$ é dissipada por condução e convecção. As lâmpadas fluorescentes produzem muito menos radiação quente por lúmen de luz que lâmpadas incandescentes; a eficiência luminosa de lâmpadas fluorescentes é muito maior que de lâmpadas incandescentes $(75-80 \mathrm{~lm} / \mathrm{W}$ para lâmpadas fluorescentes quando comparado com 16 $22 \mathrm{~lm} / \mathrm{W}$ para lâmpadas incandescentes para serviços gerais). Do total da energia luminosa das lâmpadas incandescentes, 70 - $80 \%$ se transforma em calor na região do infravermelho, tornando-se antieconômica (Sattar \& deMan, 1975).

\subsection{Testes acelerados para acompanhamento da fotoxidação}

Para avaliação dos efeitos fotoxidativos nos diferentes tipos de óleos, existem os métodos acelerados, através dos quais provoca-se uma aceleração do processo fotoxidativo, na tentativa de reproduzir a situação comercial. $O$ ranço fotoxidativo é induzido em câmaras de luz fluorescente.

Moser et al. (1965) empregaram seis lâmpadas fluorescentes de 14 W montadas em uma caixa circular de $44,5 \mathrm{~cm}$ de diâmetro por $44,5 \mathrm{~cm}$ de altura. As amostras de 150 $\mathrm{ml}$ de óleo foram colocadas em frascos de vidro transparente de $8 \mathrm{oz}(226,8 \mathrm{~g})$ e cobertas com tampas de papel celofane em temperatura ambiente de $78^{\circ} \mathrm{F}\left(25,5^{\circ} \mathrm{C}\right)$ por tempos de 
exposição de 0,5 a 40 horas. Os autores concluíram que a luz fluorescente produz mudanças de "flavor" em óleos comestíveis, em curto intervalo de tempo.

Lee \& Min (1988) avaliaram a fotoxidação de óleo de soja com clorofila e $\beta$ caroteno, utilizando-se duas caixas retangulares, uma de vidro de dimensões $60 \times 30 \times 50$ $\mathrm{cm}$ na qual foram colocadas as amostras a serem fotoxidadas, e outra caixa de madeira de dimensões $70 \times 50 \times 60 \mathrm{~cm}$, na qual foram embutidas no seu fundo quatro lâmpadas fluorescentes de $15 \mathrm{~W}$. A caixa de vidro foi posicionada a $12 \mathrm{~cm}$ da fonte de luz e as amostras colocadas a $10 \mathrm{~cm}$ do fundo da caixa de vidro, ficando a $22 \mathrm{~cm}$ da fonte de luz. A intensidade luminosa sobre as amostras foi de 4000 lux e a temperatura da caixa manteve-se constante a $10^{\circ} \mathrm{C}$. Observou-se nesse trabalho que a câmara de luz usada serviu para, num curto intervalo de tempo, estudar a ação de substâncias envolvidas na fotoxidação do óleo de soja.

Faria \& Espinoza-Atencia (1993) estudaram a fotoxidação em cabines termicamente isoladas, equipadas com lâmpadas fluorescentes com radiação espectral principal de $400-650 \mathrm{~nm}$ com dimensões de $58 \times 30 \times 20 \mathrm{~cm}$. As temperaturas usadas nas cabines foram $25^{\circ} \mathrm{C}, 30^{\circ} \mathrm{C}, 35^{\circ} \mathrm{C}$. Foram feitos testes acelerados sob intensidade luminosa de 2500 lux, usando-se $20 \mathrm{~g}$ de óleo colocados em placas de Petri cobertas com amostras das paredes das garrafas, por tempos de 0 a 120 horas, com retiradas de amostras a cada 24 horas. Segundo esses autores, testes acelerados para alimentos fotossensitivos devem simular as reais condições dos sistemas de embalagem, visando conseguir uma melhor estimativa do tempo de prateleira.

\subsection{Mecanismo de ação dos antioxidantes}

Os antioxidantes são substâncias que em pequenas quantidades interferem no processo normal de oxidação de óleos e gorduras, retardando a produção de "flavors" e odores desagradáveis (Gunstone \& Norris, 1983). Os antioxidantes alimentares são descritos como substâncias que funcionam como inibidores de radicais livres pela 
interferência no mecanismo fundamental da autoxidação. Eles reagem com radicais livres, gerados na fase de propagação para frear a reação de autoxidação (St. Angelo, 1996).

O uso de antioxidantes é regulamentado de acordo com a legislação de cada país. No Brasil o uso de antioxidantes é regulamentado pelo Ministério da Saúde, através da resolução $n^{\circ}$ 22/77 do decreto lei n 986 de 21 de abril de 1969 (Brasil, 1991).

De acordo com seu modo de ação, antioxidantes podem ser classificados como terminadores de radicais livres, quelatos de ions metálicos, que são catalisadores da oxidação lipídica, ou como sequestradores de oxigênio, reagindo com o oxigênio em sistemas fechados.

Os antioxidantes são divididos em primários e secundários. Os antioxidantes primários (BHA, BHT, ésteres do ácido gálico) interrompem a reação em cadeia, cedendo um radical hidrogênio a um radical lipídico livre, de alta energia, convertendo-o em produtos termodinamicamente estáveis (Chipault, 1962). Os antioxidantes secundários, também conhecidos como antioxidantes preventivos, agem pelo retardamento da velocidade da reação de iniciação, pela redução de hidroperóxidos (Shahidi \& Wanasundara, 1992).

O modo de ação dos antioxidantes pode ser observado de acordo com o seguinte esquema (Sherwim, 1972).

$$
\begin{aligned}
& \mathrm{ROO}^{\circ}+\mathrm{AH} \Rightarrow \mathrm{ROOH}+\mathrm{A}^{\bullet} \\
& \mathrm{RO}^{\circ}+\mathrm{AH} \Rightarrow \mathrm{A}^{*}+\mathrm{ROH} \\
& \mathrm{ROO}^{\circ}+\mathrm{A}^{\bullet} \Rightarrow \mathrm{ROOA} \\
& \mathrm{RO}^{\circ}+\mathrm{A}^{\bullet} \Rightarrow \mathrm{ROA} \\
& \mathrm{ROO}^{\circ}+\mathrm{RH} \Rightarrow \mathrm{ROOH}+\mathrm{R}^{*}
\end{aligned}
$$

Onde:

$$
\begin{aligned}
& \mathrm{AH} \text { - antioxidante } \\
& \mathrm{R}^{\bullet} \text { - Radical livre } \\
& \mathrm{ROO}^{\circ} \text { - Radical peróxido } \\
& \text { ROOH - Hidroperóxido }
\end{aligned}
$$


O antioxidante interfere na lipoxidação pela rápida doação de um átomo de hidrogênio para o radical lipídico (reações 1 e 2). As reações são de natureza exotérmica, com a energia de ativação aumentando com o aumento da energia de dissociação das ligações A-H e R-H. Portanto, a eficiência do antioxidante aumenta com a diminuição da força da ligação A-H. O radical $\mathrm{A}^{\bullet}$ que se forma é relativamente estável e reage com radicais lipídicos, podendo ser estabilizado através de recombinações que podem se processar de acordo com as reações 3 e 4 (Shahidi \& Wanasundara, 1992). Os antioxidantes fenólicos são excelentes doadores de hidrogênio ou elétrons, e seus radicais intermediários são relativamente estáveis devido ao deslocamento da ressonância e à falta de sítios ativos para o ataque de oxigênio molecular (Nawar, 1985 e Sherwin, 1978).

Os sinergistas são compostos, os quais, em ausência de antioxidantes primários, tem pouco efeito sobre a oxidação de gorduras; eles agem realçando a atividade dos antioxidantes. Podem ser compostos orgânicos ou inorgânicos e usualmente são de caráter ácido. Por essa razão também são conhecidos como antioxidantes tipo ácido. Os sinergistas são compostos polifuncionais contendo vários grupos $-\mathrm{OH}$ ou $-\mathrm{COOH}$, ou ambos, ou outros grupos similares onde o oxigênio é substituído pelo enxofre ou nitrogênio (Cheftel, 1989).

A ação dos sinergistas pode ser ilustrada como se segue (Antunes \& Canhos, 1988):

$$
\begin{aligned}
& \mathrm{ROO}^{*}+\mathrm{AH} \text { (antioxidante primário) } \longrightarrow \mathrm{ROOH}+\mathrm{A}^{*} \\
& \mathrm{~A}^{\bullet}+\mathrm{SH} \text { (sinergista) } \longrightarrow \mathrm{AH}+\mathrm{S}^{\bullet}
\end{aligned}
$$

$\mathrm{O}$ antioxidante é regenerado pelo sinergista e o radical $\mathrm{S}^{\bullet}$, menos ativo do que $\mathrm{A}^{\bullet}$ é formado. Existem indícios de que os sinergistas previnem a decomposição de peróxidos por antioxidantes primários, retardando assim o aparecimento de "off-flavors". Alguns autores admitem que a ação de sinergistas deve-se somente à inativação de metais que catalisariam a autoxidação (quelante de metais), sendo porém assunto ainda bastante controvertido (Gava, 1978). 
Frequentemente, utilizam-se combinações de antioxidantes para obterem-se melhores efeitos através do sinergismo. $O$ uso da combinação resulta em maior estabilidade do que se fossem utilizados os antioxidantes individuais separadamente. Praticamente todas as formulações comerciais de antioxidantes contém ácidos cítricos ou citratos solúveis, incluídos como quelantes metálicos (Stuckey, 1983).

$\mathrm{Na}$ fotoxidação de óleos, a inibição da ação do oxigênio singlete, forma mais reativa e responsável pelo início da reação, pode ser conseguida com supressores naturais denominados "quenchers" (sequestrantes) ( $\beta$-caroteno e $\alpha$-tocoferol), que retiram do oxigênio singlete seu excesso de energia, dissipando-a como radiação e regenerando o oxigênio triplete, mais estável (Carlsson et al., 1976). Os sequestrantes também podem inativar os sensibilizadores, nos estados ativos, evitando a formação do oxigênio singlete (Jung \& Min, 1991).

O efeito da concentração do antioxidante sobre a intensidade de autoxidação depende de muitos fatores, incluindo a estrutura do antioxidante, condições de oxidação e natureza das amostras que estão sendo oxidadas (óleos ou gorduras). Muitos antioxidantes perdem sua atividade em altas concentrações e comportam-se como próoxidantes através do envolvimento nas reações de iniciação (Shahidi \& Wanasundara, 1992). É importante observar que os antioxidantes devem ser adicionados o mais cedo possível durante a produção ou no produto acabado, pois depois de rancificados os óleos não são melhorados com a adição deles.

\subsubsection{Antioxidantes sintéticos}

Os principais antioxidantes sintéticos de uso comercial são o butileno hidroxitolueno (BHT), o butileno hidroxianisol (BHA), o tertio-butileno hidroquinona (TBHQ) e os galatos (Tabela 7). São denominados de antioxidantes de ação primária porque reagem com os radicais livres formados, transformando-os em compostos estáveis devido à presença de um grupo fenólico na estrutura que entra em ressonância (Dorko, 1995). 
Tabela 7. Concentração máxima de antioxidantes sintéticos permitida em óleos vegetais

\begin{tabular}{ll}
\hline Antioxidante & Concentração \\
\hline BHA & $0,02 \mathrm{~g} / 100 \mathrm{~g}$ \\
BHT & $0,01 \mathrm{~g} / 100 \mathrm{~g}$ \\
TBHQ & $0,02 \mathrm{~g} / 100 \mathrm{~g}$ \\
\hline
\end{tabular}

Fonte: Brasil (1991)

A atividade de antioxidantes fenólicos envolve a supressão de radicais livres peróxido que são gerados durante o processo de formação de radicais livres na autoxidação de óleos e gorduras. Os antioxidantes fenólicos são extintores do radical peróxido pela doação de hidrogênios para produzir hidroperóxidos e radicais livres fenóxido (peróxido de fenol) (Kurechi \& Kato, 1980).

O butileno hidroxianisol (BHA) e butileno hidroxitolueno (BHT) são sinergistas entre si. O BHA age como sequestrante de radicais peróxido, enquanto o BHT age como sinergista, ou regenerador de radicais BHA (Omura, 1995).

O tertio-butileno hidroquinona (TBHQ) é relativamente solúvel em óleo e gordura e não se complexa com íons de cobre e ferro, como o galato. A inclusão de um agente quelante como ácido cítrico junto com o TBHQ pode acentuar suas propriedades de estabilização. Essa combinação é usada em óleos vegetais, "shortenings" e gorduras animais (Gunstone \& Norris, 1983).

O TBHQ é considerado o melhor antioxidante de óleos de fritura para prevenção da oxidação pois resiste ao calor e, como BHA e BHT, ele proporciona uma excelente estabilidade para os produtos acabados (Dziezac, 1986).

\subsubsection{Tocoferol}

Os tocoferóis ocorrem abundantemente na natureza e são antioxidantes monofenólicos, ajudando a estabilizar muitos óleos derivados de plantas. São formados por oito diferentes compostos pertencentes a duas famílias, tocol e tocotrienóis, tendo os 
prefixos $\alpha-; \beta-; \gamma$ - ou $\delta$-, dependendo do número e posição do grupo metil ligado no anel fenol. Os alimentos vegetais contém quantidades consideráveis de diferentes tocoferóis e tocotrienóis na sua fração lipídica. Cereais, sementes oleaginosas e castanhas são fontes ricas de tocoferol. No reino animal, o tocoferol é somente encontrado em quantidadestraço. Os tocoferóis estão presentes nos óleos vegetais e estima-se que durante o processamento de óleos 30 a 40\% são perdidos (Shahidi \& Wanasundara, 1992).

A atividade antioxidante de $\alpha-\beta$ - e $\gamma$ - tocoferol depende da temperatura; a baixas temperaturas $\left(25-35^{\circ} \mathrm{C}\right)$ os três compostos apresentam atividades bastante próximas, enquanto que a $95^{\circ} \mathrm{C}$ o $\gamma$-tocoferol é muito mais ativo que o $\alpha$-tocoferol (Chipault, 1962).

De acordo com St. Angelo (1996) dentre os antioxidantes naturais os tocoferóis são os mais largamente usados. Tocoferóis são particularmente eficientes na estabilização de gorduras animais, sendo adicionados em vários tipos de alimentos. Estima-se que no Japão $50 \%$ dos antioxidantes usados são tocoferóis.

A atividade antioxidante do tocoferol é baseada no sistema redox tocoferoltocoferil quinona. Tocoferóis são terminadores de radicais livres e "quencher" de radicais lipídicos, regenerando moléculas de ácido graxo insaturado, e produzindo um radical tocoferil semiquinona. Dois radicais tocoferil semiquinona podem formar uma molécula de tocoferil quinona e regenerar uma molécula de tocoferol (Shahidi \& Wanasundara, 1992).

Os tocoferóis funcionam como antioxidantes por servirem como terminadores de radicais livres e sequestradores de moléculas de oxigênio singlete (St. Angelo, 1996).

Jung \& Min (1990) definiram as concentrações ótimas de 100 ppm para $\alpha-, 250$ ppm para $\gamma$ - e 500 ppm para $\delta$-tocoferóis para óleos de soja purificados e armazenados no escuro à temperatura de $55^{\circ} \mathrm{C}$. Os tocoferóis apresentaram significativos efeitos próoxidantes em concentrações acima destas concentrações.

Em trabalho realizado por Jung et al. (1991) observou-se o efeito antioxidante de diferentes concentrações de $\alpha$-, $\gamma$ - ou $\delta$ - tocoferol na fotoxidação de óleo de soja contendo clorofila b. Observou-se que quando as concentrações de tocoferóis 
aumentaram, os valores de peróxido diminuíram e a concentração de oxigênio aumentou. A concentração de $1,0 \times 10^{-3} \mathrm{M}$ de $\alpha$-tocoferol mostrou maior efeito antioxidante, seguido por $\gamma$-tocoferol e depois $\delta$ - tocoferol nas mesmas concentrações. $O \alpha$-tocoferol age como sequestrante de oxigênio singlete reduzindo a fotoxidação do óleo.

\subsection{3 $\beta$-Caroteno}

O termo carotenóide refere-se a um grupo de pigmentos, variando da cor amarela ao vermelho escuro, que são largamente distribuídos no reino animal e vegetal. Quimicamente os carotenóides são substâncias tetraterpênicas, formadas por oito unidades de isopreno, de tal modo que a ligação isoprênica sofre reversão na parte central da molécula, e dessa maneira os dois grupos metílicos ficam separados por três carbonos (Bobbio \& Bobbio, 1991).

Foote \& Denny (1968) atribuíram ao $\beta$-caroteno a capacidade de reprimir fisicamente a formação do oxigênio singlete, evitando a fotoxidação.

Os carotenóides $\beta$-caroteno, a cantaxantina e o $\beta$-apo-8'-carotenal recebem a energia do oxigênio singlete de forma constante, graças aos seus dienos conjugados, fazendo com que a molécula de oxigênio volte ao seu estado fundamental. Através de movimentos vibracionais e rotacionais, estes carotenóides dissipam a energia extra, retornando ao seu estado normal (Rogers \& Bates, 1980 e Burton \& Ingold, 1984). Krinsky (1989) observou que o mecanismo de proteção oferecido pelos carotenóides parece depender do número de duplas ligações existente na molécula, atingindo o máximo em pigmentos com nove ou mais duplas ligações.

Kiritsakis \& Dugan (1985) observaram que a presença de 4 ou $6 \mathrm{ppm}$ de $\beta$ caroteno diminuiu a formação de peróxido nos estágios iniciais da fotoxidação em óleos de oliva.

Segundo Fakourelis et al. (1987), o óleo de oliva estocado em garrafas de vidro na presença de luz apresentou fotoxidação reduzida pela adição de $\beta$-caroteno, que foi atribuída à ação do $\beta$-caroteno como filtro da energia luminosa. 
Warner \& Frankel (1987) verificaram que o $\beta$-caroteno teve um significativo efeito sobre a qualidade do óleo de soja. Quantidades bem maiores dos compostos voláteis, 2,4-decadienal e 2-heptanal, foram encontradas nas amostras controle do que nos óleos contendo de 1 a 20 ppm de $\beta$-caroteno.

O $\beta$-caroteno agiu como extintor de oxigênio singlete e não como extintor de clorofila em óleos adicionados de $4 \mathrm{ppm}$ de clorofila estocados sob luz. Quando as amostras foram estocadas no escuro, $o \beta$-caroteno não teve nenhum efeito na estabilidade oxidativa do óleo de soja com clorofila (Lee \& Min, 1988).

Terao (1989) estudou o efeito da atividade antioxidante do $\beta$-caroteno, zeaxantina, cantaxantina e astaxantina em solução contendo metil linoleato, ativado com 2,2'-azobis (2,4-dimetilvaleronitrila) ou AMVN. A degradação dos carotenóides foi proporcional à formação de hidroperóxidos.

Das \& Pereira (1990), analisando o uso de antioxidantes naturais em óleos comestíveis, observaram que a vitamina A e seus análogos, retinal, ácido retinóico, acetato de retinol e palmitato de retinol, mostraram potente efeito antioxidante, recomendando seu uso como uma alternativa na inibição da peroxidação lipídica em nutrição animal.

Jung \& Min (1991) estudaram a eficiência dos carotenóides $\beta$-apo-8'-carotenal, $\beta$-caroteno e cataxantina na fotoxidação do óleo de soja contendo clorofila, expostos a uma fonte de luz de 4000 lux. O índice de peróxidos do óleo de soja sem clorofila após 8 horas de armazenamento sob a ação da luz foi de $0,5 \mathrm{meq}$ de $\mathrm{O}_{2} / \mathrm{kg}$. $\mathrm{O}$ índice de peróxidos do óleo com e sem clorofila depois de 8 horas no escuro foi zero. $O$ índice de peróxido da mesma amostra com clorofila após 8 horas sob luz, foi de 75,9 meq de $\mathrm{O}_{2}$ / kg. Mais de $99 \%$ da oxidação do óleo de soja ocorreu em consequência da fotoxidação do oxigênio singlete sensibilizada pela clorofila. Menos de $1 \%$ da oxidação foi promovida pelo oxigênio triplete. Os carotenóides reduziram os índices de peróxidos, sendo a cataxantina a mais eficiente, seguida do $\beta$-caroteno e $\beta$-apo-8'-carotenal. 


\section{MATERIAIS E MÉTODOS}

\section{1 Óleos refinados de canola, milho e soja}

Os óleos usados no experimento foram obtidos das indústrias, na forma de óleo refinado, sem a adição de antioxidantes e prontos para o envase em frascos de PET. Após chegarem ao laboratório foram analisados e uma parte foi engarrafada em frascos de PET para o início do ensaio 1, descrito em 3.3, e a outra parte foi colocada em garrafas plásticas de 2 litros e congelados $\left(-18^{\circ} \mathrm{C}\right)$ para posterior utilização.

Para caracterização inicial dos óleos foram feitas as seguintes determinações:

\subsubsection{Determinação do teor de clorofila}

Foi determinada a absorbância dos óleos diluídos ou não em cloreto de metileno $\left(\mathrm{CH}_{2} \mathrm{Cl}_{2}\right)$, conforme o método $\mathrm{Cc} 13 \mathrm{~d}-55$ da AOCS (1983), nos comprimentos de onda 630,670 e $710 \mathrm{~nm}$. Os resultados foram expressos em $\mathrm{mg} / \mathrm{t}(\mathrm{ppb})$.

\subsection{2 Índice de acidez}

Foi realizado segundo as normas da AOCS (1983), dissolvendo-se amostras de $5 \mathrm{~g}$ de óleo, em triplicata, em álcool etílico, neutralizado previamente, a quente $\left(60-65^{\circ} \mathrm{C}\right)$ e, a seguir, titulando-se com solução de hidróxido de sódio (de normalidade conhecida). Determinou-se o volume gasto até o ponto de viragem, empregando-se fenolftaleína como indicador, calculando-se a quantidade de ácidos graxos livres, através da seguinte expressão: 


$$
\mathrm{IA}=\frac{\mathrm{ml} \text { gastos } \times 56,1 \times \mathrm{N}}{\text { peso da amostra }} \mathrm{mg} \mathrm{KOH} / \mathrm{g} \text { de óleo }
$$

$\mathrm{N}$ = normalidade da solução de hidróxido de sódio

\subsection{3 Índice de peróxido}

Foi determinado, segundo as normas da AOCS (1983), através da dissolução de amostras de $5 \mathrm{~g}$ de óleo, em triplicata, em solução de ácido acético e clorofórmio (3:1), adição de solução de iodeto de potássio saturada e água destilada. Titulou-se com solução de tiossulfato de sódio,de normalidade conhecida, sendo que o volume gasto, após a adição de goma de amido para a verificação do ponto de viragem, indica a concentração em peróxidos em meq $\mathrm{O}_{2} / 1000 \mathrm{~g}$ de óleo, através da seguinte fórmula:

$$
\mathrm{IP}=\frac{\mathrm{Nx}(\mathrm{A}-\mathrm{B}) \times 1000}{\text { peso da amostra }(\mathrm{g})}
$$

$\mathrm{A}=\mathrm{ml}$ de solução de tiossulfato de sódio gastos na amostra

$\mathrm{B}=\mathrm{ml}$ de solução de tiossulfato de sódio gastos no "branco"

$\mathrm{N}=$ normalidade da solução de tissulfato de sódio

\subsection{4 Índice de iodo}

Consistiu, de acordo com as normas da AOCS (1983), na adição de tetracloreto de carbono para dissolução do óleo e de solução de Wijs às amostras de 0,2 a $0,22 \mathrm{~g}$ de óleo, em triplicata. $O$ iodo liga-se às duplas ligações, reação que ocorre no escuro por 30 minutos, quando então adicionou-se solução de KI (15\%) e água destilada. Titulou-se, com solução de tiossulfato de sódio, com adição de goma de amido, o excesso de iodo no meio. Pela diferença entre os volumes gastos na titulação do "branco" e da amostra, obteve-se o número de $\mathrm{mg}$ de iodo absorvido por $100 \mathrm{mg}$ de óleo. 


$$
I I=\frac{(B-A) \times N \times 12,69}{\text { peso da amostra }(g)}
$$

$\mathrm{B}=\mathrm{ml}$ de solução de tiossulfato de sódio gastos no "branco"

$\mathrm{A}=\mathrm{ml}$ de solução de tiossulfato de sódio gastos na amostra

$\mathrm{N}=$ normalidade da solução de tiossulfato de sódio

\subsubsection{Exame espectrofotométrico sob luz ultravioleta}

Foi determinada o coeficiente de extinção dos óleos diluídos em isoctano, conforme a IUPAC (1979), nos comprimentos de onda 232 e $270 \mathrm{~nm}$. Os resultados foram expressos em $\mathrm{E}^{1 \%}{ }_{\mathrm{lcm}}$, dado pela seguinte fórmula:

$$
\mathrm{E}^{1 \%}{ }_{1 \mathrm{~cm}}=\frac{\mathrm{A}}{\mathrm{C} \times \mathrm{D}}
$$

$\mathrm{A}=$ medida da absorbância no comprimento de onda

$\mathrm{C}=$ concentração da solução, em g por $100 \mathrm{ml}$ da solução

$\mathrm{D}=$ comprimento da célula, em $\mathrm{cm}(1 \mathrm{~cm})$

\subsection{6 Índice de saponificação}

Consistiu, de acordo com as normas da AOCS (1983), na adição de $25 \mathrm{ml}$ de solução alcoólica de $\mathrm{KOH} 0,5 \mathrm{~N}$ às amostras de $2 \mathrm{~g}$, em triplicata, que foram levadas ao condensador de refluxo por 30 minutos. As amostras foram então resfriadas e tituladas com solução de $\mathrm{HCl} 0,5 \mathrm{~N}$, usando fenolftaleína como indicador. Para cálculo do índice foi usada a seguinte fórmula:

$$
\mathrm{IS}=\frac{(\mathrm{A}-\mathrm{B}) \times 28,05 \times \mathrm{F}}{\text { peso da amostra }(\mathrm{g})}
$$


$\mathrm{A}=\mathrm{ml}$ de $\mathrm{HCl} 0,5 \mathrm{~N}$ gastos na prova em branco

$\mathrm{B}=\mathrm{ml}$ de $\mathrm{HCl} 0,5 \mathrm{~N}$ gastos com a amostra

$\mathrm{F}=$ fator do $\mathrm{HCl} 0,5 \mathrm{~N}$

\subsection{Embalagem de PET (polietileno tereftalato)}

A embalagem de polietileno teraftalato utilizada nesse trabalho foi obtida da indústria produtora de embalagem para óleos vegetais. A embalagem foi submetida às seguintes avaliações:

\subsubsection{Dimensões}

Foram determinados a altura e o diâmetro da secção mediana do frasco de PET usando-se uma régua de $30 \mathrm{~cm}$.

\subsubsection{Peso}

O peso das embalagens vazias, secas e sem tampas foi determinado em balança analítica com precisão de $0,1 \mathrm{~g}$.

\subsubsection{Capacidade volumétrica}

Foi determinada com água à temperatura de $25^{\circ} \mathrm{C}$, com auxilio de proveta graduada.

\subsubsection{Transparência}

Foi avaliada de acordo com Soler et al. (1986) em espectrofotometro de varredura SHIMADZU UV-1203, usando amostras do material de dimensões 
aproximadas de $1 \times 5 \mathrm{~cm}$, utilizando-se de ar atmosférico como referência e variando-se $o$ comprimento de onda de 700 a $200 \mathrm{~nm}$. O resultado é apresentado em gráficos de porcentagem de transmitância em função do comprimento de onda.

\subsubsection{Relação superfície-volume}

Essa relação foi encontrada dividindo-se a área da superficie da embalagem PET pelo volume da mesma. As fórmulas usadas para determinação da área e do volume foram:

Área da superficie $=2 \pi \mathrm{r} . \mathrm{h}$

Volume $=\pi \mathrm{r}^{2} \cdot \mathrm{h}$

$r=$ raio da garrafa

$\mathrm{h}=$ altura da garrafa

\subsection{Ensaio 1 - Armazenamento ambiente.}

Os óleos refinados de canola, milho e soja, adicionados ou não de antioxidantes, foram acondicionados em frascos de PET (polietileno tereftalato) e armazenados em condições ambientes no Laboratório de Óleos e Gorduras do Departamento de Ciência e Tecnologia de Alimentos (ESALQ/ USP) (Figura 2). O armazenamento foi conduzido por período de seis meses, sendo que cada óleo foi armazenado em período distinto. $\mathrm{Na}$ Figura 3 são apresentadas as condições de umidade relativa e temperatura média ao longo dos meses de armazenamento. O óleo de milho foi armazenado no período de outubro de 1996 a abril de 1997; o óleo de canola foi armazenado de janeiro a julho de 1997 e o óleo de soja foi armazenado de fevereiro a agosto de 1997. 


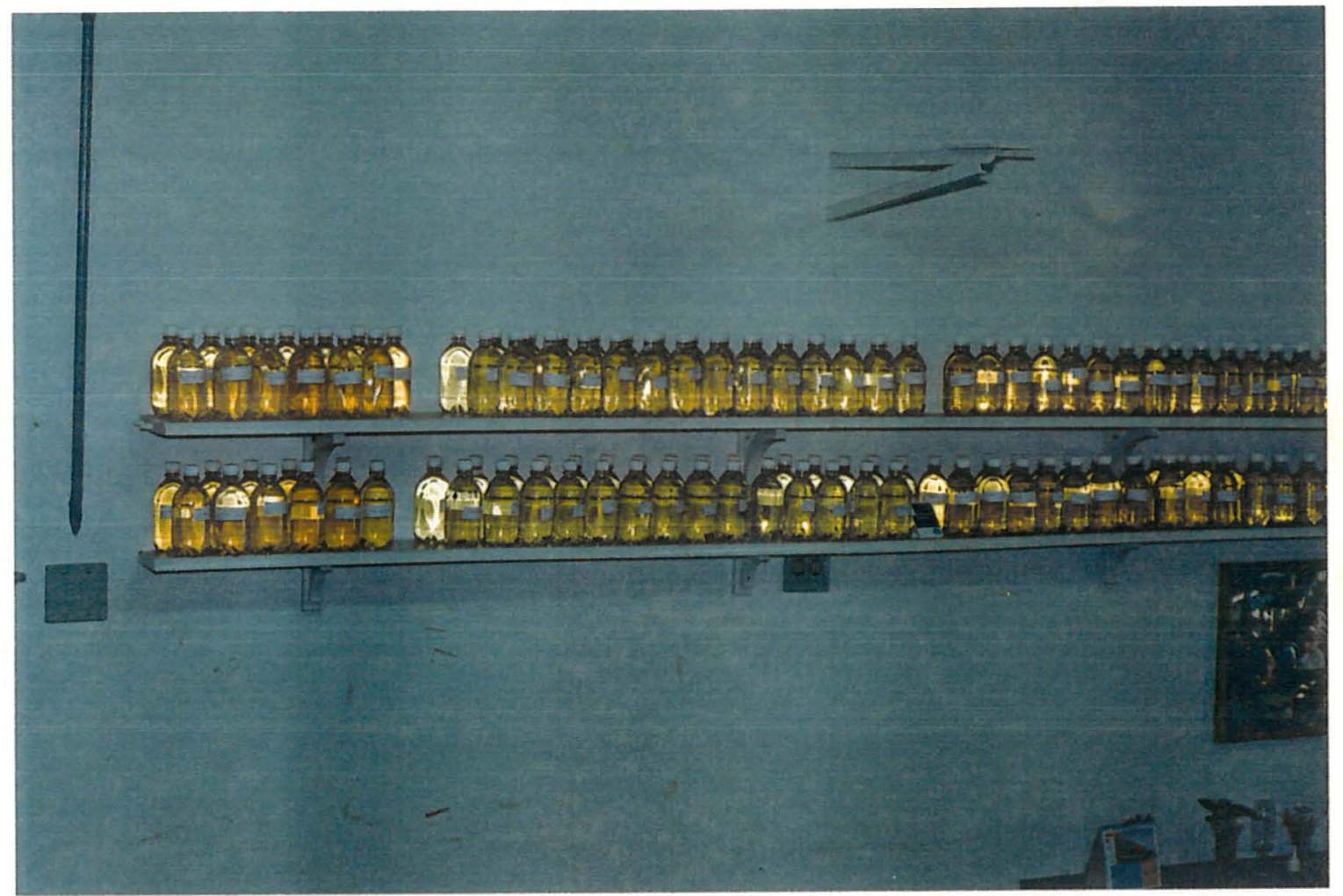

Figura 2 - Armazenamento dos óleos de canola, milho e soja embalados em frascos PET sob condições ambientes (Laboratório de Óleos e Gorduras -ESALQ/USP).

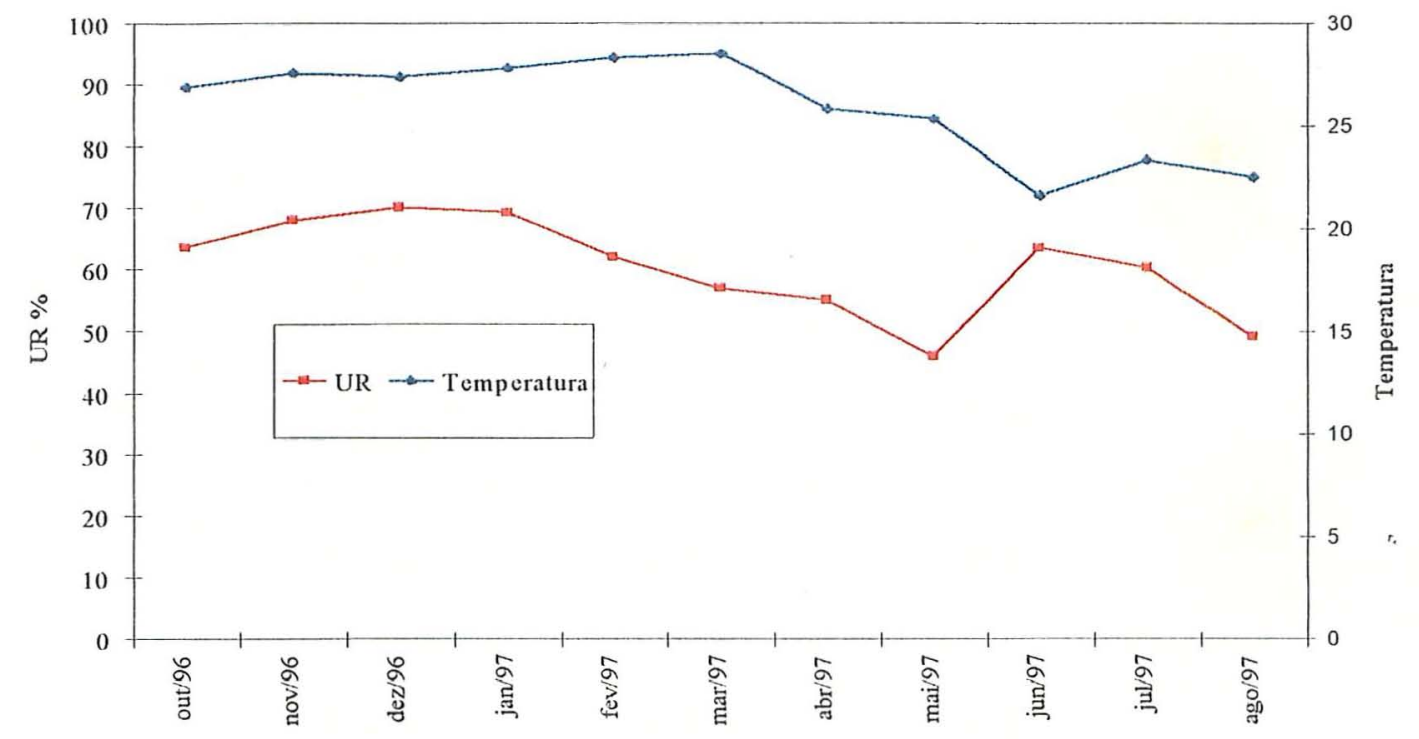

Figura 3 - Curvas de Umidade Relativa (\%) e Temperaturas médias $\left({ }^{\circ} \mathrm{C}\right)$ ao longo dos, meses de armazenamento ambiente. 
A intensidade luminosa no ambiente de armazenamento foi de 210 lux, medida com luxímetro da marca ELLE. Nos pontos de venda de óleos vegetais em embalagem de PET também encontrou-se intensidade luminosa em torno de 210 lux.

Para cada óleo foram aplicados os seguintes tratamentos:

$$
\begin{aligned}
& 1 \text { - BHT + BHA (200 ppm) } \\
& 2 \text { - BHT + BHA (200 ppm) + ácido cítrico (100 ppm) } \\
& 3 \text { - Ácido cítrico (100 ppm) } \\
& 4 \text { - Controle }
\end{aligned}
$$

Os antioxidantes foram adicionados diretamente aos óleos, sendo diluídos numa pequena quantidade e homogeneizados ao volume final sob agitação mecânica.

Os tratamentos foram conduzidos em triplicata, somando-se um total de 324 frascos (108 frascos/ óleo). As análises de caracterização foram realizadas a cada quinze dias nos três primeiros meses, e mensalmente nos meses subsequentes, excetuando-se a análise de índice de iodo, que foi realizada mensalmente em todo o ensaio. Foram realizadas as seguintes análises:

3.3.1 Índice de acidez, segundo as normas da AOCS (1983) conforme descrito no item 3.1.2;

3.3.2 Índice de peróxido, segundo as normas da AOCS (1983) de acordo com item 3.1.3;

3.3.3 Índice de iodo, segundo as normas da AOCS (1983) conforme item 3.1.4;

3.3.4 Exame espectrofotométrico sob luz ultravioleta nos comprimentos de onda 232 e 270 nm, de acordo com método da IUPAC (1979), como em 3.1.5. 


\subsubsection{Análise estatística}

Para cada óleo foi aplicado um delineamento inteiramente casualizado em esquema fatorial (4 tratamentos x 10 épocas de amostragens e para o índice de iodo 4 tratamentos x 7 épocas de amostragens), com três repetições (Gomes, 1960). Os resultados foram analisados pelo teste de Tukey em nível de significância de $5 \%$, utilizando o programa SANEST (Zonta \& Machado, 1992).

\subsection{Ensaio 2 - Fotoxidação acelerada}

O ensaio 2 foi planejado para que se pudessem comparar os resultados obtidos no armazenamento ambiente (ensaio 1) com os do teste acelerados de fotoxidação em câmara de luz.

O teste acelerado de fotoxidação foi conduzido em câmara de luz adaptada da câmara usada por Lee \& Min (1988), com variação na potência das lâmpadas usadas, alterando-se de $15 \mathrm{~W}$ para $20 \mathrm{~W}$, e consequentemente na intensidade luminosa. As lâmpadas fluorescentes de $20 \mathrm{~W}$ são as que normalmente são usadas para a iluminação nos pontos de armazenamento de óleos.

A câmara de luz empregada nesse ensaio consistiu de um compartimento retangular de dimensões $80 \times 35 \times 60 \mathrm{~cm}$, de alvenaria, com 6 lâmpadas fluorescentes de $20 \mathrm{~W}$, dispostas 3 lâmpadas na parte superior e as outras 3 na parte inferior da câmara (Figura 4). A intensidade luminosa na câmara foi de 8.370 lux. 


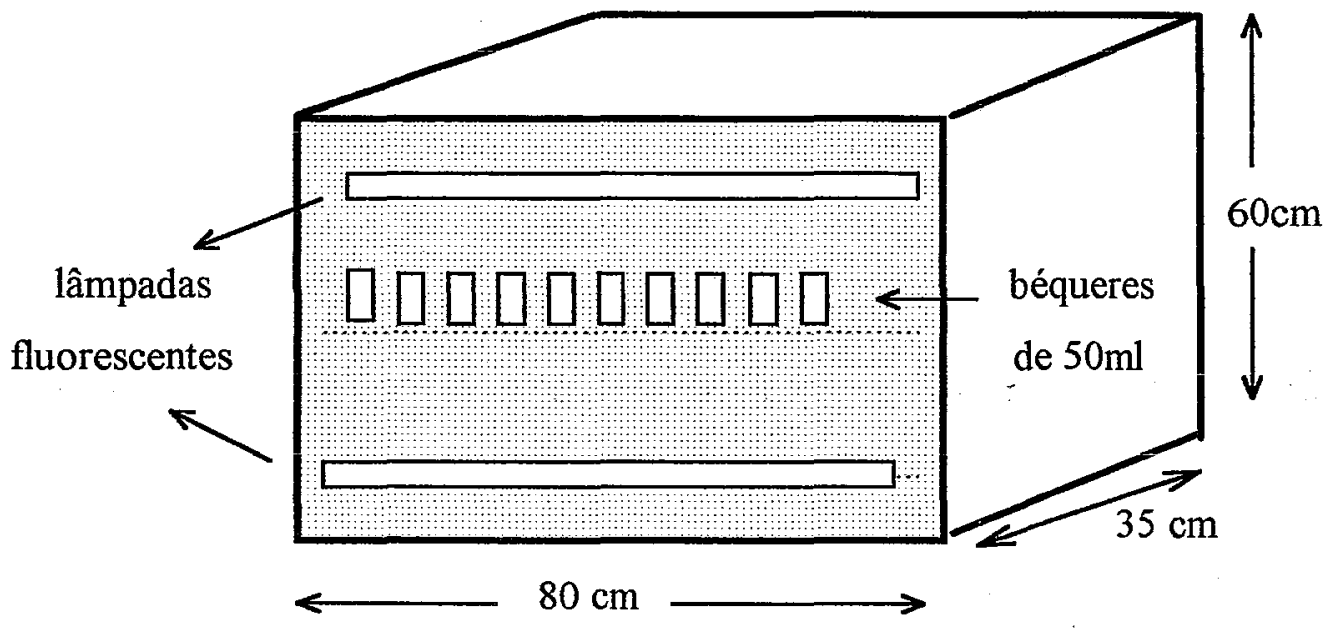

Figura 4 - Câmara de fotoxidação.

Foram avaliados os óleos de canola, milho e soja adicionados dos mesmos antioxidantes do ensaio 1:

$$
\begin{aligned}
& 1 \text { - BHT + BHA (200 ppm) } \\
& 2 \text { - BHT + BHA (200 ppm) + ácido cítrico (100 ppm) } \\
& 3 \text { - Ácido cítrico (100 ppm) } \\
& 4 \text { - Controle }
\end{aligned}
$$

Os antioxidantes foram adicionados diretamente aos óleos e homogeneizados sob agitação mecânica.

Este ensaio foi desenvolvido utilizando-se amostras de óleos de $30 \mathrm{ml}$ colocadas em béqueres de vidro de $50 \mathrm{ml}$. A cada 24 horas foram retiradas amostras de cada tratamento, totalizando 120 horas de exposição à luz. As análises realizadas nesse ensaio foram:

3.4.1 Índice de acidez, segundo as normas da AOCS (1983), conforme item 3.1.2;

3.4.2 Índice de peróxido, segundo as normas da AOCS (1983), como descrito em 3.1.3; 
3.4.3 Índice de iodo, segundo as normas da AOCS (1983), de acordo com item 3.1.4;

3.4.4 Exame espectrofotométrico sob luz ultravioleta nos comprimentos de onda 232 e 270 nm, de acordo com método da IUPAC (1979), como em 3.1.5.

\subsubsection{Análise estatística}

Para cada óleo foi aplicado um esquema fatorial em delineamento inteiramente casualizado (4 tratamentos x 6 épocas de amostragem), com 3 repetições (Gomes, 1960). Os resultados foram analisados pelo teste de Tukey em nível de significância de 5\%, utilizando o programa SANEST (Zonta \& Machado, 1992).

\subsection{Ensaio 3 - Atividade antioxidante de $\beta$-caroteno, $\alpha$-tocoferol e TBHQ.}

Este ensaio também foi realizado na câmara de fotoxidação (Figura 2), na qual se verificou a influencia da adição dos compostos $\beta$-caroteno, $\alpha$-tocoferol e TBHQ na fotoxidação dos óleos de canola, milho e soja. Os resultados foram comparados com os obtidos no ensaio 3.4 .

Foram avaliados os seguintes tratamentos:

1 - óleo $+500 \mathrm{ppm}$ de $\alpha$-tocoferol,

2 - óleo + 1 ppm de $\beta$-caroteno,

3 - óleo +200 ppm de TBHQ

4 - controle - óleo

Os antioxidantes TBHQ e $\alpha$-tocoferol foram usados nas doses máximas permitidas para a adição em óleos vegetais (FAO, 1995). O $\beta$-caroteno foi utilizado na dose de 1 ppm de acordo com Warner \& Frankel (1987), que encontraram efeito antioxidante no óleo de soja adicionado desta concentração sem alteração de coloração.

$\mathrm{O}$ antioxidante $\alpha$-tocoferol foi adicionado aos óleos na forma de solução oleosa a $95 \%$, o $\beta$-caroteno, como solução em hexano de concentração $19,61 \%$ e o TBHQ, em 
pó, foi adicionado diretamente ao óleo. Todos os antioxidantes foram previamente dissolvidos numa pequena quantidade de óleo sob agitação mecânica antes da adição ao volume final.

Para acompanhamento da qualidade dos óleos foram realizadas as análises:

3.5.1 Índice de acidez, segundo as normas da AOCS (1983), conforme descrito em 3.1.2;

3.5.2 Índice de peróxido, segundo as normas da AOCS (1983), de acordo com item 3.1.3;

3.5.3 Exame espectrofotométrico sob luz ultravioleta nos comprimentos de onda 232 e $270 \mathrm{~nm}$, de acordo com método da IUPAC (1979), de acordo com item 3.1.5.

\subsubsection{Absorbância dos óleos de canola, milho e soja no espectro visível}

Amostras de óleos de canola, milho e soja, adicionadas ou não de $\beta$-caroteno não expostas à luz no teste acelerado ou após 120 horas de exposição, foram colocadas no espectrofotômetro de varredura SHIMADZU UV-1203, sem prévia diluição, para a determinação do espectro das mesmas na região do visível $(400-700 \mathrm{~nm}$ ) (Albi et al., 1997).

\subsubsection{Análise estatística}

O ensaio foi conduzido no esquema fatorial (4 tratamento $x 6$ épocas de amostragem) e delineamento inteiramente casualizado, com três repetições (Gomes, 1960). Foi realizado teste de Tukey para médias de antioxidantes, médias de tempo e médias da interação entre antioxidante e tempo, para cada óleo separadamente. Foi considerado nível de significância de 5\%, usando-se o programa SANEST (Zonta \& Machado, 1992) para análises dos dados. 


\section{RESULTADOS}

\subsection{Caracterização inicial dos óleos}

Na Tabela 8 encontrame-se os resultados da caracterização inicial dos óleos usados no experimento. Observa-se que em relação aos índices de peróxido e de acidez, que exprimem a qualidade dos óleos, todos os três óleos usados encontram-se com valores abaixo do permitido pela legislação, $10 \mathrm{meq} / \mathrm{kg}$ de índice de peróxido e 0,6 mg de $\mathrm{KOH} / \mathrm{g}$ óleo de acidez (FAO, 1995). Quanto ao índice de iodo os óleos encontram-se dentro dos valores de identidade (110-126, 103-128 e 120-143 mg I/ $100 \mathrm{mg}$ para óleo de canola, milho e soja, respectivamente). $\mathrm{O}$ índice de saponificação dos três óleos analisados encontra-se dentro dos limites estabelecidos (188-193, 187-195 e 189-195 mg $\mathrm{KOH} / \mathrm{g}$ para os óleos de canola, milho e soja, respectivamente) (Padley et al., 1994). O teor de clorofila encontrado nos óleos de canola e soja são valores que normalmente são encontrados para óleos refinados. De acordo com Pritcheet et al. (1947), a refinação pode remover entre 74 a $92 \%$ da clorofila do óleo bruto, cujo teor é de cerca de $0,15 \mathrm{ppm}$. Os autores mencionam que o grau de remoção deste componente depende muito da quantidade de terra ativada utilizada durante a operação de clarificação, resultando na produção de óleos refinados com teor de clorofila com variação de 0,01 a $0,04 \mathrm{ppm}$. 
Tabela 8. Caracterização inicial dos óleos de canola, milho e soja refinados

\begin{tabular}{lccc}
\hline \multicolumn{1}{c}{ Características } & Canola & Milho & Soja \\
\hline Indice de Peróxido (meq $\mathrm{O}_{2} / \mathrm{kg}$ ) & 0,670 & 1,350 & 2,170 \\
Índice de Iodo (mg de $\mathrm{I} / 100 \mathrm{mg})$ & 122,59 & 116,17 & 126,96 \\
$\mathrm{E}^{1 \%}{ }_{1 \mathrm{~cm}} 232 \mathrm{~nm}$ & 4,772 & 3,366 & 4,313 \\
$\mathrm{E}^{1 \%}{ }_{1 \mathrm{lcm}} 270 \mathrm{~nm}$ & 0,777 & 1,485 & 3,173 \\
Índice de Acidez (mg de $\mathrm{KOH} / \mathrm{g})$ & 0,10 & 0,10 & 0,10 \\
Índice de Saponificação $(\mathrm{mg} \mathrm{KOH} / \mathrm{g})$ & 189,27 & 192,92 & 189,24 \\
Teor de Clorofila $(\mu \mathrm{g} / \mathrm{kg})$ & 67,40 & 0 & 41,50 \\
\hline
\end{tabular}

\subsection{Caracterização da embalagem PET}

$\mathrm{Na}$ Tabela 9 e na Figura 5 podem-se ver os resultados da caracterização da embalagem utilizada no ensaio de armazenamento ao ambiente.

Tabela 9. Características do frasco de PET

\begin{tabular}{ll}
\hline Capacidade Volumétrica & $500 \mathrm{ml}$ \\
Peso & $26,8 \mathrm{~g}$ \\
Espessura de parede & $0,26 \mathrm{~mm}$ \\
Relação superficie / volume & 0,66 \\
Dimensões & altura $18 \mathrm{~cm} \times$ diâmetro $6 \mathrm{~cm}$ \\
Formato & Cilíndrico \\
\hline
\end{tabular}

As embalagens de PET são mais leves quando comparadas com as embalagens de lata de folha de flandres que são usadas para comercialização de óleos vegetais (Soler et al., 1986).

A medida da relação superficie - volume das embalagens comerciais de óleos vegetais foi obtida no laboratório, encontrando-se valores ao redor de 0,66 . Observa-se que as embalagens usadas nesse ensaio, embora de menor volume do que as embalagens 
de PET normalmente usadas para a comercialização de óleos, mantiveram a mesma relação superficie - volume das outras $(0,66)$.

Através da Figura 5 observa-se que a transmitância da embalagem é constante acima de $400 \mathrm{~nm}$ e que o material da embalagem barra a passagem de luz de comprimentos de onda inferiores à $300 \mathrm{~nm}$.

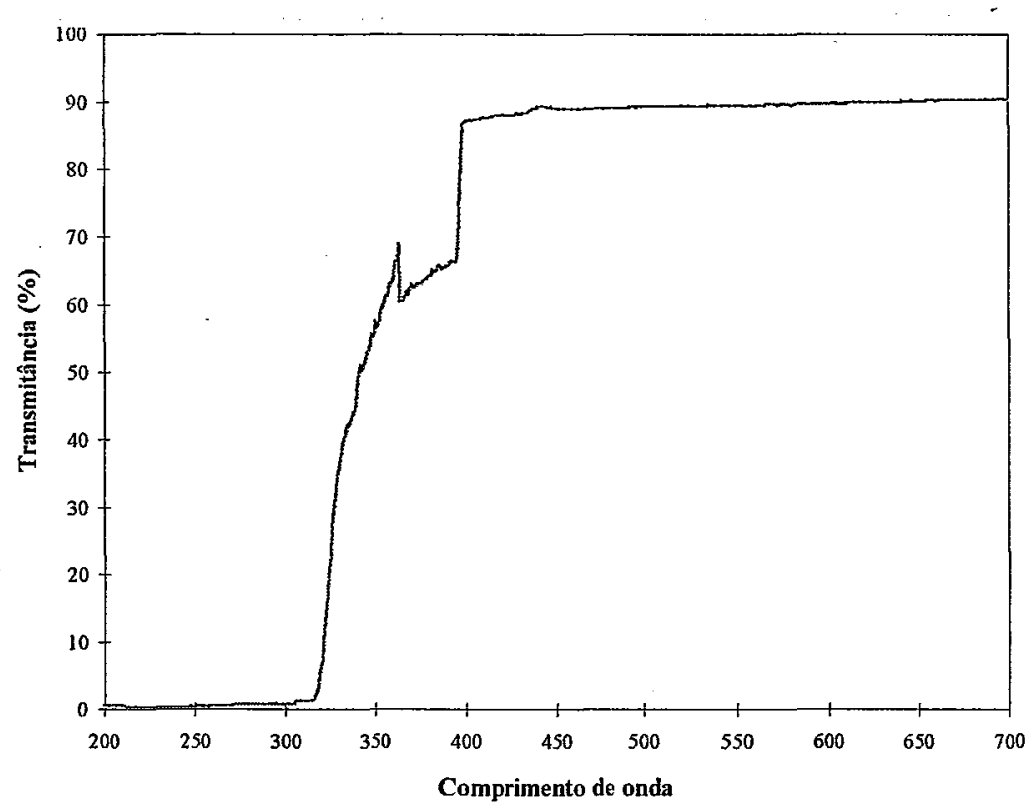

Figura 5 - Variação da transmitância da embalagem de PET com a variação do comprimento.

De acordo com Bekbölet (1990), as embalagens de materiais que transmitem comprimentos de onda entre 490 e $589,5 \mathrm{~nm}$ podem proteger os óleos contra o desenvolvimento de ranço. 


\subsection{Ensaio de armazenamento ambiente}

\subsection{1 Índice de acidez}

$\mathrm{O}$ índice de acidez indica o conteúdo de ácidos graxos livres presentes no óleo, em sua maior parte resultantes da hidrólise dos triglicerídeos. Os resultados obtidos do armazenamento ambiente podem ser vistos na Tabela 10 .

Tabela 10. Índice de acidez (mg KOH/ g de óleo) de óleos de canola, milho e soja embalados em frascos PET e armazenados sob condições ambientes.

\begin{tabular}{|c|c|c|c|c|c|c|c|c|c|c|}
\hline \multirow[b]{2}{*}{ Tratamentos } & \multicolumn{10}{|c|}{ Tempo (dias) } \\
\hline & 0 & 15 & 30 & 45 & 60 & 75 & 90 & 120 & 150 & 180 \\
\hline $\mathrm{Cl}$ & $0,11 \mathrm{a}$ & $0,10 a$ & $0,10 \mathrm{a}$ & $0,10 \mathrm{a}$ & $0,10 \mathrm{a}$ & $0,11 \mathrm{a}$ & $0,10 \mathrm{a}$ & $0,14 a$ & $0,15 a$ & $0,21 \mathrm{a}$ \\
\hline $\mathrm{C} 2$ & $0,10 \mathrm{a}$ & $0,10 \mathrm{a}$ & $0,10 a$ & $0,10 \mathrm{a}$ & $0,10 \mathrm{a}$ & $0,10 \mathrm{a}$ & $0,10 \mathrm{a}$ & $0,14 a$ & $0,16 a$ & $0,21 a$ \\
\hline $\mathrm{C} 3$ & $0,10 \mathrm{a}$ & $0,10 a$ & $0,12 \mathrm{a}$ & $0,10 \mathrm{a}$ & $0,10 \mathrm{a}$ & $0,10 \mathrm{a}$ & $0,10 \mathrm{a}$ & $0,14 a$ & $0,16 a$ & $0,21 a$ \\
\hline $\mathrm{C} 4$ & $0,10 a$ & $0,10 a$ & $0,10 \mathrm{a}$ & $0,10 \mathrm{a}$ & $0,10 \mathrm{a}$ & $0,10 a$ & $0,10 \mathrm{a}$ & $0,14 a$ & $0,16 a$ & $0,21 a$ \\
\hline \multicolumn{11}{|l|}{$\mathrm{CV}=6,72 \%$} \\
\hline M1 & $0,05 a$ & $0,10 \mathrm{a}$ & $0,10 \mathbf{a}$ & $0,10 \mathrm{a}$ & $0,10 \mathrm{a}$ & $0,10 \mathrm{~b}$ & $0,14 a$ & $0,20 \mathrm{a}$ & $0,15 a$ & $0,16 \mathrm{a}$ \\
\hline M2 & $0,05 a$ & $0,11 \mathrm{a}$ & $0,10 \mathrm{a}$ & $0,10 \mathrm{a}$ & $0,10 \mathrm{a}$ & $0,10 \mathrm{~b}$ & $0,14 a$ & $0,20 \mathrm{a}$ & $0,16 \mathrm{a}$ & $0,16 \mathrm{a}$ \\
\hline M3 & $0,05 a$ & $0,10 a$ & $0,10 \mathrm{a}$ & $0,10 a$ & $0,10 \mathrm{a}$ & $0,12 b$ & $0,14 a$ & $0,20 \mathrm{a}$ & $0,16 a$ & $0,16 \mathrm{a}$ \\
\hline M4 & $0,05 a$ & $0,10 \mathrm{a}$ & $0,10 \mathrm{a}$ & $0,10 \mathrm{a}$ & $0,10 \mathrm{a}$ & $0,16 a$ & $0,12 \mathrm{a}$ & $0,20 \mathrm{a}$ & $0,16 a$ & $0,14 a$ \\
\hline \multicolumn{11}{|c|}{$\mathrm{CV}=11,45 \%$} \\
\hline S1 & $0,10 a$ & $0,10 \mathrm{c}$ & $0,21 a$ & $0,17 b$ & $0,19 a$ & $0,21 b$ & $0,21 a$ & $0,25 \mathrm{a}$ & $0,30 a$ & $0,42 a$ \\
\hline S2 & $0,10 \mathrm{a}$ & $0,10 \mathrm{c}$ & $0,21 \mathrm{a}$ & $0,20 \mathrm{ab}$ & $0,19 a$ & $0,27 \mathrm{a}$ & $0,21 \mathrm{a}$ & $0,25 \mathrm{a}$ & $0,30 \mathrm{a}$ & $0,42 a$ \\
\hline S3 & $0,10 a$ & $0,14 \mathrm{ab}$ & $0,17 \mathrm{~b}$ & $0,21 \mathrm{ab}$ & $0,19 a$ & $0,22 \mathrm{~b}$ & $0,21 a$ & $0,25 a$ & $0,30 \mathrm{a}$ & $0,42 \mathrm{a}$ \\
\hline S4 & $0,10 \mathrm{a}$ & $0,16 a$ & $0,18 \mathrm{ab}$ & $0,20 \mathrm{~b}$ & $0,19 a$ & $0,21 b$ & $0,21 a$ & $0,25 a$ & $0,30 \mathrm{a}$ & $0,42 a$ \\
\hline
\end{tabular}

CV - coeficiente de variação

Os resultados constituem médias de três repetições; as médias seguidas pela mesma letra, na vertical, não diferem significativamente pelo teste de Tukey, a $5 \%$

Legenda: C - óleo de canola; M - óleo de milho; S - óleo de soja

$1-\mathrm{BHT}+\mathrm{BHA}(200 \mathrm{ppm})$

2 - BHT + BHA (200 ppm) + ácido cítrico (100 ppm)

3 - Ácido cítrico (100 ppm)

4 - Controle

Pelos dados obtidos pode-se observar que o índice de acidez aumentou ao longo do armazenamento para todos os óleos, sendo que esse aumento foi maior para o óleo de 
soja, o qual apresentou valor final 4 vezes superior ao inicial, mas não chegou ao valor máximo permitido para a utilização de óleos refinados.

A adição dos antioxidantes BHT, BHA e ácido cítrico nos tratamentos propostos não apresentou diferença estatísticamente significativa em relação ao controle pela análise do índice de acidez em nenhum dos óleos analisados.

O índice de acidez do óleo de canola manteve-se constante até 90 dias de armazenamento, ocorrendo um aumento gradativo a partir daí até completar os 6 meses de armazenamento. Já para o óleo de milho foi observado um aumento após 75 dias de armazenamento para os tratamentos 3 e 4. Para o óleo de milho o índice de acidez oscilou até 0,20 , mas ao final dos seis meses de armazenamento apresentou valores ao redor de 0,16 . No óleo de soja foram observados aumentos para o índice de acidez a partir dos 15 dias de armazenamento para os tratamentos 3 e 4 . Ao final de 180 dias de armazenamento foram encontrados valores de 0,42 para todos os tratamentos.

Pelos dados resultados obtidos pelo indice de acidez observou-se que provavelmente durante a fotoxidação dos óleos a reação de hidrólise foi pequena, resultando numa pequena variação desse índice.

\subsubsection{Indice de peróxido}

Os peróxidos são compostos formados pela oxidação de ácidos graxos na reação de ranço, refletindo o estado de conservação do óleo, portanto, quanto maior o índice de peróxido pior o seu estado de conservação.

Pela análise dos resultados (Tabela 11) observou-se que o índice de peróxido aumentou para os três óleos ao longo dos 180 dias de armazenamento, mas não foram encontrandos valores acima de $10 \mathrm{meq}$ de $\mathrm{O}_{2} / \mathrm{kg}$, limite máximo permitido pela legislação para consumo de óleos refinados.

O óleo de canola, com maior conteúdo de clorofila inicial, apresentou maior variação entre o índice de peróxido inicial e final. De acordo com Kaya et al. (1993), que estudaram a estabilidade oxidativa de óleos de girassol e oliva em frascos de vidro e de PET, no armazenamento de óleos vegetais em embalagens de PET ocorre um declínio da 
qualidade ao longo do tempo de armazenamento, sobretudo nos óleos com clorofila. Os autores encontraram que a estabilidade dos óleos foi maior nos frascos de vidro coloridos, seguidos pelos frascos de vidro transparentes e nos frascos de PET a estabilidade foi menor.

Não foram encontrados diferenças estatísticas significativas ao longo dos 6 meses de armazenamento para nenhum dos tratamentos feitos. Isso demonstra que a adição dos antioxidantes BHT, BHA e ácido cítrico, no período avaliado, não apresentou efeito significativo em controlar a oxidação de óleos vegetais de diferentes composições em ácidos graxos.

Tabela 11. Índice de peróxido (meq de $\mathrm{O}_{2} / \mathrm{kg}$ de óleo) de óleos de canola, milho e soja embalados em frascos PET e armazenados sob condições ambientes.

\begin{tabular}{|c|c|c|c|c|c|c|c|c|c|c|}
\hline \multirow[b]{2}{*}{ Tratamentos } & \multicolumn{10}{|c|}{ Tempo (dias) } \\
\hline & 0 & 15 & 30 & 45 & 60 & 75 & 90 & 120 & 150 & 180 \\
\hline $\mathrm{Cl}$ & $0,50 \mathrm{a}$ & $1,95 a$ & $2,74 a$ & $4,13 \mathrm{ab}$ & $2,59 a$ & $2,92 a$ & $3,18 \mathrm{ab}$ & $3,35 b$ & $3,31 a$ & $3,80 \mathrm{ab}$ \\
\hline $\mathrm{C} 2$ & $0,68 a$ & $1,78 \mathrm{a}$ & $2,21 b$ & $3,74 b$ & $2,68 a$ & $2,85 a$ & $3,40 \mathrm{ab}$ & $3,52 b$ & $3,13 a$ & $3,80 \mathrm{ab}$ \\
\hline C3 & $0,70 \mathrm{a}$ & $1,94 a$ & $2,42 \mathrm{ab}$ & $2,98 a$ & $2,75 a$ & $2,74 a$ & $3,57 \mathrm{a}$ & $3,28 b$ & $3,15 a$ & $3,69 b$ \\
\hline $\mathrm{C} 4$ & $0,80 a$ & $1,72 a$ & $2,30 \mathrm{~b}$ & $2,96 a$ & $2,68 a$ & $2,61 a$ & $3,77 b$ & $3,97 a$ & $3,37 a$ & $4,10 a$ \\
\hline \multicolumn{11}{|l|}{$\mathrm{CV}=6,72 \%$} \\
\hline M1 & $1,45 a$ & $1,45 a$ & $1,71 \mathrm{a}$ & $2,08 \mathrm{a}$ & $2,64 a$ & $2,55 a$ & $2,97 a$ & $3,08 a$ & $2,98 b$ & $3,45 a$ \\
\hline M2 & $1,30 \mathrm{a}$ & $1,35 a$ & $2,09 a$ & $2,12 \mathrm{a}$ & $2,64 a$ & $3,00 \mathrm{a}$ & $2,99 a$ & $2,94 a$ & $3,95 a$ & $3,42 \mathrm{a}$ \\
\hline M3 & $1,30 \mathrm{a}$ & $1,51 \mathrm{a}$ & $1,93 a$ & $2,19 a$ & $2,68 \mathrm{a}$ & $2,33 a$ & $2,82 \mathrm{a}$ & $2,87 a$ & $3,11 b$ & $3,31 \mathrm{a}$ \\
\hline M4 & $1,40 \mathrm{a}$ & $1,63 a$ & $1,99 a$ & $2,29 a$ & $2,66 a$ & $2,60 \mathrm{a}$ & $2,67 a$ & $3,47 \mathbf{a}$ & $2,96 b$ & $3,41 \mathrm{a}$ \\
\hline \multicolumn{11}{|l|}{$\mathrm{CV}=14,87 \%$} \\
\hline S1 & $.2,28 \mathrm{a}$ & $2,39 a$ & $2,35 \mathrm{a}$ & $3,08 \mathrm{a}$ & $3,16 a$ & $2,65 a$ & $2,97 a$ & $2,94 a$ & $3,22 \mathrm{a}$ & $4,29 b$ \\
\hline $\mathbf{S} 2$ & $2,09 a$ & $2,63 a$ & $2,44 a$ & $3,12 \mathrm{a}$ & $3,20 a$ & $2,73 a$ & $2,80 \mathrm{a}$ & $3,25 \mathrm{a}$ & $3,40 a$ & $3,80 \mathrm{a}$ \\
\hline S3 & $2,02 a$ & $2,57 a$ & $2,16 a$ & $2,72 \mathrm{a}$ & $3,17 \mathrm{a}$ & $2,68 a$ & $2,78 a$ & $3,15 a$ & $3,03 a$ & $3,73 a$ \\
\hline S4 & $2,29 a$ & $2,38 a$ & $2,18 \mathrm{a}$ & $2,82 \mathrm{a}$ & $3,20 a$ & $2,58 \mathrm{a}$ & $2,66 a$ & $3,01 a$ & $3,34 a$ & $3,71 \mathrm{a}$ \\
\hline$I=7,14 \%$ & & & & & & & & & & \\
\hline
\end{tabular}

CV - coeficiente de variação

Os resultados constituem médias de três repetições; as médias seguidas pela mesma letra, na vertical, não diferem significativamente pelo teste de Tukey, a $5 \%$

Legenda: C - óleo de canola; $\mathrm{M}$ - óleo de milho; $\mathrm{S}$ - óleo de soja

$1-\mathrm{BHT}+\mathrm{BHA}(200 \mathrm{ppm})$

2 - BHT + BHA (200 ppm) + ácido cítrico (100 ppm)

3 - Ácido cítrico (100 ppm)

4 - Controle 


\subsubsection{Exame espectrofotométrico sob luz ultravioleta}

Os coeficientes de extinção obtidos com a absorção em ultravioleta medidos em 232 e $270 \mathrm{~nm}$ podem ser vistos nas Tabelas 12 e 13, respectivamente.

A oxidação de óleos é acompanhada pela formação de produtos que apresentam absorção na região do ultravioleta. Esses produtos são dienos conjugados com intensa absorção em $232 \mathrm{~nm}$ e trienos conjugados com absorção em $270 \mathrm{~nm}$.

De acordo com Gray (1978), as determinações de dienos conjugados (232 nm) não informam o grau de oxidação de óleos e gorduras, pois o efeito deste tipo de reação sobre diferentes ácidos graxos insaturados varia em qualidade e magnitude. Entretanto, as variações nas concentrações de dienos com o tempo oferecem dados suficientes para o acompanhamento da oxidação de uma mesma amostra.

Segundo Patterson (1989), óleos vegetais com coeficiente de extinção em $232 \mathrm{~nm}$ ao redor de 5 não poderiam ser classificados como óleos de primeira classe, e coeficiente de extinção em $270 \mathrm{~nm}$ ao redor de 5 poderia indicar óleos em estado de avançada oxidação. 
Tabela 12. Coeficiente de extinção em $232 \mathrm{~nm}$ de óleos de canola, milho e soja em frascos PET e armazenados sob condições ambientes.

\begin{tabular}{ccccccccccc}
\hline & \multicolumn{10}{c}{ Tempo (dias) } \\
\cline { 2 - 9 } Tratamentos & 0 & 15 & 30 & 45 & 60 & 75 & 90 & 120 & 150 & 180 \\
\hline C1 & $4,68 \mathrm{a}$ & $5,02 \mathrm{a}$ & $5,76 \mathrm{a}$ & $4,64 \mathrm{ab}$ & $4,65 \mathrm{a}$ & $4,99 \mathrm{ab}$ & $4,93 \mathrm{ab}$ & $5,07 \mathrm{a}$ & $4,98 \mathrm{a}$ & $4,95 \mathrm{a}$ \\
C2 & $4,93 \mathrm{a}$ & $5,15 \mathrm{a}$ & $5,44 \mathrm{ab}$ & $4,94 \mathrm{a}$ & $4,69 \mathrm{a}$ & $5,24 \mathrm{a}$ & $5,11 \mathrm{a}$ & $4,73 \mathrm{a}$ & $5,00 \mathrm{a}$ & $5,01 \mathrm{a}$ \\
C3 & $4,75 \mathrm{a}$ & $4,82 \mathrm{a}$ & $5,30 \mathrm{bc}$ & $4,61 \mathrm{ab}$ & $4,64 \mathrm{a}$ & $4,83 \mathrm{~b}$ & $4,66 \mathrm{~b}$ & $4,88 \mathrm{a}$ & $5,08 \mathrm{a}$ & $5,08 \mathrm{a}$ \\
C4 & $4,74 \mathrm{a}$ & $5,00 \mathrm{a}$ & $5,04 \mathrm{c}$ & $4,52 \mathrm{~b}$ & $4,63 \mathrm{a}$ & $5,00 \mathrm{ab}$ & $5,14 \mathrm{a}$ & $4,70 \mathrm{a}$ & $4,96 \mathrm{a}$ & $5,11 \mathrm{a}$ \\
CV=3,66\% & & & & & & & & & \\
\hline M1 & $3,54 \mathrm{a}$ & $3,36 \mathrm{a}$ & $3,17 \mathrm{a}$ & $4,22 \mathrm{a}$ & $3,48 \mathrm{ab}$ & $4,09 \mathrm{a}$ & $3,39 \mathrm{a}$ & $3,32 \mathrm{a}$ & $3,54 \mathrm{a}$ & $3,66 \mathrm{a}$ \\
M2 & $3,30 \mathrm{a}$ & $3,28 \mathrm{a}$ & $3,26 \mathrm{a}$ & $3,98 \mathrm{a}$ & $3,49 \mathrm{a}$ & $3,84 \mathrm{a}$ & $3,42 \mathrm{a}$ & $3,30 \mathrm{a}$ & $3,41 \mathrm{a}$ & $3,56 \mathrm{a}$ \\
M3 & $3,24 \mathrm{a}$ & $3,29 \mathrm{a}$ & $3,34 \mathrm{a}$ & $3,79 \mathrm{a}$ & $3,36 \mathrm{ab}$ & $4,12 \mathrm{a}$ & $3,32 \mathrm{a}$ & $3,35 \mathrm{a}$ & $3,36 \mathrm{a}$ & $3,48 \mathrm{a}$ \\
M4 & $3,38 \mathrm{a}$ & $3,25 \mathrm{a}$ & $3,12 \mathrm{a}$ & $4,04 \mathrm{a}$ & $2,97 \mathrm{~b}$ & $4,19 \mathrm{a}$ & $3,41 \mathrm{a}$ & $3,32 \mathrm{a}$ & $3,33 \mathrm{a}$ & $3,41 \mathrm{a}$ \\
CV=6,92\% & & & & & & & & & & \\
\hline S1 & $4,40 \mathrm{a}$ & $4,11 \mathrm{a}$ & $5,13 \mathrm{a}$ & $4,18 \mathrm{a}$ & $4,10 \mathrm{a}$ & $4,18 \mathrm{a}$ & $4,44 \mathrm{ab}$ & $4,58 \mathrm{ab}$ & $4,47 \mathrm{ab}$ & $4,52 \mathrm{a}$ \\
S2 & $4,26 \mathrm{ab}$ & $3,99 \mathrm{a}$ & $4,29 \mathrm{~b}$ & $4,03 \mathrm{a}$ & $4,26 \mathrm{a}$ & $4,24 \mathrm{a}$ & $4,42 \mathrm{ab}$ & $4,80 \mathrm{a}$ & $4,39 \mathrm{~b}$ & $4,51 \mathrm{a}$ \\
S3 & $4,45 \mathrm{a}$ & $4,10 \mathrm{a}$ & $4,09 \mathrm{~b}$ & $4,26 \mathrm{a}$ & $4,29 \mathrm{a}$ & $4,20 \mathrm{a}$ & $4,56 \mathrm{a}$ & $4,54 \mathrm{~b}$ & $4,51 \mathrm{ab}$ & $4,50 \mathrm{a}$ \\
S4 & $4,15 \mathrm{~b}$ & $3,94 \mathrm{a}$ & $4,09 \mathrm{~b}$ & $4,22 \mathrm{a}$ & $4,23 \mathrm{a}$ & $4,08 \mathrm{a}$ & $4,30 \mathrm{~b}$ & $4,41 \mathrm{~b}$ & $4,65 \mathrm{a}$ & $4,47 \mathrm{a}$ \\
CV=2,59\% & & & & & & & & & & \\
\hline
\end{tabular}

CV - coeficiente de variação

Os resultados constituem médias de três repetições; as médias seguidas pela mesma letra, na vertical, não diferem significativamente pelo teste de Tukey, a 5\%

Legenda: C - óleo de canola; $\mathrm{M}$ - óleo de milho; S - óleo de soja

$1-\mathrm{BHT}+\mathrm{BHA}(200 \mathrm{ppm})$

2 - BHT + BHA (200 ppm) + ácido cítrico (100 ppm)

3 - Ácido cítrico (100 ppm)

4 - Controle

O coeficiente de extinção em $232 \mathrm{~nm}$ (Tabela 12) variou durante o armazenamento para os três óleos, mas de modo geral não apresentou aumento significativo com o tempo.

Gutierrez et al. (1997) também não observaram aumento dos dienos conjugados em óleo bruto de castanha-do-pará armazenados sob condições ambientes por período de 6 meses.

Analisando-se o coeficiente de extinção em $270 \mathrm{~nm}$ observa-se oscilação de valores sem tendência ao aumento para os óleos de canola, milho e soja nos 4 tratamentos (Tabela 13). 
Tabela 13. Coeficiente de extinção em $270 \mathrm{~nm}$ de óleos de canola, milho e soja embalados em frascos de PET e armazenados sob condições ambientes.

\begin{tabular}{|c|c|c|c|c|c|c|c|c|c|c|}
\hline \multirow[b]{2}{*}{ Tratamentos } & \multicolumn{10}{|c|}{ Tempo (dias) } \\
\hline & 0 & 15 & 30 & 45 & 60 & 75 & 90 & 120 & 150 & 180 \\
\hline $\mathrm{Cl}$ & $0,83 a$ & $0,79 \mathrm{ab}$ & $1,03 a$ & $0,60 a$ & $0,66 a$ & $0,75 \mathrm{ab}$ & $0,73 \mathrm{ab}$ & $0,71 a$ & $0,80 a$ & $0,74 a$ \\
\hline $\mathrm{C} 2$ & $0,81 a$ & $0,84 \mathrm{a}$ & $0,99 a$ & $0,64 a$ & $0,68 \mathrm{a}$ & $0,86 a$ & $0,74 a$ & $0,65 a$ & $0,80 a$ & $0,76 a$ \\
\hline $\mathrm{C} 3$ & $0,73 a$ & $0,72 b$ & $0,93 \mathrm{ab}$ & $0,60 a$ & $0,65 a$ & $0,71 b$ & $0,62 b$ & $0,65 a$ & $0,77 a$ & $0,78 a$ \\
\hline $\mathrm{C} 4$ & $0,73 a$ & $0,77 a b$ & $0,81 \mathrm{~b}$ & $0,57 \mathrm{a}$ & $0,63 a$ & $0,83 a$ & $0,77 a$ & $0,63 a$ & $0,78 a$ & $0,79 a$ \\
\hline \multicolumn{11}{|c|}{$\mathrm{CV}=7,36 \%$} \\
\hline M1 & $1,52 \mathrm{a}$ & $1,39 a$ & $1,26 a$ & $1,77 b$ & $1,46 a$ & $1,72 \mathrm{a}$ & $1,42 \mathrm{a}$ & $1,45 a$ & $1,43 a$ & $1,49 a$ \\
\hline M2 & $1,43 a$ & $1,35 a$ & $1,27 \mathrm{a}$ & $1,79 \mathrm{a}$ & $1,45 a$ & $1,68 a$ & $1,43 a$ & $1,45 a$ & $1,37 a$ & $1,47 a$ \\
\hline M3 & $1,58 \mathrm{a}$ & $1,47 \mathrm{a}$ & $1,35 \mathrm{a}$ & $1,58 b$ & $1,41 a$ & $1,75 \mathrm{a}$ & $1,40 \mathrm{a}$ & $1,43 a$ & $1,35 \mathrm{a}$ & $1,44 \mathrm{a}$ \\
\hline M4 & $1,40 \mathrm{a}$ & $1,30 \mathrm{a}$ & $1,19 a$ & $1,65 \mathrm{ab}$ & $1,17 \mathrm{~b}$ & $1,81 \mathrm{a}$ & $1,42 a$ & $1,41 a$ & $1,35 a$ & $1,40 \mathrm{a}$ \\
\hline \multicolumn{11}{|l|}{$C V=6,75 \%$} \\
\hline S1 & $3,21 a$ & $3,00 \mathrm{a}$ & $3,31 a$ & $3,05 a$ & $3,00 a$ & $3,07 a$ & $3,44 a$ & $3,54 a$ & $3,45 \mathrm{a}$ & $3,46 a$ \\
\hline $\mathbf{S} 2$ & $3,13 a$ & $2,96 a$ & $3,07 a$ & $3,00 a$ & $3,09 a$ & $3,09 \mathrm{a}$ & $4,12 b$ & $3,57 \mathrm{a}$ & $3,39 a$ & $3,45 a$ \\
\hline S3 & $3,30 a$ & $3,04 a$ & $2,98 \mathrm{a}$ & $3,09 a$ & $3,06 a$ & $3,05 a$ & $3,48 \mathrm{a}$ & $3,51 \mathrm{a}$ & $3,51 a$ & $3,48 \mathrm{a}$ \\
\hline S4 & $3,06 a$ & $2,92 \mathrm{a}$ & $2,97 a$ & $3,09 a$ & $3,02 a$ & $3,01 a$ & $3,44 a$ & $3,44 a$ & $3,55 \mathrm{a}$ & $3,48 a$ \\
\hline$C V=5,99 \%$ & & & & & & & & & & \\
\hline
\end{tabular}

$\mathrm{CV}$ - coeficiente de variação

Os resultados constituem médias de três repetições; as médias seguidas pela mesma letra, na vertical, não diferem significativamente pelo teste de Tukey, a $5 \%$

Legenda: C - óleo de canola; $\mathrm{M}$ - óleo de milho; S - óleo de soja

$1-\mathrm{BHT}+\mathrm{BHA}(200 \mathrm{ppm})$

2 - BHT + BHA (200 ppm) + ácido cítrico (100 ppm)

3 - Ácido cítrico (100 ppm)

4 - Controle

Assim como os outros índices, os coeficientes de extinção em $232 \mathrm{~nm}$ e $270 \mathrm{~nm}$ não conseguiram detectar influência da presença de antioxidantes nos óleos de canola, milho e soja.

\subsection{4 Índice de iodo}

Nas Figuras 6, 7 e 8 encontram-se os resultados do índice de iodo ao longo de 6 meses de armazenamento ao ambiente.

$\mathrm{O}$ índice de iodo indica o grau de insaturação das cadeias de ácidos graxos, portanto quanto mais alto é seu valor, mais insaturado é o óleo e mais íntegras estão as duplas ligações presentes nas moléculas de ácidos graxos insaturados, em relação à 
oxidação. A diminuição do índice de iodo é usada para acompanhar a redução dos ácidos dienóicos durante a oxidação.

Foi observada uma diminuição no índice de iodo dos óleos de canola e milho ao longo dos 6 meses de armazenamento, sendo que no óleo de soja, ele se manteve constante. Ao final dos 6 meses de armazenamento todos tratamentos dos três óleos se encontraram dentro da faixa indicada para óleos refinados.

Não foram encontradas variações estatísticas entre os tratamentos em nenhum dos óleos.

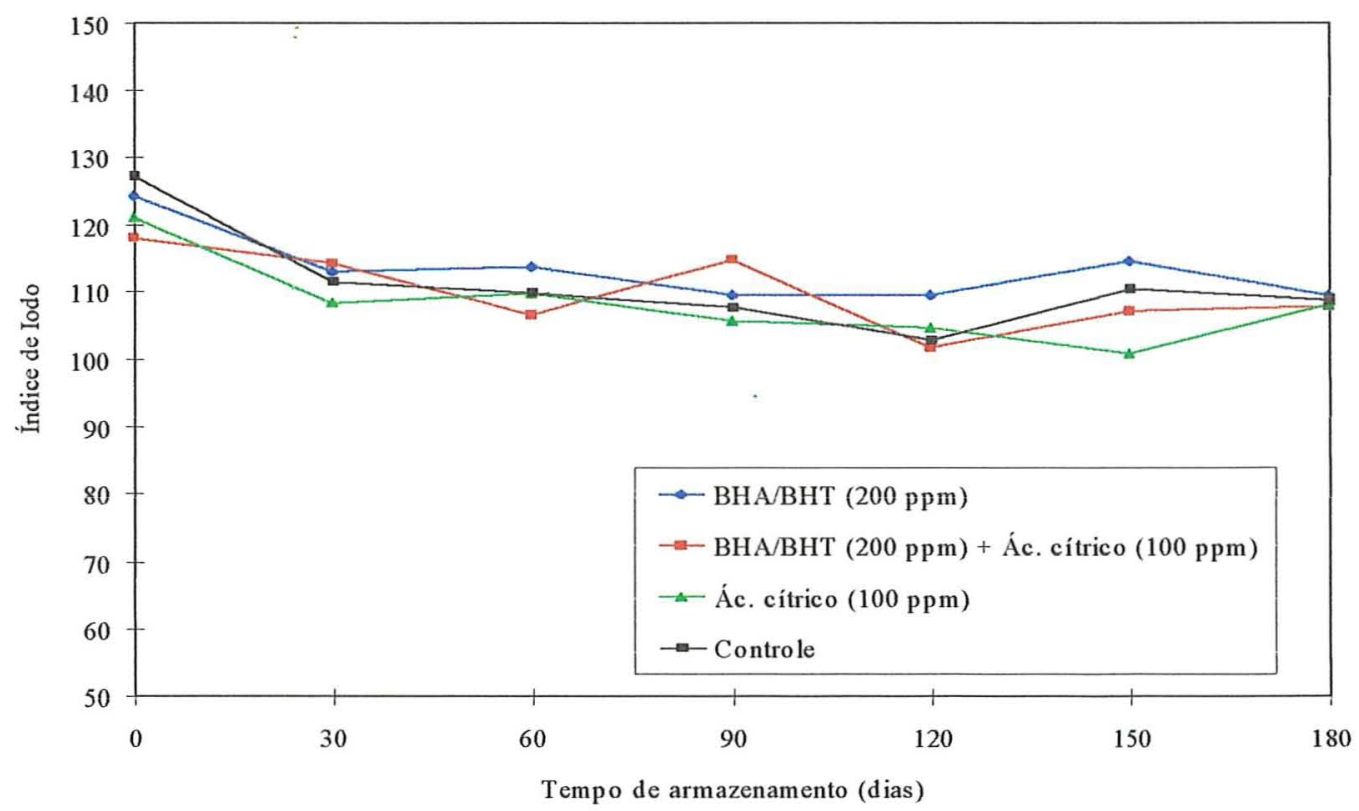

Figura 6 - Índice de iodo (mg de iodo/ $100 \mathrm{mg}$ de óleo) do óleo de canola embalado em frascos PET e armazenado sob condições ambientes. 


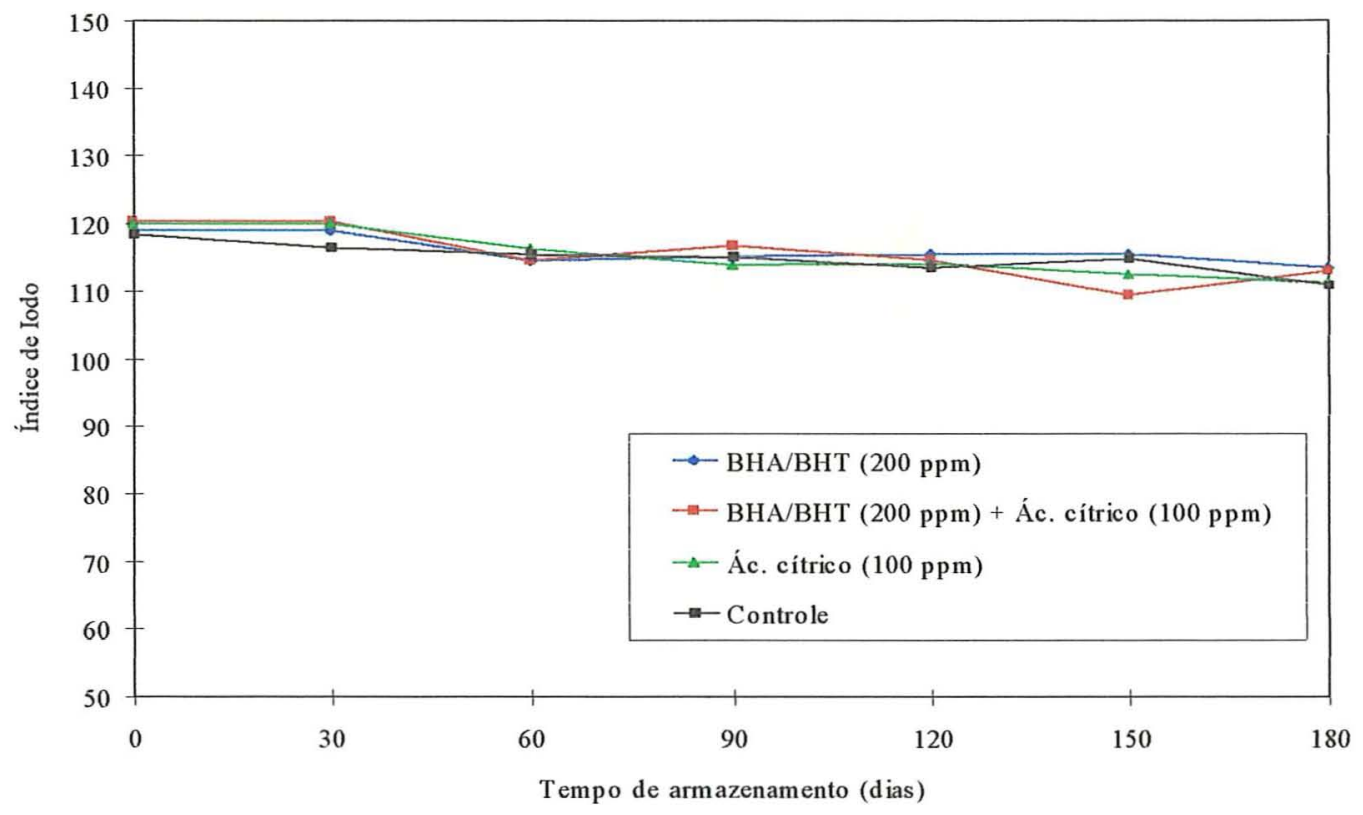

Figura 7 - Índice de iodo (mg de iodo/ $100 \mathrm{mg}$ de óleo) do óleo de milho embalado em frascos PET e armazenado sob condições ambientes.

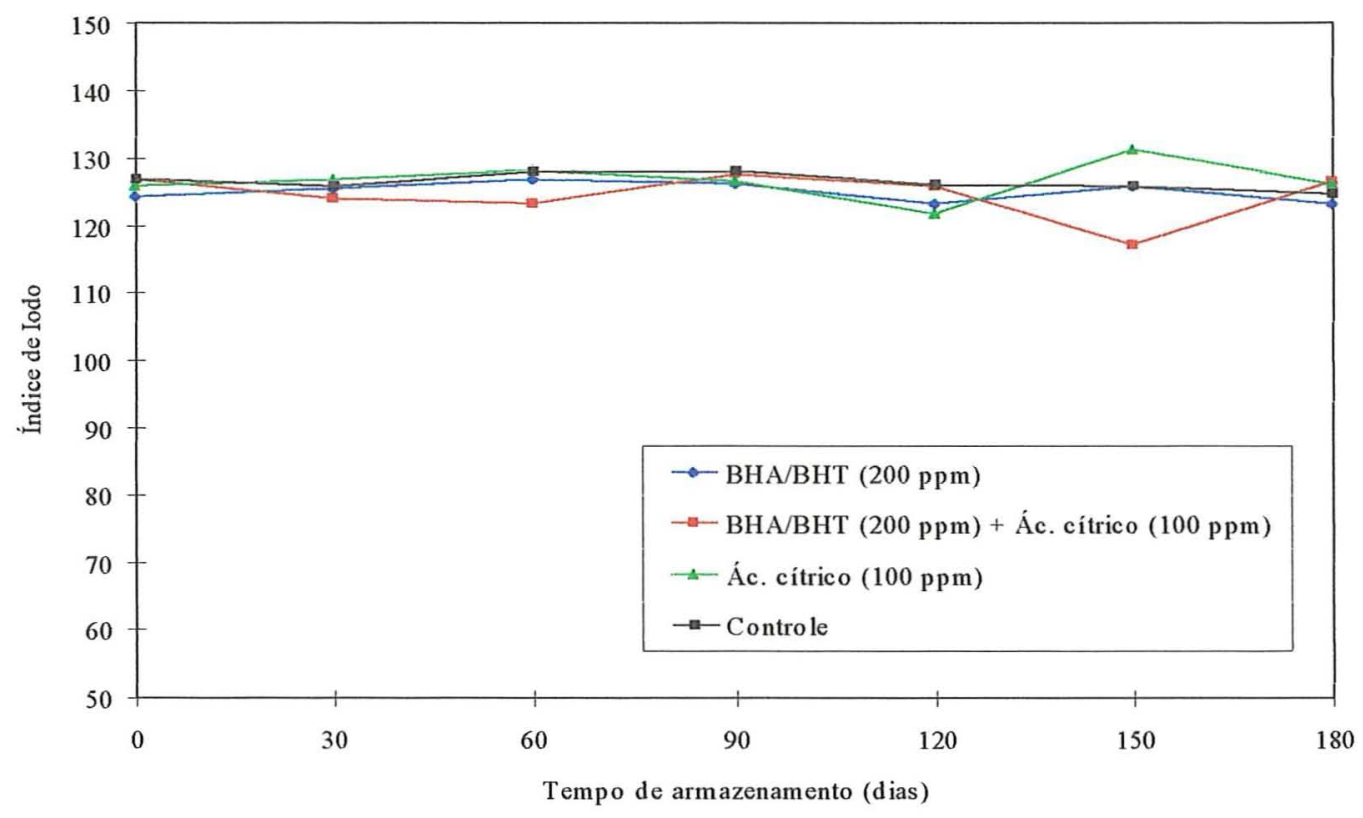

Figura 8 - Índice de iodo (mg de iodo/ $100 \mathrm{mg}$ de óleo) do óleo de soja embalado em frascos de PET e armazenado sob condições ambientes. 


\subsection{Fotoxidação acelerada}

\subsection{1 Índice de acidez}

Os resultados da variação do índice de acidez na câmara de luz para os óleos de canola, milho e soja nos tratamentos com adição dos antioxidantes BHA, BHT e ácido cítrico podem ser vistos na Tabela 14.

Tabela 14. Índice de acidez (mg de $\mathrm{KOH} / \mathrm{g}$ de óleo) dos óleos de canola, milho e soja submetidos à fotoxidação acelerada por 120 horas.

\begin{tabular}{|c|c|c|c|c|c|c|}
\hline \multirow[b]{2}{*}{ Tratamentos } & \multicolumn{6}{|c|}{ Tempo (dias) } \\
\hline & 0 & 24 & 48 & 72 & 96 & 120 \\
\hline $\mathrm{Cl}$ & $0,10 \mathrm{a}$ & $0,10 b$ & $0,10 a$ & $0,10 \mathrm{a}$ & $0,12 b$ & $0,16 a$ \\
\hline $\mathrm{C} 2$ & $0,10 \mathrm{a}$ & $0,12 b$ & $0,10 \mathrm{a}$ & $0,10 \mathrm{a}$ & $0,16 a$ & $0,16 a$ \\
\hline C3 & $0,10 a$ & $0,17 a$ & $0,10 \mathrm{a}$ & $0,10 \mathbf{a}$ & $0,15 a$ & $0,19 b$ \\
\hline $\mathrm{C} 4$ & $0,10 \mathrm{a}$ & $0,10 b$ & $0,10 \mathrm{a}$ & $0,10 \mathrm{a}$ & $0,15 a$ & $0,19 b$ \\
\hline \multicolumn{7}{|c|}{$\mathrm{CV}=11,53 \%$} \\
\hline M1 & $0,10 \mathrm{a}$ & $0,12 a$ & $0,17 \mathrm{a}$ & $0,12 b$ & $0,12 a$ & $0,10 \mathrm{~b}$ \\
\hline M2 & $0,10 \mathrm{a}$ & $0,14 a$ & $0,17 \mathrm{a}$ & $0,19 a$ & $0,16 a$ & $0,11 \mathrm{ab}$ \\
\hline M3 & $0,10 \mathrm{a}$ & $0,12 \mathrm{a}$ & $0,16 a$ & $0,17 a b$ & $0,14 a$ & $0,16 a$ \\
\hline M4 & $0,09 a$ & $0,12 a$ & $0,16 a$ & $0,17 a b$ & $0,14 a$ & $0,14 a b$ \\
\hline \multicolumn{7}{|l|}{$\mathrm{CV}=19,03 \%$} \\
\hline S1 & $0,10 a$ & $0,12 b$ & $0,12 a$ & $0,19 a$ & $0,14 b$ & $0,17 \mathrm{a}$ \\
\hline S2 & $0,10 \mathrm{a}$ & $0,16 a b$ & $0,14 a$ & $0,15 a$ & $0,21 \mathrm{a}$ & $0,21 \mathrm{a}$ \\
\hline S3 & $0,10 a$ & $0,16 a b$ & $0,15 a$ & $0,17 \mathbf{a}$ & $0,14 b$ & $0,19 a$ \\
\hline S4 & $0,10 \mathrm{a}$ & $0,19 b$ & $0,15 a$ & $0,16 a$ & $0,12 b$ & $0,19 a$ \\
\hline $\mathrm{CV}=19,48^{\circ}$ & & & & & & \\
\hline
\end{tabular}

$\mathrm{CV}$ - coeficiente de variação

Os resultados constituem médias de três repetições; as médias seguidas pela mesma letra, na vertical, não diferem significativamente pelo teste de Tukey, a 5\%

Legenda: C - óleo de canola; $\mathrm{M}$ - óleo de milho; S - óleo de soja

$1-\mathrm{BHT}+\mathrm{BHA}(200 \mathrm{ppm})$

2 - BHT + BHA (200 ppm) + ácido cítrico (100 ppm)

3 - Ácido cítrico (100 ppm)

4 - Controle

O índice de acidez oscilou ao longo das 120 horas de exposição à luz nos tratamentos propostos para os três óleos, havendo um aumento, porém não significativo 
estatisticamente. Também não foi constatado em nenhum dos óleos diferenças significativas constantes que pudessem sugerir a escolha do melhor tratamento.

Os tratamentos 1 e 2 no óleo de canola, após 120 horas de luz, foram os melhores, apresentando diferenças significativas em relação aos demais. No óleo de milho, após 120 horas de exposição à luz, foram encontradas diferenças significativas para os tratamentos 1 e 3 , sendo o tratamento 1 o que apresentou menor índice de acidez, já para o óleo de soja para o mesmo período de exposição à luz, não foram encontradas diferenças significativas entre os tratamentos.

Não foi encontrada correlação positiva entre o aumento do tempo de exposição à luz e o aumento do índice de acidez. Isso indica, assim com no armazenamento ambiente, a não existência de hidrólise nos óleos durante a exposição dos mesmos à luz.

De acordo com Nawar (1985), a existência de ácidos graxos livres num óleo não tem efeito marcante sobre a estabilidade oxidativa. Entretanto em óleos comerciais, a presença de elevado número de ácidos graxos livres pode aumentar a incorporação de metais catalíticos do equipamento ou tanques de armazenamento e portanto aumentar a velocidade de oxidação.

\subsection{2 Índice de peróxido}

\subsubsection{Comparação entre os óleos de canola, milho e soja sob luz sem a adição de antioxidantes}

A Figura 9 apresenta a variação do índice de peróxido ao longo de 120 horas de exposição à luz para os óleos de canola, milho e soja sem adição de antioxidantes (controle). 


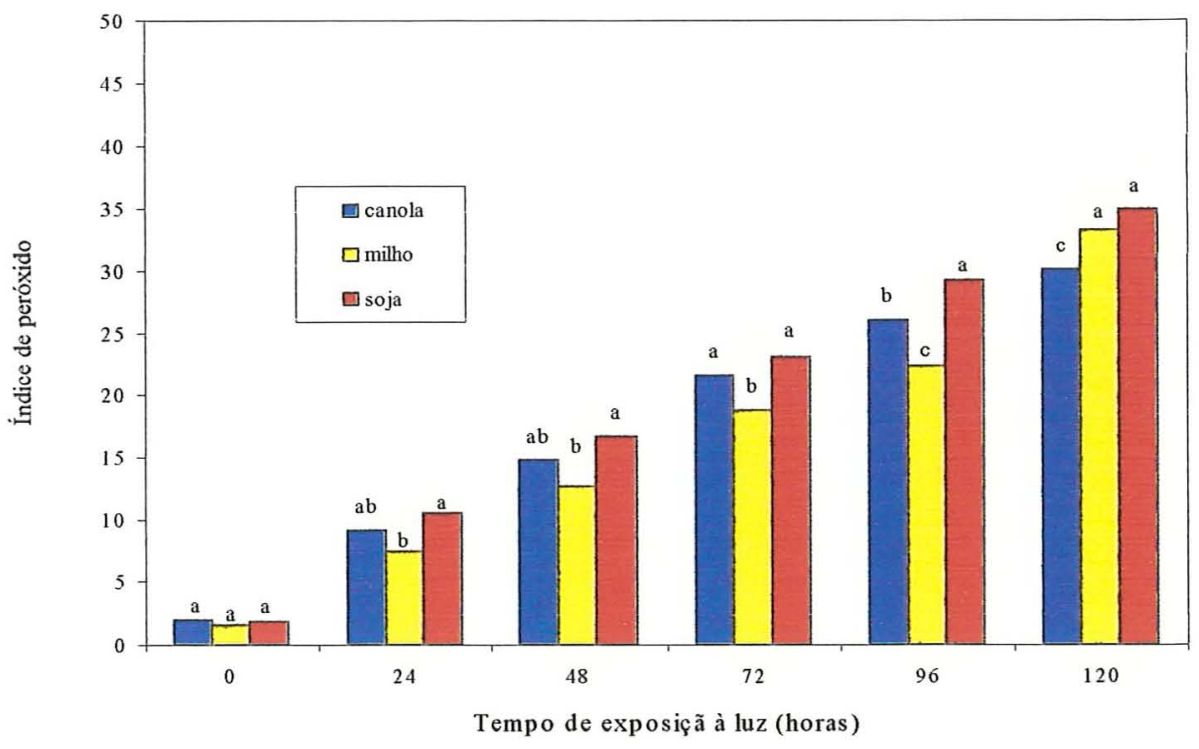

Figura 9 - Comportamento dos óleos de canola, milho e soja em câmara de fotoxidação sem adição de antioxidantes após diferentes tempos de exposição à luz (índice de peróxido meq $\mathrm{O}_{2} / \mathrm{kg}$ de óleo).

O índice de peróxido aumentou linearmente ao longo de 120 horas de fotoxidação para os três óleos. Na Tabela 15 pode-se observar a equação da reta obtida pela regressão entre o índice de peróxido e o tempo de exposição à luz para os três óleos.

Tabela 15. Equação da reta obtida por regressão linear, coeficientes de determinação $\left(\mathrm{R}^{2}\right)$ e de correlação (r ) para os valores de índice de peróxido (IP) dos óleos de canola, milho e soja expostos à fotoxidação induzida por tempos diferentes (TL).

\begin{tabular}{cccc}
\hline Óleos & \multicolumn{1}{c}{ Equação da reta } & $\mathrm{R}^{2}$ & $\mathrm{r}$ \\
\hline Canola & $\mathrm{IP}=0,2352 \mathrm{TL}+3,1452$ & 0,9897 & 0,9948 \\
Milho & $\mathrm{IP}=0,2489 \mathrm{TL}+1,812$ & 0,9796 & 0,9897 \\
Soja & $\mathrm{IP}=0,2713 \mathrm{TL}+3,1114$ & 0,9958 & 0,9979 \\
\hline
\end{tabular}


Observa-se que com o aumento do tempo de exposição à luz aumenta a oxidação dos óleos. De acordo com Sattar \& deMan (1975), no mecanismo de oxidação fotoquímica a quantidade de hidroperóxidos formada é proporcional ao total da quantidade de luz absorvida e quando as luzes são apagadas não há acúmulo de hidroperóxidos.

Comparando-se os óleos quanto à estabilidade oxidativa após 24 horas de exposição à luz, o óleo de soja apresentou aumento do índice de peróxido seguido pelo óleo de canola e o mais estável foi o de milho. O primeiro intervalo de 24 horas de exposição à luz provocou maior aumento do índice de peróxido, tanto para o óleo de soja como para o óleo de canola, os demais intervalos apresentaram menores variações. Isto sugere que a presença de fotossensibilizadores, no caso clorofila, assim como a composição em ácidos graxos de um óleo vegetal podem acelerar o início do processo fotoxidativo.

Sattar \& deMan (1976) analisaram diferentes tempos de exposição à luz dos óleos de canola, milho, soja e do leite bovino em cabine de luz com intensidade luminosa de $500 \mathrm{ft}-\mathrm{c}(5000 \mathrm{lux})$ e com temperaturas de $15^{\circ} \mathrm{C}$ e $30^{\circ} \mathrm{C}$. Observaram que devido à presença de sensibilizadores, antioxidantes e outros inibidores naturais, o grau de insaturação de óleos e gorduras pode não ser o único responsável pelos resultados de oxidação.

De acordo com Neumann et al. (1991); o grau de insaturação dos ácidos graxos teve efeito na suscetibilidade de oxidação dos óleos brutos de soja, girassol e amendoim. Para os autores a tendência relativa à fotoxidação foi soja $>$ girassol $>$ amendoim. $O$ óleo de soja demonstrou ser o mais instável, não somente devido à presença de ácidos graxos insaturados, como também devido à ausência de constituintes naturais capazes de promover um efeito antioxidante protetor. 


\subsubsection{Comparação do índice de peróxido dos óleos de canola, milho e soja sob luz adicionados de antioxidantes}

Na Tabela 16 tem-se a variação do índice de peróxido entre os tratamentos dos óleos de canola, milho e soja.

Tabela 16. Índice de peróxido (meq $\mathrm{O}_{2} / \mathrm{kg}$ de óleo) dos óleos de canola, milho e soja submetidos à fotoxidação acelerada por 120 horas.

\begin{tabular}{|c|c|c|c|c|c|c|}
\hline \multirow[b]{2}{*}{ Tratamentos } & \multicolumn{6}{|c|}{ Tempo (horas) } \\
\hline & 0 & 24 & 48 & 72 & 96 & 120 \\
\hline $\mathrm{Cl}$ & $1,95 \mathrm{a}$ & $9,54 a$ & $14,89 a$ & $20,69 a$ & $25,41 \mathrm{a}$ & $30,71 a$ \\
\hline $\mathrm{C} 2$ & $1,96 \mathrm{a}$ & $9,69 a$ & $15,07 \mathrm{a}$ & $21,07 a$ & $25,21 \mathrm{a}$ & $31,16 a$ \\
\hline C3 & $1,97 \mathrm{a}$ & $9,48 \mathrm{a}$ & $14,99 a$ & $21,15 a$ & $26,47 a$ & $31,17 a$ \\
\hline C4 & $1,98 \mathrm{a}$ & $9,15 a$ & $14,91 \mathrm{a}$ & $21,75 a$ & $25,96 a$ & $30,05 a$ \\
\hline \multicolumn{7}{|l|}{$\mathrm{CV}=4,10 \%$} \\
\hline M1 & $1,73 a$ & $8,76 a$ & $12,80 \mathrm{a}$ & $20,28 \mathrm{a}$ & $24,77 \mathrm{ab}$ & $32,56 \mathrm{a}$ \\
\hline M2 & $1,91 \mathrm{a}$ & $7,96 a$ & $13,64 a$ & $20,41 \mathrm{a}$ & $26,36 a$ & $32,60 \mathrm{a}$ \\
\hline M3 & $1,51 \mathrm{a}$ & $7,29 a$ & $13,08 \mathrm{a}$ & $19,36 \mathrm{a}$ & $25,32 \mathrm{ab}$ & $30,87 a$ \\
\hline M4 & $1,53 \mathrm{a}$ & $7,48 \mathrm{a}$ & $12,74 a$ & $18,81 \mathrm{a}$ & $22,28 \mathrm{~b}$ & $33,24 a$ \\
\hline \multicolumn{7}{|c|}{$\mathrm{CV}=10,12 \%$} \\
\hline S1 & $2,45 a$ & $11,53 a$ & $16,95 \mathrm{a}$ & $23,89 a$ & $29,66 a$ & $34,06 a$ \\
\hline S2 & $2,68 \mathrm{a}$ & $10,73 a$ & $16,91 \mathbf{a}$ & $24,21 \mathrm{a}$ & $29,65 a$ & $34,92 \mathrm{a}$ \\
\hline S3 & $2,12 \mathrm{a}$ & $10,87 a$ & $16,98 \mathbf{a}$ & $24,30 a$ & $30,57 a$ & $34,27 \mathrm{a}$ \\
\hline S4 & $1,92 a$ & $10,45 \mathrm{a}$ & $16,69 \mathrm{a}$ & $23,09 a$ & $29,21 \mathrm{a}$ & $34,96 \mathrm{a}$ \\
\hline $\mathrm{CV}=8,56 \%$ & & & & & & \\
\hline
\end{tabular}

Os resultados constituem médias de três repetições; as médias seguidas pela mesma letra, na vertical, não diferem significativamente pelo teste de Tukey, a 5\%

Legenda: C - óleo de canola; $\mathrm{M}$ - óleo de milho; $\mathrm{S}$ - óleo de soja

$$
\begin{aligned}
& 1 \text { - BHT + BHA(200 ppm) } \\
& 2 \text { - BHT + BHA }(200 \mathrm{ppm})+\text { ácido cítrico }(100 \mathrm{ppm}) \\
& 3 \text { - Ácido cítrico }(100 \mathrm{ppm}) \\
& 4 \text { - Controle }
\end{aligned}
$$

A adição dos antioxidantes BHT, BHA e ácido cítrico nos tratamentos propostos não apresentou, de modo geral, alterações na estabilidade oxidativa dos óleos em comparação ao tratamento controle. Para os óleos de canola e soja não foram encontradas variações significativas entre os tratamentos em nenhum dos intervalos de exposição à luz. O óleo de milho apresentou diferenças significativas entre os tratamentos BHT + BHA + ácido ć́trico (2) e o controle (4), sendo que este foi o melhor, 
apresentando menor índice de peróxido após 24,48 e 72 horas de exposição a luz. Contudo estatisticamente não foram encontradas diferenças com os demais.

Pelo dados analisados observou-se que os antioxidantes usados não foram eficientes para controlar a fotoxidação. Morrison et al. (1981) também observaram que os antioxidantes fenólicos (BHA/ BHT, propil-galato e TBHQ) não tiveram efeito na stabilidade de óleo de girassol armazenado em vidros transparentes na presença de luz fluorescente.

Em trabalho realizado por Warner \& Frankel (1987) a adição de 100 ppm de ácido cítrico em óleo de soja adicionado de diferentes níveis de $\beta$-caroteno $(0,1,5,10$, 15 e $20 \mathrm{ppm}$ ) não apresentou resultado positivo no retardamento da fotoxidação para nenhum dos níveis de $\beta$-caroteno testados pela análise do índice de peróxido.

\subsubsection{Exame espectrofotométrico sob luz ultravioleta}

Os resultados obtidos pela exposição à luz dos óleos refinados de canola, milho e soja mostram que ocorreu um aumento do coeficiente de extinção em $232 \mathrm{~nm}$, mas não foram encontradas variações para o coeficiente de extinção em $270 \mathrm{~nm}$ (Tabelas 17 e 18). 
Tabela 17. Coeficiente de extinção em $232 \mathrm{~nm}$ dos óleos de canola, milho e soja submetidos à fotoxidação acelerada por 120 horas.

\begin{tabular}{|c|c|c|c|c|c|c|}
\hline \multirow{2}{*}{ Tratamentos } & \multicolumn{6}{|c|}{ Tempo (horas) } \\
\hline & 0 & 24 & 48 & 72 & 96 & 120 \\
\hline $\mathrm{Cl}$ & $5,25 a$ & $5,24 a$ & $5,58 a$ & $6,50 a$ & $6,34 a$ & $7,49 a$ \\
\hline $\mathrm{C} 2$ & $4,96 a$ & $5,24 a$ & $5,50 \mathrm{a}$ & $5,86 a$ & $6,47 a$ & $7,21 \mathrm{a}$ \\
\hline C3 & $5,02 \mathrm{a}$ & $5,37 a$ & $5,69 a$ & $6,10 \mathrm{a}$ & $6,68 \mathrm{a}$ & $7,42 \mathrm{a}$ \\
\hline C4 & $5,00 \mathrm{a}$ & $5,47 a$ & $5,62 a$ & $6,20 a$ & $7,08 \mathrm{a}$ & $7,09 a$ \\
\hline \multicolumn{7}{|c|}{$\mathrm{CV}=5,96 \%$} \\
\hline M1 & $2,04 a$ & $3,70 \mathrm{a}$ & $3,93 a$ & $4,92 a$ & $5,03 a b$ & $6,04 a$ \\
\hline M2 & $2,17 \mathrm{a}$ & $3,65 a$ & $4,09 \mathrm{a}$ & $4,75 \mathrm{ab}$ & $5,19 a$ & $6,00 \mathrm{a}$ \\
\hline M3 & $1,76 a$ & $3,50 \mathrm{a}$ & $4,04 a$ & $4,64 a b$ & $4,89 a b$ & $5,75 a$ \\
\hline M4 & $1,73 a$ & $3,30 a$ & $3,95 a$ & $4,29 b$ & $4,46 b$ & $5,83 a$ \\
\hline \multicolumn{7}{|l|}{$\mathrm{CV}=6,36 \%$} \\
\hline S1 & $4,47 a b$ & $4,52 a$ & $5,28 \mathrm{a}$ & $5,35 a$ & $6,54 a$ & $6,84 a$ \\
\hline S2 & $4,96 \mathrm{a}$ & $4,35 a$ & $5,37 a$ & $5,46 a$ & $6,59 a$ & $7,41 \mathrm{a}$ \\
\hline S3 & $4,12 b$ & $4,19 a$ & $5,88 \mathrm{a}$ & $5,46 a$ & $6,39 a$ & $6,88 \mathrm{a}$ \\
\hline S4 & $4,08 b$ & $4,21 \mathrm{a}$ & $5,13 a$ & $5,53 a$ & $6,44 a$ & $6,76 a$ \\
\hline $\mathrm{CV}=6,66 \%$ & & & & & & \\
\hline
\end{tabular}

$\mathrm{CV}$ - coeficiente de variação

Os resultados constituem médias de três repetições; as médias seguidas pela mesma letra, na vertical, não diferem significativamente pelo teste de Tukey, a $\mathbf{5 \%}$

Legenda: C - óleo de canola; M - óleo de milho; S - óleo de soja

$$
\begin{aligned}
& 1-\mathrm{BHT}+\mathrm{BHA}(200 \mathrm{ppm}) \\
& 2 \text { - BHT }+\mathrm{BHA}(200 \mathrm{ppm})+\text { ácido cítrico }(100 \mathrm{ppm}) \\
& 3 \text { - Ácido cítrico }(100 \mathrm{ppm}) \\
& 4 \text { - Controle }
\end{aligned}
$$


Tabela 18. Coeficiente de extinção em $270 \mathrm{~nm}$ dos óleos de canola, milho e soja submetidos à fotoxidação acelerada por 120 horas.

\begin{tabular}{|c|c|c|c|c|c|c|}
\hline \multirow[b]{2}{*}{ Tratamentos } & \multicolumn{6}{|c|}{ Tempo (horas) } \\
\hline & 0 & 24 & 48 & 72 & 96 & 120 \\
\hline $\mathrm{Cl}$ & $0,85 a$ & $0,74 a$ & $0,71 a$ & $0,87 a$ & $0,79 a$ & $0,86 a$ \\
\hline $\mathrm{C} 2$ & $0,77 a$ & $0,68 \mathrm{a}$ & $0,69 a$ & $0,64 b$ & $0,78 a$ & $0,68 \mathrm{a}$ \\
\hline C3 & $0,77 a$ & $0,78 \mathrm{a}$ & $0,73 a$ & $0,74 \mathrm{ab}$ & $0,74 a$ & $0,68 \mathrm{a}$ \\
\hline C4 & $0,82 \mathrm{a}$ & $0,79 a$ & $0,72 \mathrm{a}$ & $0,66 b$ & $0,92 \mathrm{a}$ & $-0,76 a$ \\
\hline \multicolumn{7}{|c|}{$\mathrm{CV}=11,00 \%$} \\
\hline M1 & $1,23 a$ & $1,46 a$ & $1,36 a$ & $1,47 a$ & $1,23 a$ & $1,35 \mathrm{a}$ \\
\hline M2 & $1,23 a$ & $1,56 a$ & $1,40 \mathrm{a}$ & $1,35 \mathrm{ab}$ & $1,25 \mathrm{a}$ & $1,36 \mathrm{a}$ \\
\hline M3 & $1,20 a$ & $1,53 a$ & $1,45 a$ & $1,40 \mathrm{ab}$ & $1,21 \mathrm{a}$ & $1,31 \mathrm{a}$ \\
\hline M4 & $1,18 \mathrm{a}$ & $1,40 \mathrm{a}$ & $1,39 a$ & $1,29 b$ & $1,25 a$ & $1,28 \mathrm{a}$ \\
\hline \multicolumn{7}{|l|}{$\mathrm{CV}=5,40 \%$} \\
\hline S1 & $3,35 a$ & $2,87 a$ & $3,00 a$ & $2,78 \mathrm{a}$ & $2,86 a$ & $2,77 \mathrm{a}$ \\
\hline S2 & $3,23 a$ & $2,89 a$ & $3,03 a$ & $2,86 a$ & $2,88 \mathrm{a}$ & $2,92 \mathrm{a}$ \\
\hline S3 & $2,94 b$ & $2,78 a$ & $2,99 a$ & $2,81 \mathrm{a}$ & $2,79 a$ & $2,77 a$ \\
\hline S4 & $3,00 \mathrm{~b}$ & $2,80 \mathrm{a}$ & $2,88 \mathrm{a}$ & $2,84 a$ & $2,86 a$ & $2,76 a$ \\
\hline $\mathrm{CV}=2,97 \%$ & & & & & & \\
\hline
\end{tabular}

$\mathrm{CV}$ - coeficiente de variação

Os resultados constituem médias de três repetições; as médias seguidas pela mesma letra, na vertical, não diferem significativamente pelo teste de Tukey, a $5 \%$

Legenda: C - óleo de canola; $\mathrm{M}$ - óleo de milho; $\mathrm{S}$ - óleo de soja

$1-\mathrm{BHT}+\mathrm{BHA}(200 \mathrm{ppm})$

2 - BHT + BHA (200 ppm) + ácido cítrico (100 ppm)

3 - Ácido cítrico (100 ppm)

4 - Controle

Nos óleos de canola e soja não foram encontradas variações significativas entre os tratamentos para cada tempo de exposição à luz. Para o óleo de canola o aumento do coeficiente de extinção em $232 \mathrm{~nm}$ passou a ser significativo, ou seja diferente do valor inicial, a partir de 72 horas de exposição à luz, enquanto que para o óleo de soja foi a partir de 48 horas.

No óleo de milho foram encontradas variações no coeficiente de extinção em 232 nm entre os tratamentos 1 e 4 após 72 horas de exposição à luz, e entre os tratamentos 2 e 4 após 96 horas. 0 tratamento 4 (controle) apresentou menor coeficiente de extinção médio em $232 \mathrm{~nm}$, diferindo estatisticamente dos tratamentos 1 e 2. Para fim de seleção, a adição de antioxidantes ao óleo de milho também não trouxe beneficios, assim como observado para os outros óleos analisados. 
O coeficiente de extinção em $232 \mathrm{~nm}$ aumentou com o aumento do tempo de exposição à luz, sendo que esse aumento foi menos intenso que o encontrado para o índice de peróxido.

No teste de fotoxidação acelerado o índice de peróxido apresentou valores crescentes em todos os intervalos de 24 horas, sendo acompanhado pelo coeficiente de extinção em $232 \mathrm{~nm}$. A correlação entre o coeficiente de extinção em $232 \mathrm{~nm}$ e o índice de peróxido, nos três óleos adicionados dos tratamentos propostos, pode ser vista nas Figuras 10,11 e 12 .

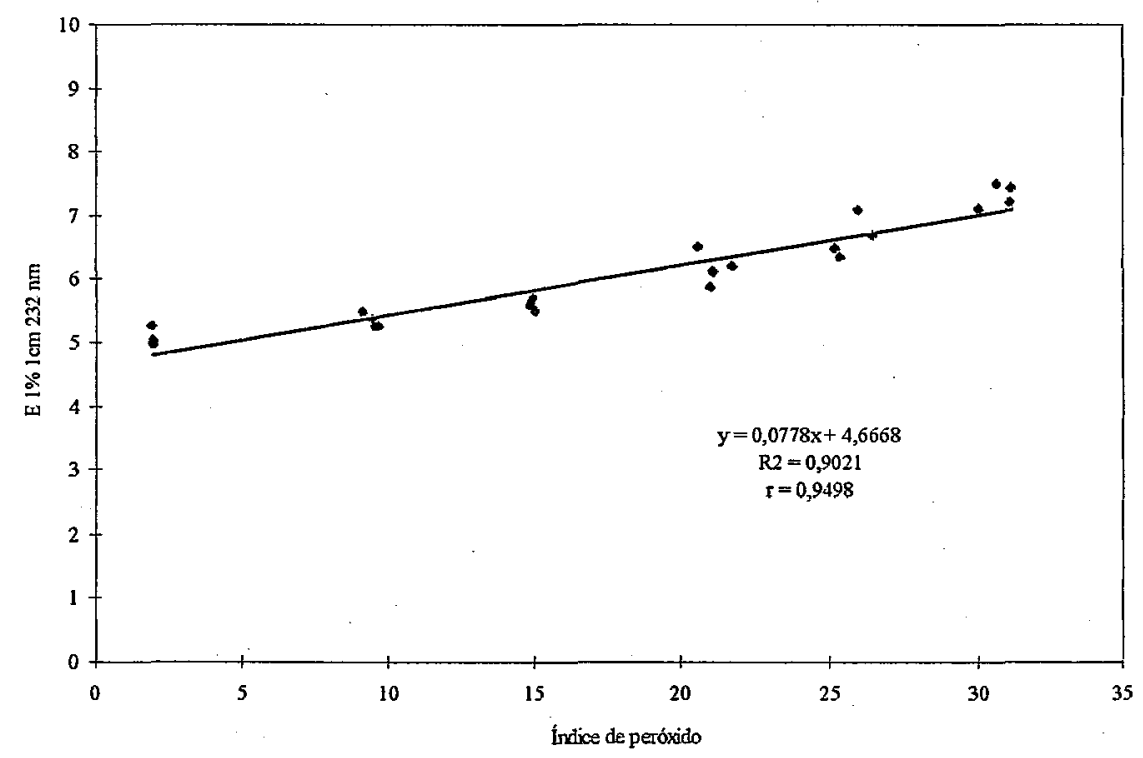

Figura 10 - Correlação entre índice de peróxido e coeficiente de extinção em $232 \mathrm{~nm}$ do óleo de canola sob fotoxidação acelerada. 


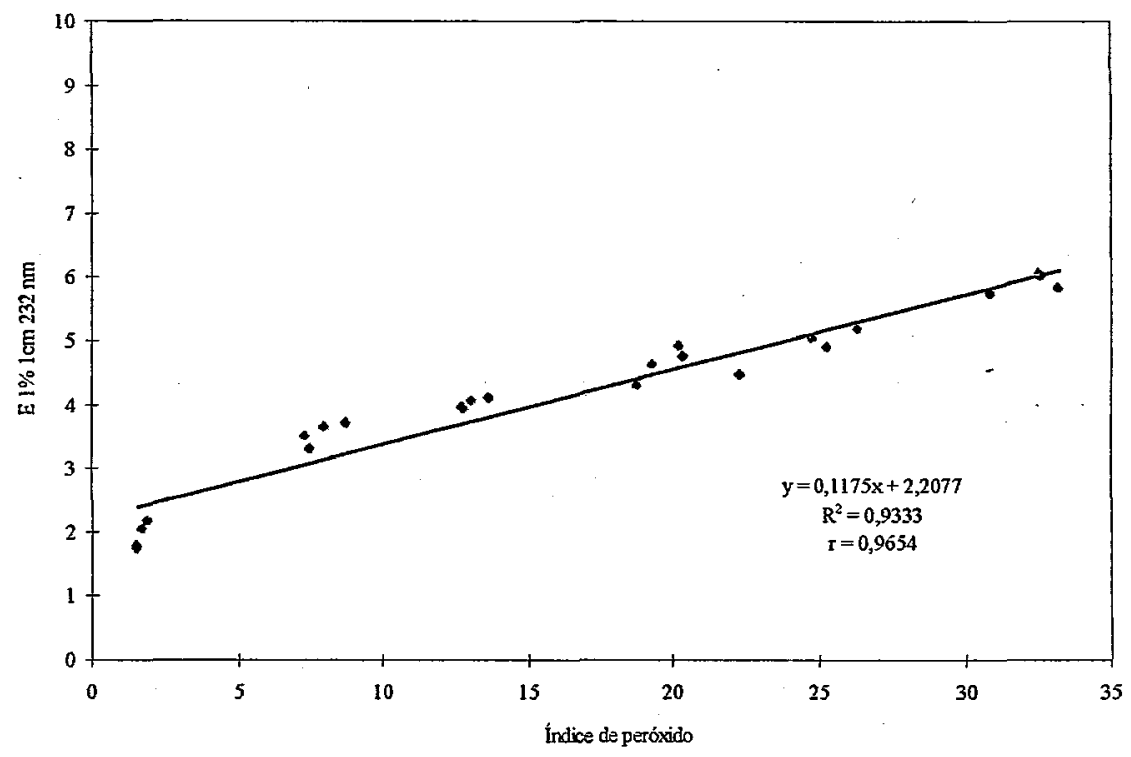

Figura 11 - Correlação entre índice de peróxido e coeficiente de extinção em 232 nm do óleo de milho sob fotoxidação acelerada.

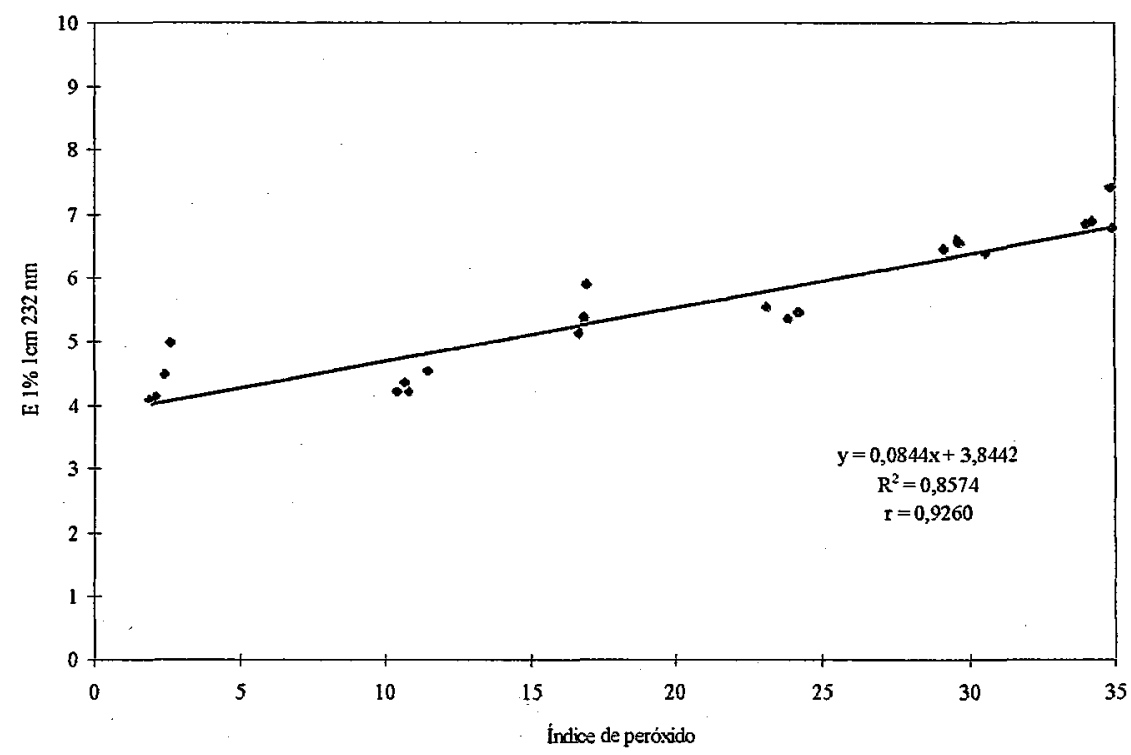

Figura 12 - Correlação entre índice de peróxido e coeficiente de extinção em $232 \mathrm{~nm}$ do óleo de soja sob fotoxidação acelerada. 
De acordo com Shahidi (1995), o aumento da absorção em $232 \mathrm{~nm}$ é proporcional à formação de peróxidos nos estágios iniciais de oxidação.

\subsection{4 Índice de iodo}

Os resultados do índice de iodo dos óleos de canola, milho e soja sob fotoxidação acelerada são representados nas Figuras 13, 14 e 15. Observa-se pelos resultados que, assim como para o armazenamento ambiente, o índice de iodo dos óleos de canola e milho reduziu ao longo de 120 horas de exposição à luz e o do óleo de soja se manteve. Também, como no armazenamento ambiente, não foram encontradas variações significativas entre os tratamentos.

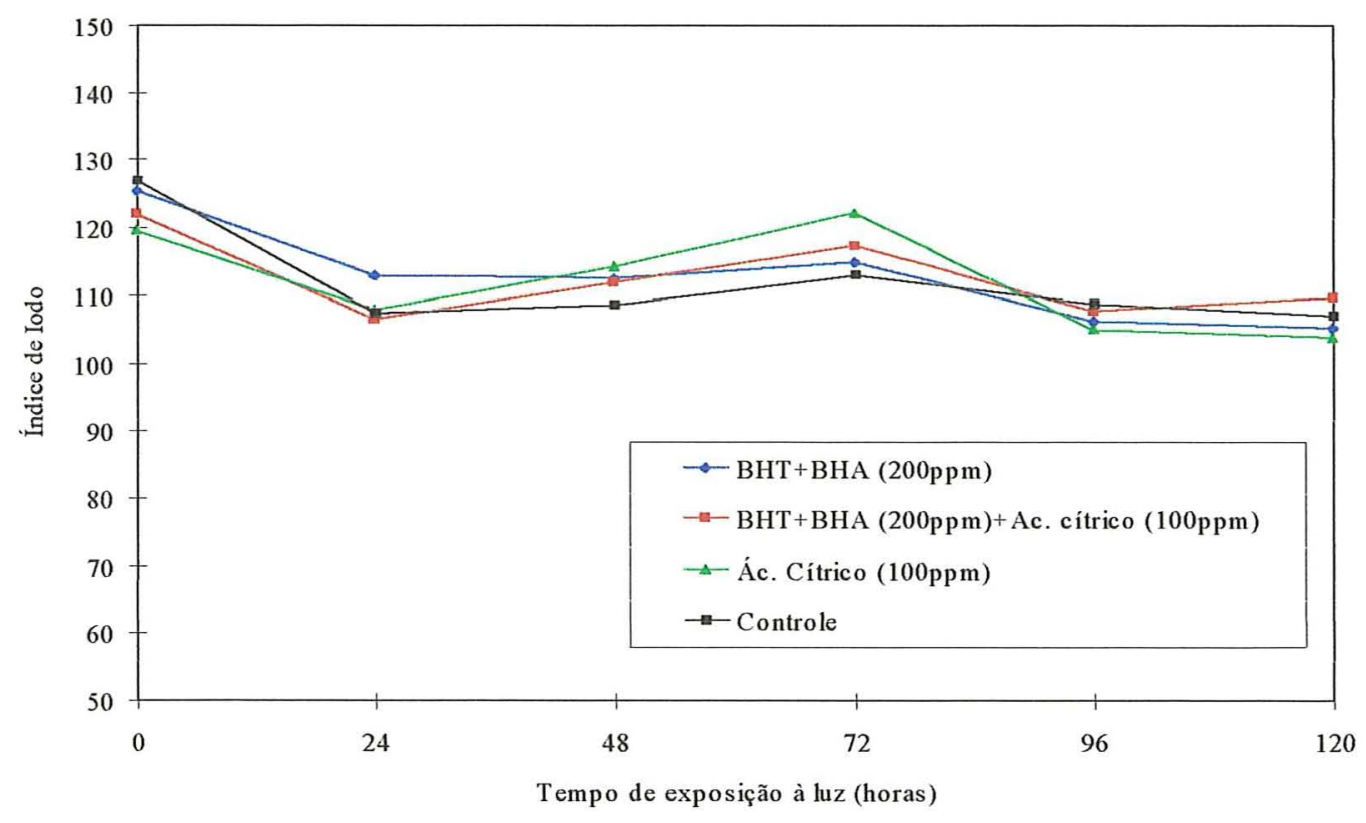

Figura 13 - Índice de iodo (mg de iodo/ $100 \mathrm{mg}$ ) do óleo de canola submetido à fotoxidação acelerada por 120 horas. 


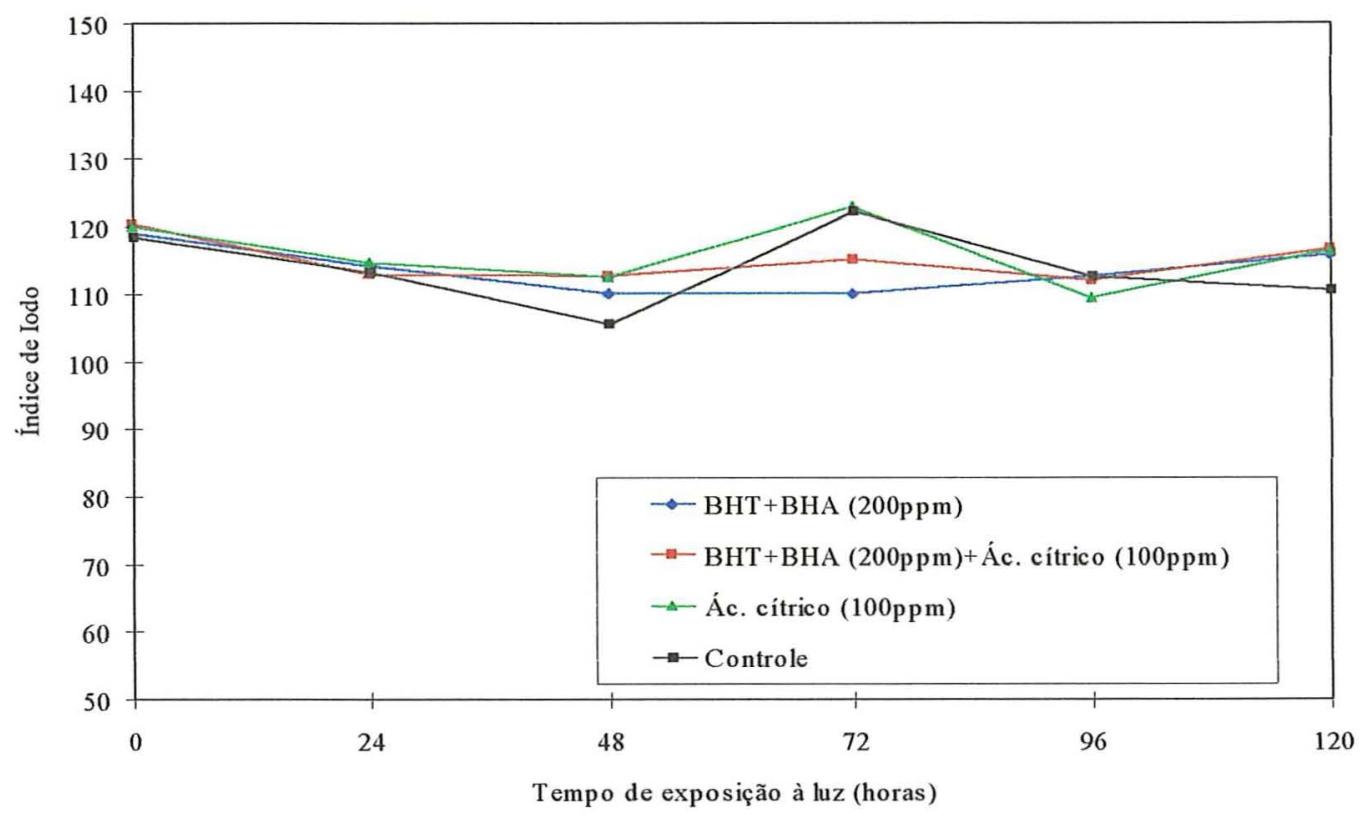

Figura 14 - Índice de iodo (mg de iodo/ $100 \mathrm{mg}$ ) do óleo de milho submetido à fotoxidação acelerada por 120 horas.

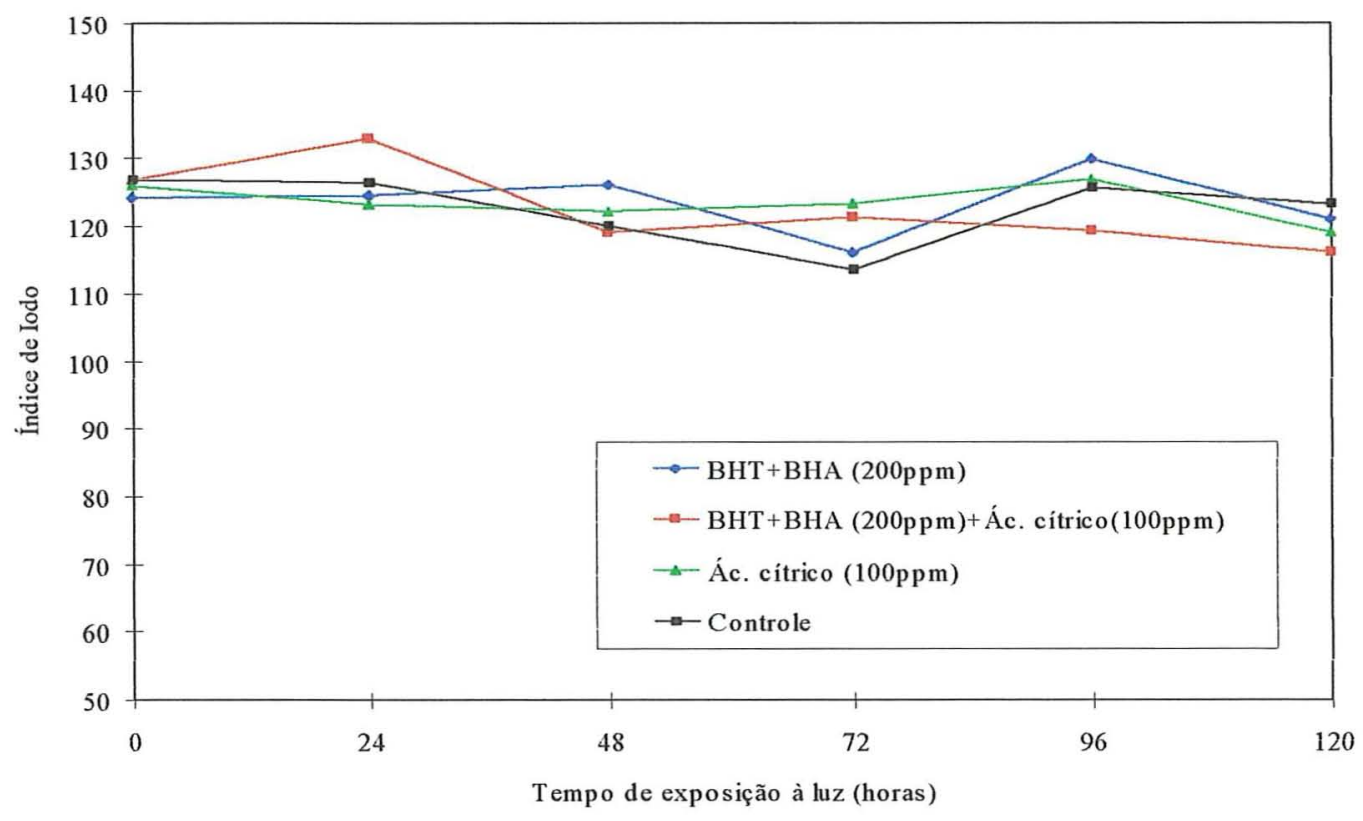

Figura 15 - Índice de iodo (mg de iodo/ $100 \mathrm{mg}$ ) do óleo de soja submetido à fotoxidação acelerada por 120 horas. 


\subsection{Correlação entre armazenamento ambiente e fotoxidação acelerada.}

Dos índices analíticos adotados para acompanhamento dos ensaios de armazenamento ambiente e para o teste acelerado de fotoxidação, o melhor para correlacionar estes ensaios foi o índice de peróxido, pois apresentou aumento tanto no teste acelerado como no armazenamento ambiente. $\mathrm{O}$ valor máximo de peróxidos atingido pelos óleos de canola, milho e soja após 180 dias de armazenamento ambiente esteve entre 3 e 4 . Esses valores foram obtidos após poucas horas de exposição à luz no teste acelerado de fotoxidação. Para verificar a relação existente entre esses dois ensaios foi construído um gráfico correlacionando o tempo de armazenamento ambiente com o tempo de exposição à luz necessário para se atingir um mesmo valor de peróxidos. Foi fixado o valor de $3 \mathrm{meq} \mathrm{de} \mathrm{O}_{2} / \mathrm{kg}$ de óleo e o número de dias e de horas necessários para cada tratamento atingir este valor foi colocado nos eixos de $\mathrm{x}$ e $\mathrm{y}$, respectivamente, para correlacionar o armazenamento ambiente com o teste acelerado de fotoxidação dos óleos de canola, milho e soja nos diferentes tratamentos. Estes valores foram obtidos das curvas de índice de peróxido em função do tempo para todos os tratamentos, tanto sob condições ambientes como na câmara de fotoxidação. Estes dados, colocados em gráfico, forneceram um coeficiente de correlação entre o teste acelerado (TF) e o armazenamento ambiente (TA) de 0,94 (Figura 16). Pode-se observar pela análise do coeficiente de correlação que os tratamentos adotados não apresentaram efeito em retardar a fotoxidação tanto no armazenamento ambiente quanto no teste acelerado, confirmando a boa resposta do índice de peróxido nos dois ensaios. A equação da regressão obtida com esses pontos foi: $\mathrm{TF}=0,0528 \mathrm{TA}-0,4031$. 


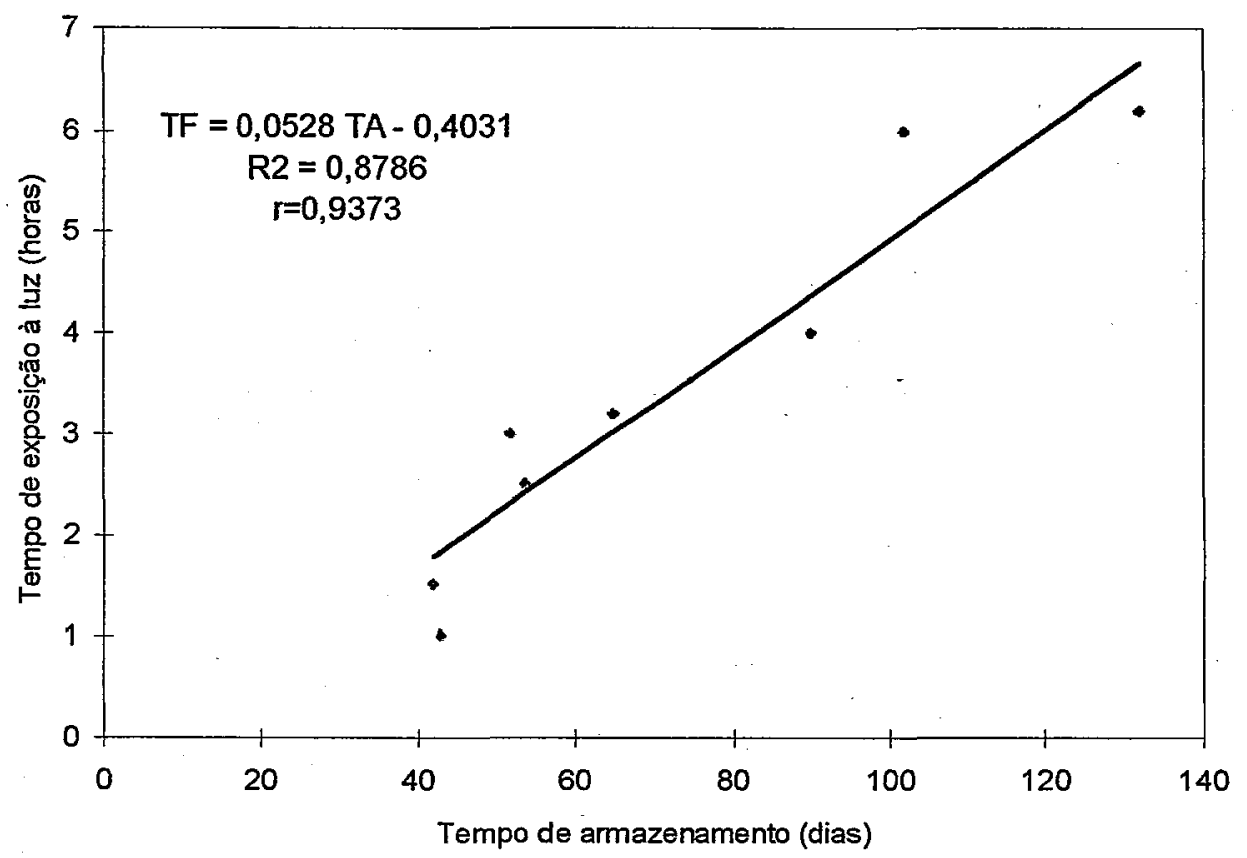

Figura 16 - Correlação entre armazenamento ambiente e teste acelerado de fotoxidação dos óleos de canola, milho e soja adicionados de diferentes antioxidantes.

Através da Figura 16 podem-se observar uma correlação positiva entre o que ocorre na câmara de fotoxidação proposta nesse trabalho com o armazenamento ambiente, ou seja pode-se esperar que diferenças entre os tratamentos que ocorram no armazenamento ambiente se repitam no ensaio acelerado e vice-versa.

Dentre as vantagens da utilização do teste acelerado de fotoxidação pode-se citar o curto intervalo de tempo para a sua aplicação, visto que, de acordo com a equação obtida, 24 horas de exposição à luz na câmara de luz representam o mesmo que 460 dias de armazenamento ambiente para os óleos embalados em embalagens transparentes de PET; outra vantagem seria o controle da fonte de luz, premitindo a melhor comparação entre os resultados obtidos em varios ensaios.

Foram encontrados na literatura vários tipos de cabines de luz para a execução de testes acelerados, seria, no entanto, recomendável que houvesse uma padronização dessas 
cabines, fixando valores de intensidade luminosa e temperaturas para que houvesse uma melhor comparação dos resultados de diferentes pesquisadores.

\subsection{Atividade antioxidante de $\beta$-caroteno, $\alpha$-tocoferol e TBHQ.}

\subsection{1 Índice de acidez}

Os resultados da variação do índice de acidez para os óleos de canola, milho e soja nos diferentes tratamentos pode ser visto na Tabela 19.

Analisando-se os resultados pode-se observar que para o óleo de canola não foram encontradas variações entre os tratamentos testados após 120 horas de exposição à luz. Nesse mesmo período, no óleo de milho, os tratamentos 2 ( 1 ppm de $\beta$-caroteno) e 3 ( $200 \mathrm{ppm}$ de TBHQ) apresentaram diferenças estatísticas com os demais, sendo que estes apresentaram maiores valores. Já para o óleo de soja, após 120 horas de exposição à luz o tratamento 2 ( $1 \mathrm{ppm}$ de $\beta$-caroteno) apresentou diferença estatística significativa com os demais tratamentos, apresentando maiores valores.

Conforme ocorreu com o ensaio 2 não foram encontrados bruscos aumentos no índice de acidez nos óleos vegetais ao longo de 120 horas de exposição à luz. 
Tabela 19. Índice de acidez (mg KOH/ g de óleo) dos óleos de canola, milho e soja adicionados de $\alpha$-tocoferol, $\beta$-caroteno e TBHQ e submetidos à fotoxidação acelerada por 120 horas.

\begin{tabular}{|c|c|c|c|c|c|c|}
\hline \multirow[b]{2}{*}{ Tratamentos } & \multicolumn{6}{|c|}{ Tempo de exposição a luz (horas) } \\
\hline & 0 & 24 & 48 & 72 & 96 & 120 \\
\hline $\mathrm{Cl}$ & $0,08 \mathrm{~b}$ & $0,09 c$ & $0,10 b$ & $0,10 \mathbf{a}$ & $0,10 a$ & $0,11 \mathrm{a}$ \\
\hline $\mathrm{C} 2$ & $0,10 \mathrm{ab}$ & $0,15 a$ & $0,15 a$ & $0,11 \mathrm{a}$ & $0,11 a$ & $0,10 \mathrm{a}$ \\
\hline C3 & $0,11 b$ & $0,11 b$ & $0,10 b$ & $0,10 \mathrm{a}$ & $0,10 \mathrm{a}$ & $0,10 \mathrm{a}$ \\
\hline $\mathrm{C} 4$ & $0,10 \mathrm{ab}$ & $0,10 \mathrm{bc}$ & $0,10 \mathrm{~b}$ & $0,11 \mathrm{a}$ & $0,10 \mathrm{a}$ & $0,11 \mathrm{a}$ \\
\hline \multicolumn{7}{|c|}{$\mathrm{CV}=9,41 \%$} \\
\hline M1 & $0,10 \mathrm{a}$ & $0,15 \mathrm{c}$ & $0,10 b$ & $0,10 \mathrm{~b}$ & $0,10 c$ & $0,10 \mathrm{~b}$ \\
\hline M2 & $0,10 \mathrm{a}$ & $0,19 \mathrm{a}$ & $0,21 a$ & $0,20 \mathrm{a}$ & $0,21 \mathrm{a}$ & $0,16 \mathrm{a}$ \\
\hline M3 & $0,10 \mathbf{a}$ & $0,16 b c$ & $0,10 b$ & $0,10 \mathrm{~b}$ & $0,16 b$ & $0,14 a$ \\
\hline M4 & $0,10 \mathrm{a}$ & $0,19 a$ & $0,10 \mathrm{~b}$ & $0,10 b$ & $0,10 c$ & $0,10 \mathrm{~b}$ \\
\hline \multicolumn{7}{|l|}{$\mathrm{CV}=9,57 \%$} \\
\hline S1 & $0,10 a$ & $0,16 \mathrm{~b}$ & $0,16 a$ & $0,16 b$ & $0,10 b$ & $0,16 a$ \\
\hline $\mathbf{S} 2$ & $0,10 a$ & $0,21 \mathrm{a}$ & $0,15 \mathrm{a}$ & $0,21 a$ & $0,21 a$ & $0,10 \mathrm{~b}$ \\
\hline S3 & $0,10 \mathrm{a}$ & $0,16 b$ & $0,16 a$ & $0,16 b$ & $0,10 b$ & $0,16 a$ \\
\hline S4 & $0,10 \mathrm{a}$ & $0,16 \mathrm{~b}$ & $0,16 a$ & $0,16 b$ & $0,10 b$ & $0,16 a$ \\
\hline$C V=9,70 \%$ & & & & & & \\
\hline
\end{tabular}

Os resultados constituem médias de 3 repetições; as médias seguidas pela mesma letra, na vertical, não diferem significativamente pelo teste de Tukey, a $5 \%$.

Legenda: C - óleo de canola; $\mathrm{M}$ - óleo de milho; S - óleo de soja

$1-\alpha$-Tocoferol (500 ppm)

2 - $\beta$-Caroteno ( $1 \mathrm{ppm})$

3 - TBHQ (200 ppm)

4 - Controle

\subsection{2 Índice de peróxido}

Os resultados da variação do índice de peróxido para os óleos de canola, milho e soja adicionados de $500 \mathrm{ppm}$ de $\alpha$-tocoferol, $1 \mathrm{ppm}$ de $\beta$-caroteno e $200 \mathrm{ppm}$ de TBHQ podem ser vistos nas Figuras 17, 18 e 19. 


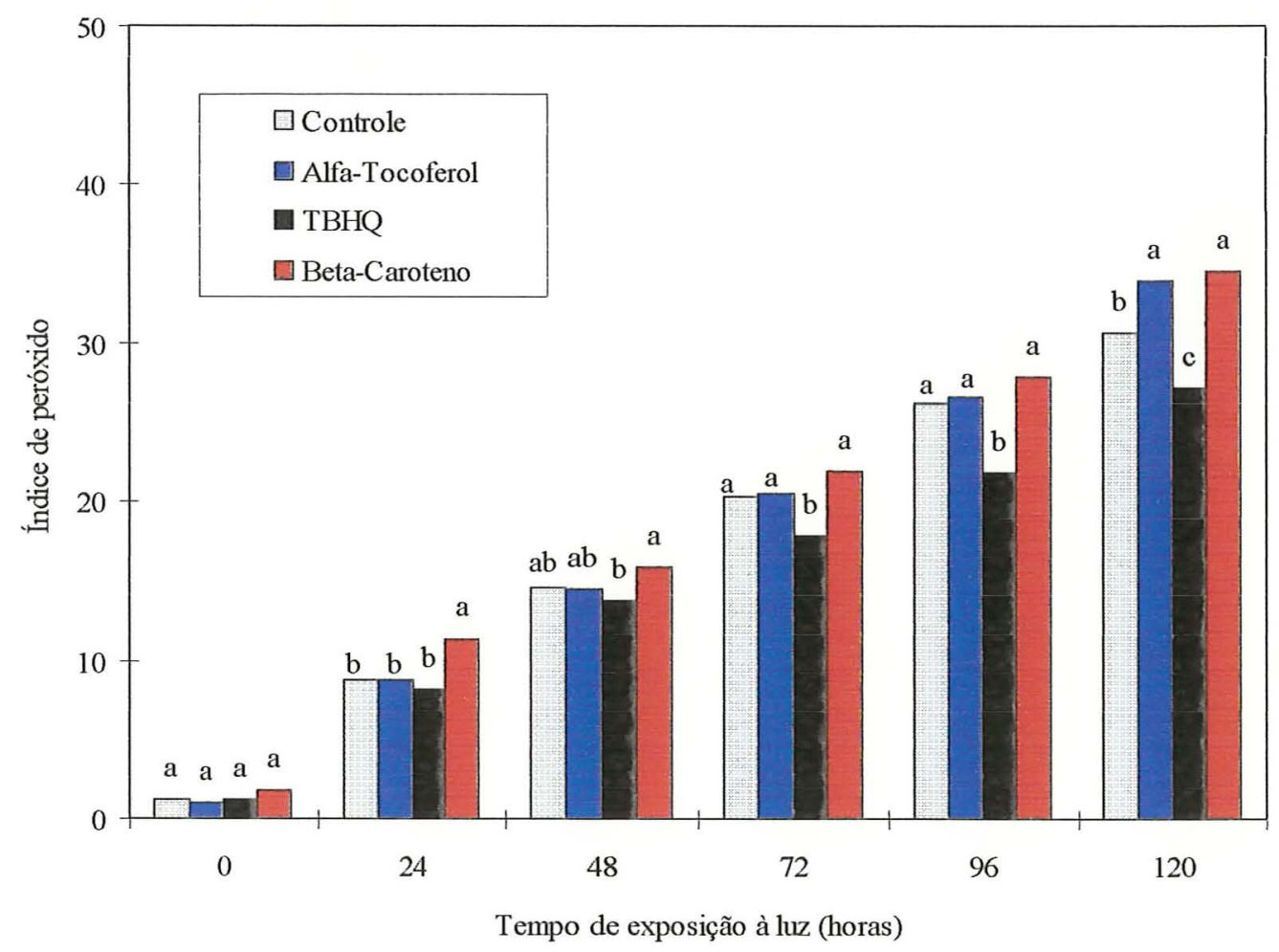

Figura 17 - Variação do índice de peróxido (meq $\mathrm{O}_{2} / \mathrm{kg}$ de óleo) para o óleo de canola adicionado de 500 ppm de $\alpha$-tocoferol, 1 ppm de $\beta$-caroteno e 200 ppm de TBHQ e submetido à fotoxidação acelerada. Os resultados constituem médias de 3 repetições; as médias seguidas pela mesma letra, nos intervalos de tempos, não diferem significativamente pelo teste de Tukey, a 5\%. 


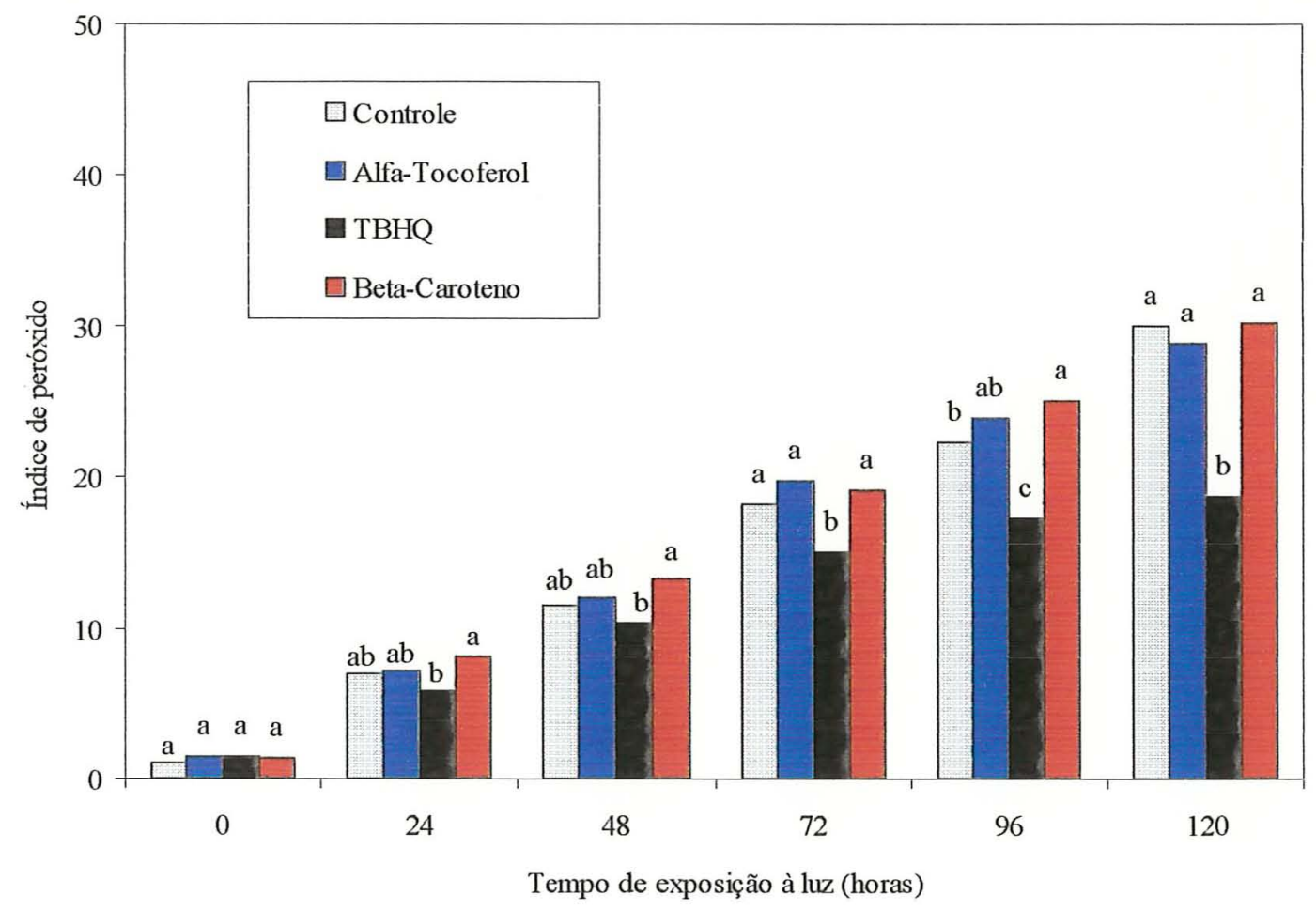

Figura 18 - Variação do índice de peróxido (meq $\mathrm{O}_{2} / \mathrm{kg}$ de óleo) para o óleo de milho adicionado de $500 \mathrm{ppm}$ de $\alpha$-tocoferol, $1 \mathrm{ppm}$ de $\beta$-caroteno e $200 \mathrm{ppm}$ de TBHQ e submetido à fotoxidação acelerada. Os resultados constituem médias de 3 repetições; as médias seguidas pela mesma letra, nos intervalos de tempos, não diferem significativamente pelo teste de Tukey, a 5\%. 


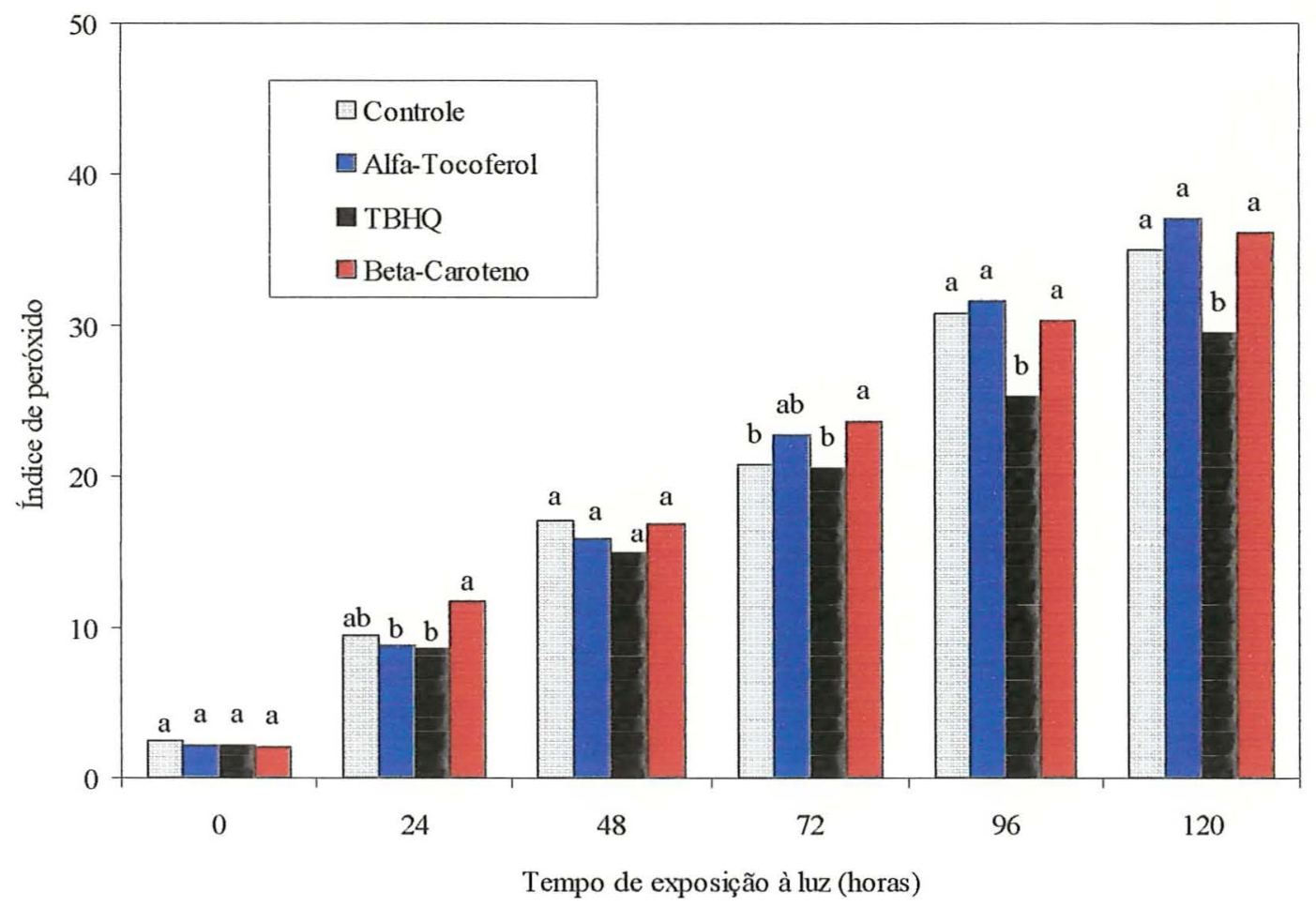

Figura 19 - Variação do índice de peróxido (meq $\mathrm{O}_{2} / \mathrm{kg}$ de óleo) para o óleo de soja adicionado de $500 \mathrm{ppm}$ de $\alpha$-tocoferol, $1 \mathrm{ppm}$ de $\beta$-caroteno e $200 \mathrm{ppm}$ de TBHQ e submetido à fotoxidação acelerada. Os resultados constituem médias de 3 repetições; as médias seguidas pela mesma letra, nos intervalos de tempos, não diferem significativamente pelo teste de Tukey, a 5\%.

O melhor tratamento em todos os óleos foi o 1 (TBHQ 200 ppm), apresentando diferenças estatísticas no índice de peróxido em relação ao controle após 72 horas de exposição a luz para os óleos de canola e milho e após 96 horas para o óleo de soja. Segundo Hawrysh et al. (1989), análises químicas (TBA e índice de peróxido) indicaram que o TBHQ na concentração de $0,02 \%$ (200 ppm) retardou mudanças oxidativas em óleo de canola acondicionado em frascos de vidro e exposto à luz (1400 lux) quando armazenado por 16 semanas. Entretanto esse efeito protetor não foi refletido nas análises de "flavor". A adição do TBHQ também foi efetiva para retardar mudanças oxidativas 
que ocorreram durante o teste de estufa $\left(60^{\circ} \mathrm{C}\right)$ nos óleos de soja e girassol (Sherwin \& Thompson, 1967).

A adição de $\alpha$-tocoferol (500 ppm) não apresentou efeito protetor significativo em nenhum dos óleos após 120 horas de exposição à luz. No entanto após 24 horas de exposição à luz pela análise do índice de peróxido pode-se observar que para o óleo de soja as amostras adicionadas de $\alpha$-tocoferol apresentavam valores menores. Isto sugere que o $\alpha$-tocoferol na concentração usada pode ter algum efeito protetor na fotoxidação do óleo de soja por curto intervalo de exposição à luz. A concentração ótima de tocoferóis para a estabilidade oxidativa do óleo de soja é de 500 - 1000 ppm (Sherwin, 1978).

O tratamento 2 ( $1 \mathrm{ppm}$ de $\beta$-caroteno) apresentou maiores valores para índice de peróxido nos três óleos. Após 24 horas de exposição à luz, a adição de 1 ppm de $\beta$ caroteno teve efeito pró-oxidante noṣ três óleos analisados, apresentando maior valor de peróxido que os demais tratamentos. De acordo com Warner \& Frankel (1987), a deterioração iniciada pela luz em óleo de soja refinado foi eficazmente inibida pela adição de 5 a 10 ppm de $\beta$-caroteno e a adição de $1 \mathrm{ppm}$ apresentou pequeno efeito protetor. Segundo os mesmos autores, adições de 5 ou 10 ppm de $\beta$-caroteno apresentaram alteração na coloração de óleo de soja que passou a ter tonalidade fortemente alaranjada.

\subsubsection{Comparação entre todos os tratamentos testados na fotoxidação acelerada}

Nas Tabelas 20, 21 e 22 podem-se observar os resultados de índice de peróxido dos diferentes tratamentos usados nos ensaios de fotoxidação acelerada em câmara de luz para os óleos de canola, milho e soja. 
Tabela 20. Índice de peróxido (meq $\mathrm{O}_{2} / \mathrm{kg}$ de óleo) do óleo de canola adicionado de diferentes antioxidantes nos dois ensaios de fotoxidação acelerada.

\begin{tabular}{lcccccc}
\hline & \multicolumn{6}{c}{ Tempo de exposição } \\
\cline { 2 - 7 } \multicolumn{1}{c}{ Tratamentos } & 0 & 24 & 48 & 72 & 96 & 120 \\
\hline Controle 1 & $1,21 \mathrm{a}$ & $8,73 \mathrm{~b}$ & $14,55 \mathrm{ab}$ & $20,36 \mathrm{a}$ & $26,16 \mathrm{ab}$ & $30,69 \mathrm{~b}$ \\
$\alpha$-Tocoferol (500 ppm) & $1,03 \mathrm{a}$ & $8,76 \mathrm{~b}$ & $14,43 \mathrm{ab}$ & $20,51 \mathrm{a}$ & $26,59 \mathrm{ab}$ & $33,94 \mathrm{a}$ \\
TBHQ (200 ppm) & $1,23 \mathrm{a}$ & $8,17 \mathrm{~b}$ & $13,76 \mathrm{~b}$ & $17,80 \mathrm{~b}$ & $21,84 \mathrm{c}$ & $27,16 \mathrm{c}$ \\
$\beta$-Caroteno (1 ppm) & $1,83 \mathrm{a}$ & $11,33 \mathrm{a}$ & $15,85 \mathrm{a}$ & $21,88 \mathrm{a}$ & $27,91 \mathrm{a}$ & $34,56 \mathrm{a}$ \\
Controle 2 & $1,98 \mathrm{a}$ & $9,15 \mathrm{~b}$ & $14,91 \mathrm{ab}$ & $21,75 \mathrm{a}$ & $25,96 \mathrm{ab}$ & $30,05 \mathrm{~b}$ \\
BHT + BHA (200 ppm) & $1,95 \mathrm{a}$ & $9,54 \mathrm{ab}$ & $14,89 \mathrm{ab}$ & $20,69 \mathrm{a}$ & $25,41 \mathrm{~b}$ & $30,71 \mathrm{~b}$ \\
BHT + BHA (200 ppm) + Ácido & $1,96 \mathrm{a}$ & $9,69 \mathrm{ab}$ & $15,07 \mathrm{ab}$ & $21,07 \mathrm{a}$ & $25,21 \mathrm{~b}$ & $31,15 \mathrm{~b}$ \\
citrico (100 ppm) & & & & & & \\
Acido Cítrico (100 ppm) & $1,97 \mathrm{a}$ & $9,47 \mathrm{ab}$ & $14,99 \mathrm{ab}$ & $21,15 \mathrm{a}$ & $26,47 \mathrm{ab}$ & $31,17 \mathrm{~b}$ \\
\hline
\end{tabular}

Coeficiente de variação $=4,64 \%$

Os resultados constituem médias de três repetições; as médias seguidas pela mesma letra, na vertical, não diferem significativamente pelo teste de Tukey, a $5 \%$.

Tabela 21. Índice de peróxido (meq $\mathrm{O}_{2} / \mathrm{kg}$ de óleo) do óleo de milho adicionado de diferentes antioxidantes nos dois ensaios de fotoxidação acelerada.

\begin{tabular}{lcccccc}
\hline & \multicolumn{7}{c}{ Tempo de exposição } \\
\cline { 2 - 7 } \multicolumn{1}{c}{ Tratamentos } & 0 & 24 & 48 & 72 & 96 & 120 \\
\hline Controle 1 & $1,02 \mathrm{a}$ & $6,98 \mathrm{a}$ & $11,51 \mathrm{ab}$ & $18,15 \mathrm{bc}$ & $22,29 \mathrm{~b}$ & $29,94 \mathrm{bc}$ \\
$\alpha$-Tocoferol (500 ppm) & $1,43 \mathrm{a}$ & $7,17 \mathrm{a}$ & $12,01 \mathrm{ab}$ & $19,76 \mathrm{ab}$ & $23,92 \mathrm{ab}$ & $28,83 \mathrm{c}$ \\
TBHQ (200 ppm) & $1,39 \mathrm{a}$ & $5,85 \mathrm{a}$ & $10,33 \mathrm{~b}$ & $15,03 \mathrm{c}$ & $17,26 \mathrm{c}$ & $18,70 \mathrm{~d}$ \\
$\beta$-Caroteno (1 ppm) & $1,34 \mathrm{a}$ & $8,16 \mathrm{a}$ & $13,25 \mathrm{ab}$ & $19,13 \mathrm{ab}$ & $25,01 \mathrm{ab}$ & $30,18 \mathrm{abc}$ \\
Controle 2 & $1,53 \mathrm{a}$ & $7,48 \mathrm{a}$ & $12,74 \mathrm{ab}$ & $18,81 \mathrm{ab}$ & $22,28 \mathrm{~b}$ & $33,24 \mathrm{a}$ \\
BHT + BHA (200 ppm) & $1,73 \mathrm{a}$ & $8,76 \mathrm{a}$ & $12,80 \mathrm{ab}$ & $20,28 \mathrm{ab}$ & $24,77 \mathrm{ab}$ & $32,56 \mathrm{ab}$ \\
BHT + BHA (200 ppm)+Ácido & $1,91 \mathrm{a}$ & $7,96 \mathrm{a}$ & $13,64 \mathrm{a}$ & $20,41 \mathrm{a}$ & $26,36 \mathrm{a}$ & $32,59 \mathrm{ab}$ \\
cítrico (100 ppm) & & & & & & \\
Acido Cítrico (100 ppm) & $1,51 \mathrm{a}$ & $7,30 \mathrm{a}$ & $13,08 \mathrm{ab}$ & $19,36 \mathrm{ab}$ & $25,32 \mathrm{ab}$ & $30,87 \mathrm{abc}$ \\
\hline
\end{tabular}

Coeficiente de variação $=8,38 \%$

Os resultados constituem médias de três repetições; as médias seguidas pela mesma letra, na vertical, não diferem significativamente pelo teste de Tukey, a 5\%. 
Tabela 22. Índice de peróxido (meq $\mathrm{O}_{2} / \mathrm{kg}$ de óleo) do óleo de soja adicionado de diferentes antioxidantes nos dois ensaios de fotoxidação acelerada.

\begin{tabular}{lcccccc}
\hline & \multicolumn{7}{c}{ Tempo de exposição } \\
\cline { 2 - 7 } \multicolumn{1}{c}{ Tratamentos } & 0 & 24 & 48 & 72 & 96 & 120 \\
\hline Controle 1 & $2,44 \mathrm{a}$ & $9,42 \mathrm{a}$ & $17,06 \mathrm{a}$ & $20,70 \mathrm{ab}$ & $30,76 \mathrm{a}$ & $35,02 \mathrm{a}$ \\
$\alpha$-Tocoferol (500 ppm) & $2,19 \mathrm{a}$ & $8,68 \mathrm{a}$ & $15,81 \mathrm{a}$ & $22,67 \mathrm{ab}$ & $31,58 \mathrm{a}$ & $37,07 \mathrm{a}$ \\
TBHQ (200 ppm) & $2,20 \mathrm{a}$ & $8,49 \mathrm{a}$ & $14,90 \mathrm{a}$ & $20,56 \mathrm{~b}$ & $25,28 \mathrm{~b}$ & $29,46 \mathrm{~b}$ \\
$\beta$ & $2,06 \mathrm{a}$ & $11,71 \mathrm{a}$ & $16,84 \mathrm{a}$ & $23,58 \mathrm{ab}$ & $30,33 \mathrm{a}$ & $36,11 \mathrm{a}$ \\
C-Caroteno (1 ppm) & $1,92 \mathrm{a}$ & $10,45 \mathrm{a}$ & $16,69 \mathrm{a}$ & $23,09 \mathrm{ab}$ & $29,21 \mathrm{a}$ & $34,96 \mathrm{a}$ \\
Controle 2 & $2,45 \mathrm{a}$ & $11,53 \mathrm{a}$ & $16,95 \mathrm{a}$ & $23,89 \mathrm{ab}$ & $29,66 \mathrm{a}$ & $34,06 \mathrm{a}$ \\
BHT + BHA (200 ppm) & $2,67 \mathrm{a}$ & $10,73 \mathrm{a}$ & $16,91 \mathrm{a}$ & $24,21 \mathrm{a}$ & $29,65 \mathrm{a}$ & $34,92 \mathrm{a}$ \\
BHT + BHA (200 ppm)+Ácido & & & & & & \\
cítrico (100 ppm) & $2,12 \mathrm{a}$ & $10,87 \mathrm{a}$ & $16,98 \mathrm{a}$ & $24,30 \mathrm{a}$ & $30,58 \mathrm{a}$ & $34,27 \mathrm{a}$ \\
\hline Acido Cítrico (100 ppm) & & & & & &
\end{tabular}

Coeficiente de variação $=5,79 \%$

Os resultados constituem médias de três repetições; as médias seguidas pela mesma letra, na vertical, não diferem significativamente pelo teste de Tukey, a 5\%.

Péla análise do índice de peróxido de todos os tratamentos testados o TBHQ (200 ppm) foi o melhor nos três óleos analisados. Observa-se que o TBHQ manteve os valores de peróxido mais baixos em todos os intervalos de 24 horas quando comparados com os demais tratamentos, mas diferenças significativas só foram encontradas a partir de 72 horas de exposição à luz para os óleos de canola e milho e após 96 horas para o óleo de soja. Como já foi dito anteriormente, a adição dos antioxidantes nos tratamentos propostos, excetuando-se o tratamento TBHQ (200 ppm) não apresentou efeito protetor sobre o controle da fotoxidação dos óleos refinados.

Em trabalho realizado por Sherwin \& Thompson (1967) também foram obtidos melhores resultados com a adição de TBHQ na estabilidade oxidativa, realizada em teste de estufa $\left(60^{\circ} \mathrm{C}\right)$, para os óleos de algodão e soja quando comparada com a adição dos antioxidantes BHA, BHT e galato de propila.

\subsubsection{Exame espectrofotométrico sob luz ultravioleta}

As mudanças no coeficiente de extinção em $232 \mathrm{~nm}$ dos óleos de canola, milho e soja adicionados dos tratamentos $500 \mathrm{ppm}$ de $\alpha$-tocoferol, $1 \mathrm{ppm}$ de $\beta$-caroteno e 200 
ppm de TBHQ e submetidos à fotoxidação acelerada são ilustradas nas Figuras 20, 21 e 22.

Observa-se pela análises dos resultados do coeficiente de extinção em 232 nm que houve um aumento desse índice com o aumento do tempo de exposição a luz para todos os tratamentos.

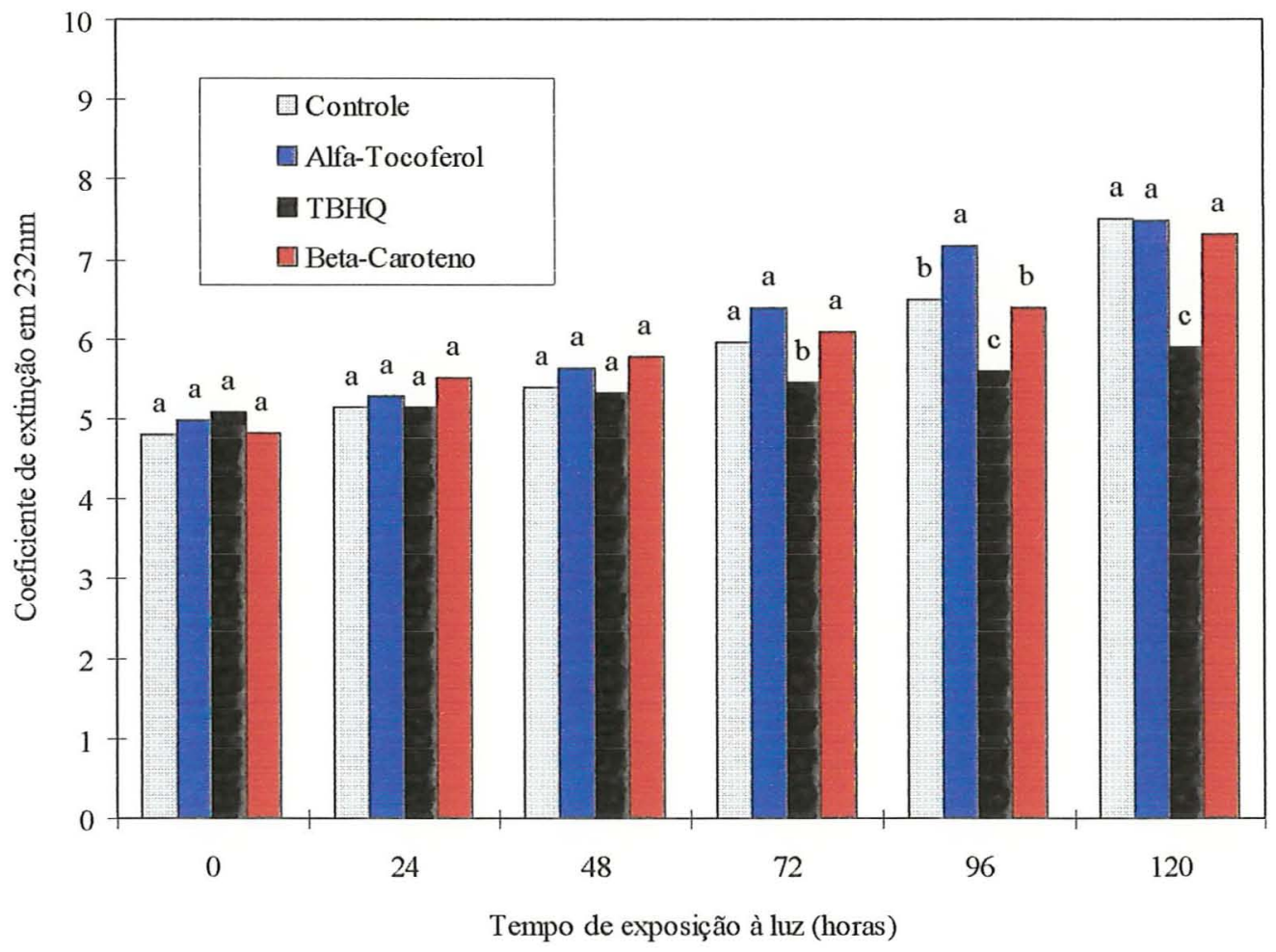

Figura 20 - Variação do coeficiente de extinção em $232 \mathrm{~nm}$ para o óleo de canola adicionado de 500 ppm de $\alpha$-tocoferol, 1 ppm de $\beta$-caroteno e 200 ppm de TBHQ e submetido à fotoxidação acelerada. Os resultados constituem médias de 3 repetições; as médias seguidas pela mesma letra, nos intervalos de tempos, não diferem significativamente pelo teste de Tukey a 5\%. 


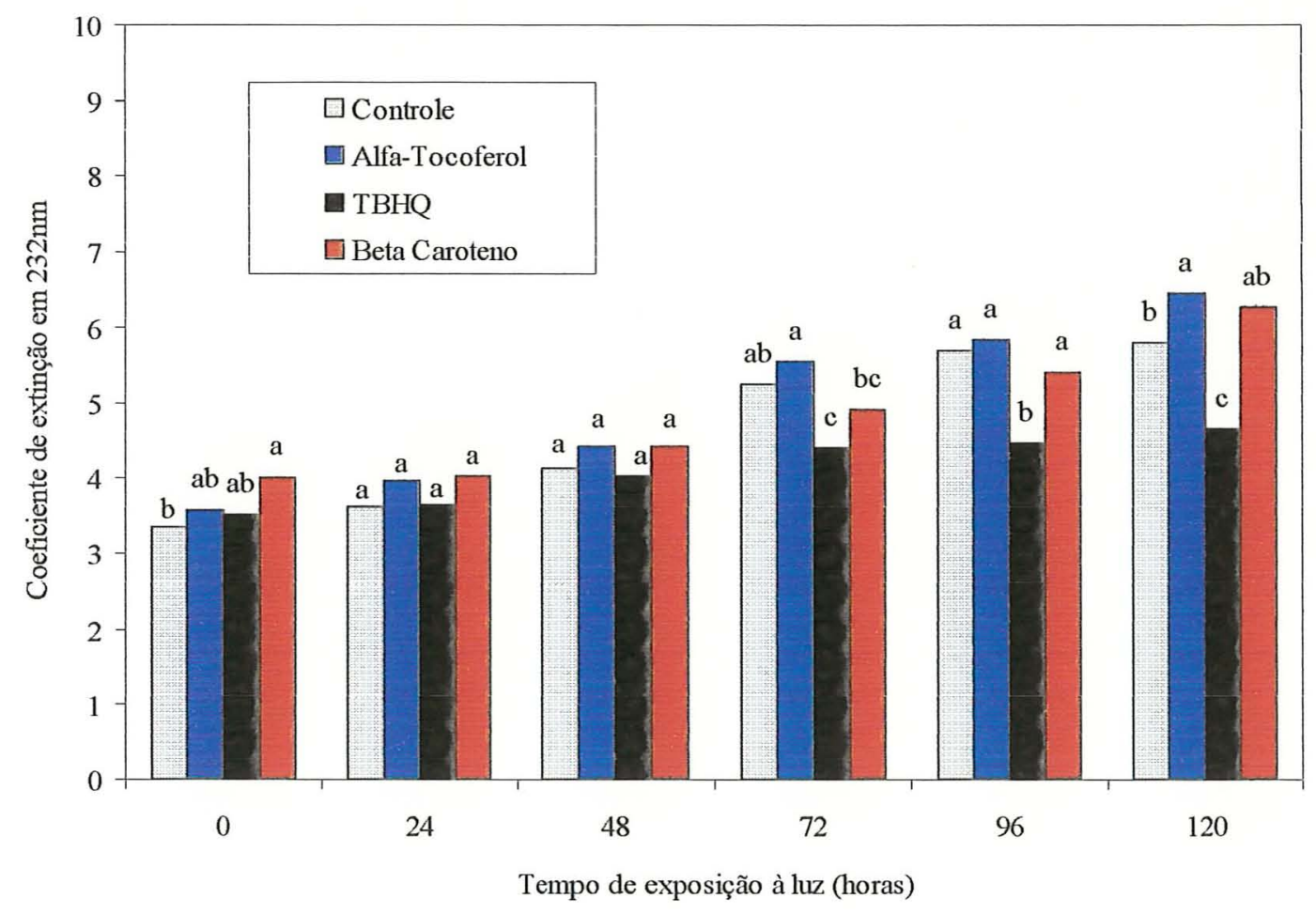

Figura 21 - Variação do coeficiente de extinção em $232 \mathrm{~nm}$ para o óleo de milho adicionado de $500 \mathrm{ppm}$ de $\alpha$-tocoferol, $1 \mathrm{ppm}$ de $\beta$-caroteno e $200 \mathrm{ppm}$ de TBHQ e submetido à fotoxidação acelerada. Os resultados constituem médias de 3 repetições; as médias seguidas pela mesma letra, nos intervalos de tempos, não diferem significativamente pelo teste de Tukey a $5 \%$. 


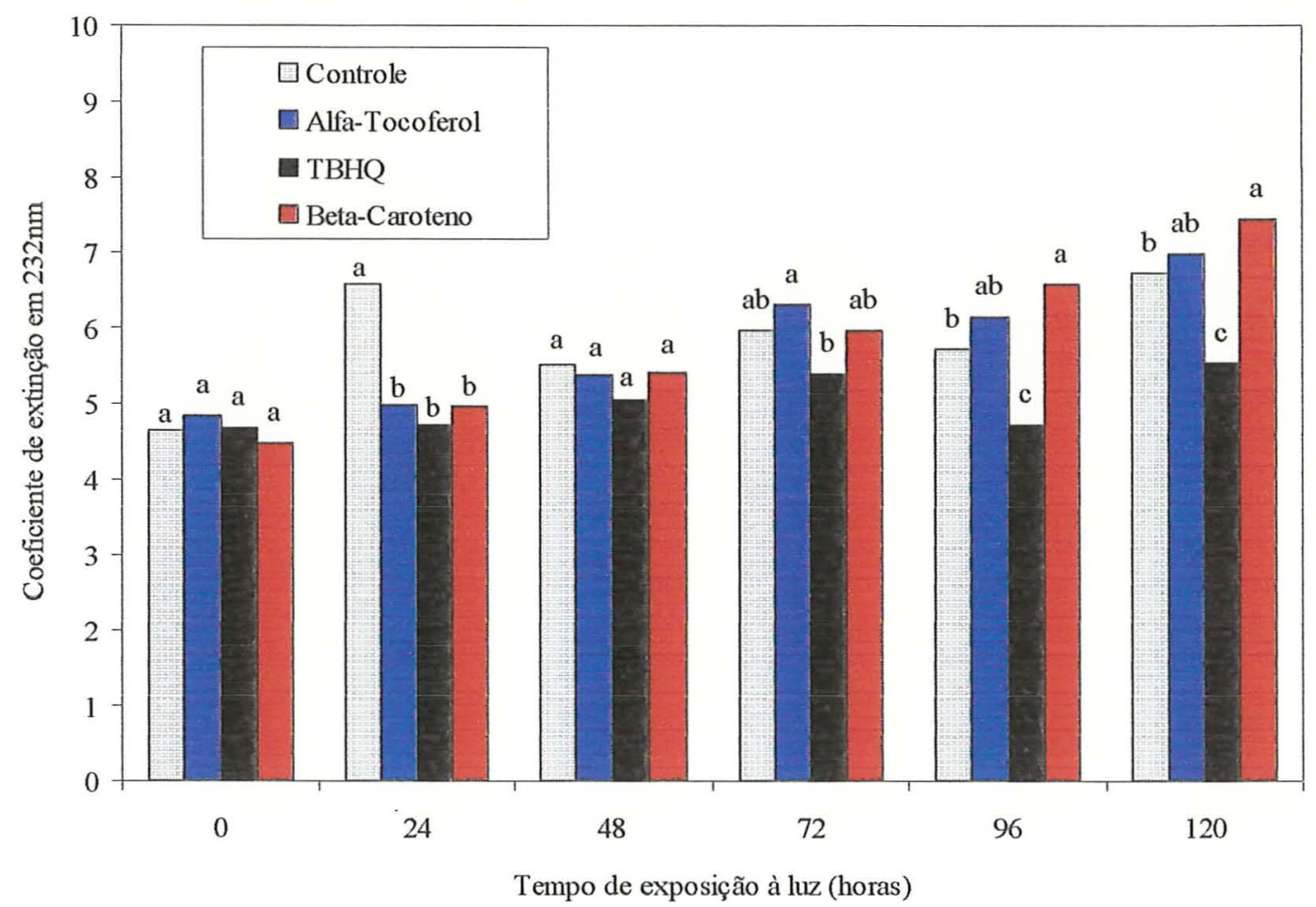

Figura 22 - Variação do coeficiente de extinção em $232 \mathrm{~nm}$ para o óleo de soja adicionado de $500 \mathrm{ppm}$ de $\alpha$-tocoferol, 1 ppm de $\beta$-caroteno e 200 ppm de TBHQ e submetido à fotoxidação acelerada. Os resultados constituem médias de 3 repetições; as médias seguidas pela mesma letra, nos intervalos de tempos, não diferem significativamente pelo teste de Tukey a 5\%.

O melhor tratamento com menores coeficientes de extinção em $232 \mathrm{~nm}$ foi o tratamento 1, assim como para o índice de peróxido. Observou-se também que para os óleos de canola e milho o tratamento 3 ( $\alpha$-tocoferol - $500 \mathrm{ppm}$ ) apresentou as maiores médias, ou seja, apresentando os piores resultados para esse índice.

O coeficiente de correlação encontrado para o índice de peróxido e o coeficiente de extinção em $232 \mathrm{~nm}$ foi 0,9116 para o óleo de canola; 0,9505 para o de milho e 0,774 para o óleo de soja. Nota-se que houve correlação positiva em todos os óleos e que para os óleos de canola e milho foram encontrados valores de coeficiente de correlação (r) 
bem próximos de 1 e para o óleo de soja foi encontrado valor menor. De acordo com Gomes (1960) o valor do coeficiente de correlação quando próximo de 1 será a probabilidade de existir uma relação linear definida entre as variáveis analisadas. Observando-se as Figuras 20, 21 e 22 nota-se que somente no óleo de milho foi encontrada diferença estatística no coeficiente de extinção em $232 \mathrm{~nm}$ na caracterização inicial ( 0 hora de exposição à luz) para a adição do $\beta$-caroteno, que apresentou coeficientes maiores, e o controle. Essa diferença provavelmente ocorreu devido ao óleo de milho refinado apresentar maior concentração de carotenóides que os outros óleos analisados.

Pela análise dos resultados o tratamento 1 foi o que se manteve por mais tempo sem que o coeficiente de extinção em $232 \mathrm{~nm}$ diferisse estatisticamente do valor inicial. Isso sugere que durante a fotoxidação acelerada o TBHQ retardou a oxidação dos óleos por mais tempo, visto que as variações nas concentrações de dienos conjugados (absorbância em $232 \mathrm{~nm}$ ) com o tempo oferecem dados suficientes para o acompanhamento da oxidação na mesma amostra (Gray, 1978).

Pelos dados apresentados na Tabela 23 observa-se que o coeficiente de extinção em $270 \mathrm{~nm}$ não apresentou tendência definida, ou seja não aumentou como era esperado, visto que houve aumento do índice de peróxido e do coeficiente de extinção em $232 \mathrm{~nm}$, indicando oxidação dos óleos. 
Tabela 23. Coeficiente de extinção em $270 \mathrm{~nm}$ dos óleos de canola, milho e soja adicionados de $\alpha$-tocoferol, $\beta$-caroteno e TBHQ e submetidos à fotoxidação acelerada por 120 horas.

\begin{tabular}{|c|c|c|c|c|c|c|}
\hline \multirow[b]{2}{*}{ Tratamentos } & \multicolumn{6}{|c|}{ Tempo de exposição a luz (horas) } \\
\hline & 0 & 24 & 48 & 72 & 96 & 120 \\
\hline $\mathrm{Cl}$ & $0,890 \mathrm{a}$ & $0,781 \mathrm{a}$ & $0,768 a$ & $0,813 a$ & $0,738 \mathrm{ab}$ & $0,719 a$ \\
\hline $\mathrm{C} 2$ & $0,880 a$ & $0,833 a$ & $0,771 a$ & $0,828 \mathrm{a}$ & $0,640 \mathrm{~b}$ & $0,783 a$ \\
\hline C3 & $0,831 a$ & $0,778 \mathrm{a}$ & $0,747 a$ & $0,785 a$ & $0,852 \mathrm{a}$ & $0,739 a$ \\
\hline $\mathrm{C} 4$ & $0,744 a$ & $0,793 a$ & $0,741 \mathrm{a}$ & $0,760 \mathrm{a}$ & $0,763 \mathrm{ab}$ & $0,856 a$ \\
\hline \multicolumn{7}{|l|}{$\mathrm{CV}=10,798 \%$} \\
\hline$\overline{\mathrm{M1}}$ & $1,550 \mathrm{a}$ & $1,373 b$ & $1,572 \mathrm{a}$ & $1,520 \mathrm{a}$ & $1,443 a$ & $1,508 a$ \\
\hline M2 & $1,438 \mathrm{a}$ & $1,637 \mathrm{a}$ & $1,540 \mathrm{a}$ & $1,508 \mathrm{a}$ & $1,406 a$ & $1,515 \mathrm{a}$ \\
\hline M3 & $1,570 \mathrm{a}$ & $1,542 \mathrm{ab}$ & $1,504 a$ & $1,565 a$ & $1,513 a$ & $1,553 \mathrm{a}$ \\
\hline M4 & $1,467 \mathrm{a}$ & $1,497 \mathrm{ab}$ & $1,490 \mathrm{a}$ & $1,679 \mathrm{a}$ & $1,557 \mathrm{a}$ & $1,477 \mathrm{a}$ \\
\hline \multicolumn{7}{|l|}{$\mathrm{CV}=5,375 \%$} \\
\hline$\overline{\mathrm{S} 1}$ & $3,642 a$ & $3,405 b$ & $3,316 a$ & $3,262 \mathrm{a}$ & $3,105 a$ & $3,123 b$ \\
\hline S2 & $3,600 \mathrm{ab}$ & $3,141 b$ & $3,394 a$ & $3,269 a$ & $3,143 a$ & $3,246 a$ \\
\hline S3 & $3,539 \mathrm{ab}$ & $3,449 b$ & $3,313 a$ & $3,345 a$ & $3,146 a$ & $3,126 \mathrm{ab}$ \\
\hline S4 & $3,518 b$ & $3,873 \mathrm{a}$ & $3,364 a$ & $3,261 a$ & $3,054 a$ & $3,122 b$ \\
\hline \multicolumn{7}{|l|}{$\mathrm{CV}=1,667 \%$} \\
\hline \multicolumn{7}{|c|}{$\begin{array}{l}\text { CV - Coeficiente de variação } \\
\text { Os resultados constituem médias de } 3 \text { repetições; as médias seguid } \\
\text { diferem significativamente pelo teste de Tukey, a } 5 \% \text {. } \\
\text { Legenda: } C \text { - óleo de canola; } \mathrm{M} \text { - óleos de milho; } \mathrm{S} \text { - óleo de soja }\end{array}$} \\
\hline
\end{tabular}

\subsubsection{Espectro de absorção dos óleos adicionados de $\beta$-caroteno}

O $\beta$-caroteno é adicionado no processamento de gorduras e óleos para produzir uma coloração amarela, em óleos de saladas é adicionado na concentração de 0,6-1,2 ppm e em óleo de fritura 1,2-3,0 ppm (Warnel \& Frankel, 1987). No presente trabalho a adição de 1 ppm de $\beta$-caroteno apresentou uma acentuada mudança na coloração dos óleos de canola, milho e soja tornando os óleos alaranjados. 
Visando comprovar as mudanças na coloração e consequentemente de absorção de luz dos óleos adicionados de $\beta$-caroteno foi traçado o espectro de absorção dos mesmos na faixa do visível (400 - $700 \mathrm{~nm})$ e comparou-se com o espectro dos óleos não adicionados de antioxidantes. Foi também feito o espectro de absorção das amostras dos três óleos analisados adicionadas de $\beta$-caroteno e expostas à fotoxidação acelerada por 120 horas (Figuras 23, 24 e 25).

O espectro de absorção com a adição de 1 ppm de $\beta$-caroteno, apresentou um aumento na região de absorção do $\beta$-caroteno, 477, 450 e 425 nm (Goodwin, 1954), comprovando a alteração de cor dos óleos, sendo que essa alteração foi semelhante nos três óleos. Ao final de 120 horas de exposição à luz houve uma redução na faixa correspondente ao $\beta$-caroteno, indicando provável degradação do mesmo pela luz.

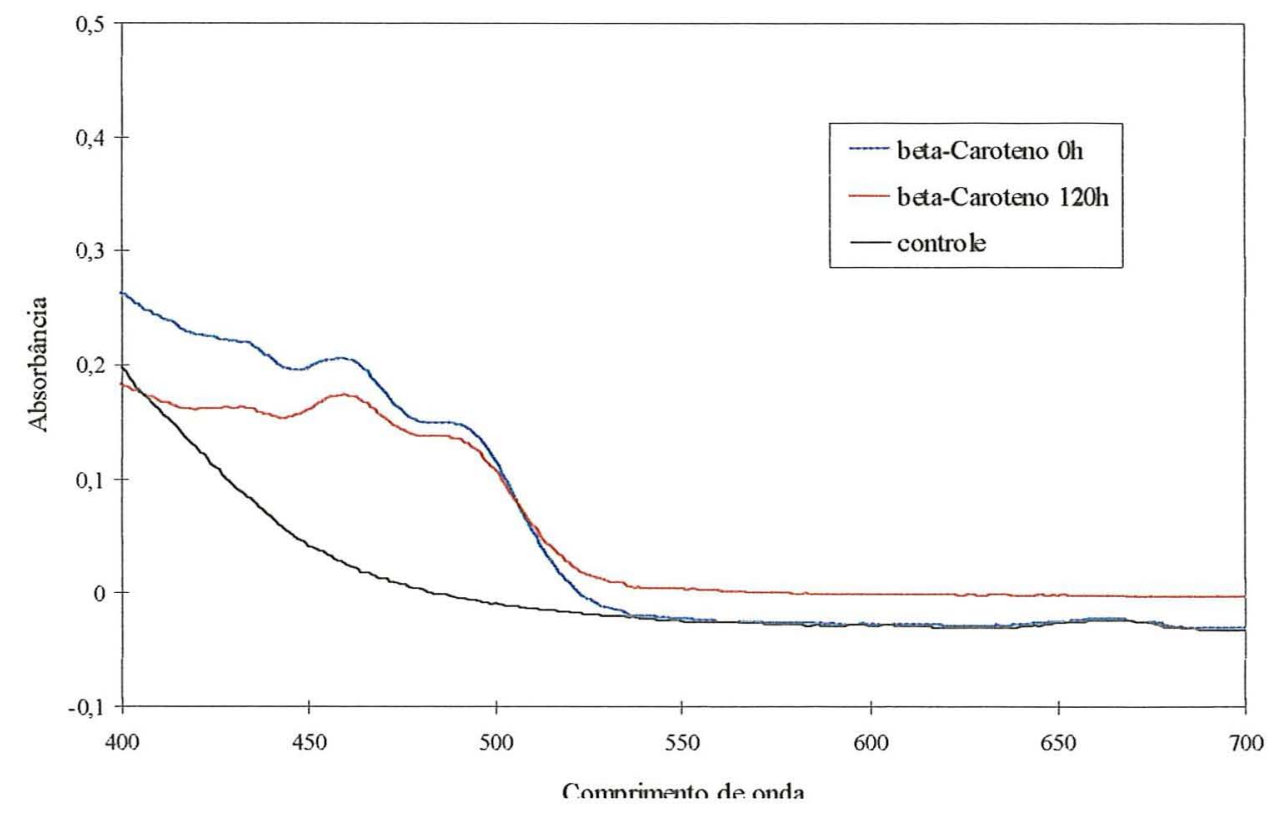

Figura 23 - Absorbância do óleo de canola no espectro visível (400 - $700 \mathrm{~nm}$ ) com e sem a adição de $\beta$-caroteno. 


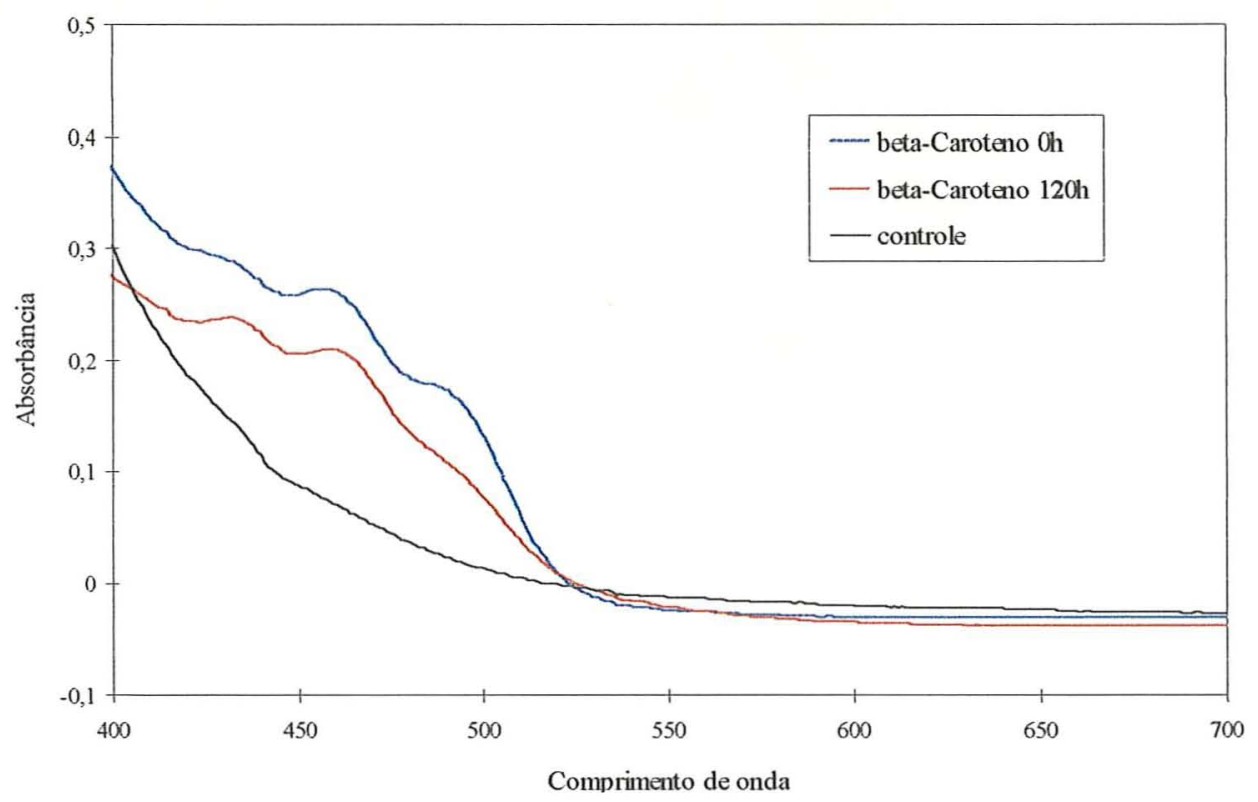

Figura 24 - Absorbância do óleo de milho no espectro visível (400 - 700 nm). com e sem a adição de $\beta$-caroteno.

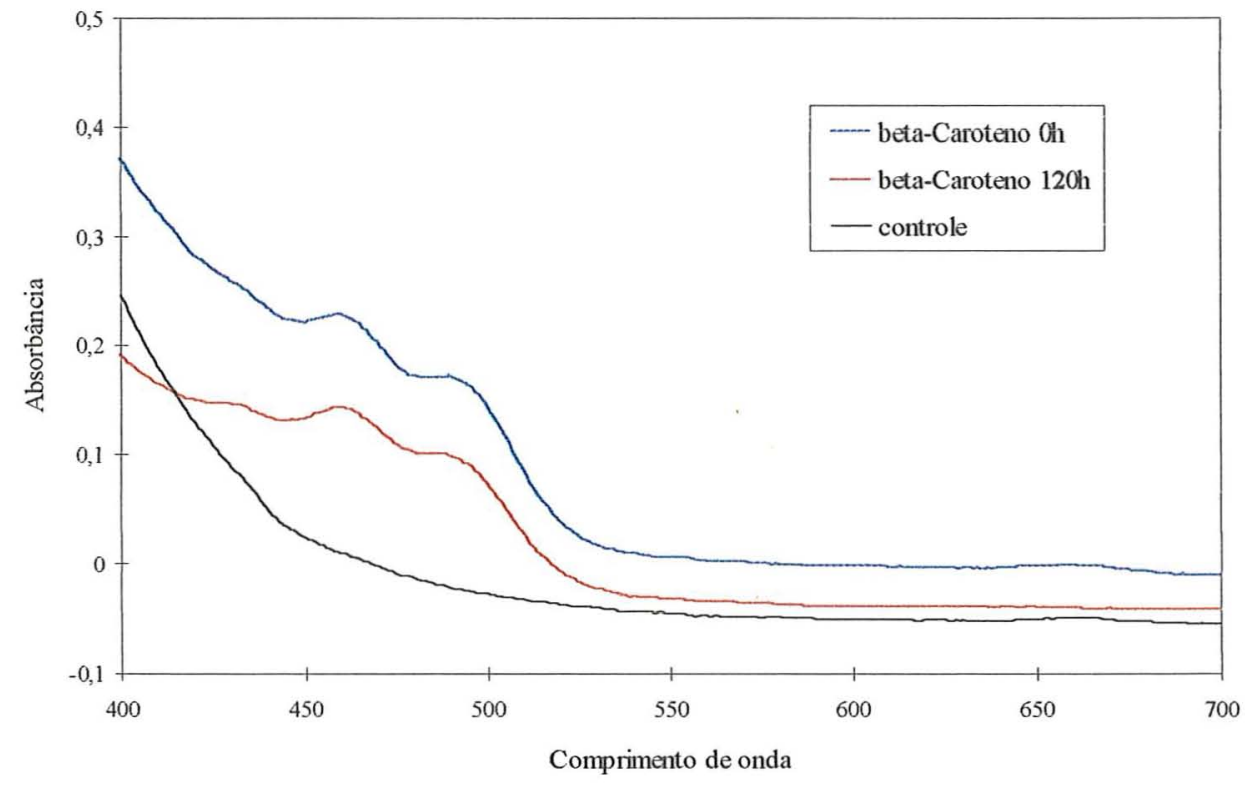

Figura 25 - Absorbância do óleo de soja no espectro visível (400 - $700 \mathrm{~nm}$ ) com e sem a adição de $\beta$-caroteno. 
Alguns pesquisadores afirmaram que os carotenóides atuam como antioxidantes devido à sua susceptibilidade de oxidação (Burton, 1989 e Farag et al., 1989), competindo com os lipídios do sistema oxidativo e tornando-os menos vulneráveis à oxidação. Nesse trabalho verificou-se que a oxidação do $\beta$-caroteno quando adicionado aos óleos contribuiu para aumentar o índice de peróxido, não havendo redução da fotoxidação lipídica como era esperado. 


\section{CONCLUSÕES}

- A utilização do teste acelerado de fotoxidação, nas condições propostas neste trabalho, é viável, encontrando-se correlação positiva com o armazenamento ambiente.

- O antioxidante TBHQ na concentração de $200 \mathrm{ppm}$ foi o melhor tratamento no teste acelarado de fotoxidação quando comparado com os demais tratamentos analisados neste trabalho.

- Os tratamentos $\alpha$-tocoferol (500 ppm) e $\beta$-caroteno (1 ppm) não apresentaram efeito protetor na estabilidade fotoxidativa dos óleos de canola, milho e soja.

- Foi encontrada correlação positiva entre o índice de peróxido e o coeficiente de extinção a $232 \mathrm{~nm}$ para acompanhamento da fotoxidação acelerada dos óleos refinados.

- Os antioxidantes BHA, BHT e ácido cítrico nas concentrações e misturas testadas não apresentaram efeito protetor no armazenamento ambiente. 


\section{REFERÊNCIAS BIBLIOGRÁFICAS}

ALBUQUERQUE, A. J.; ANJOS, C. A. R. PET - Packaging for edible oils. In: INTERNATIONAL MEETING ON FATS \& OILS TECHNOLOGY, Campinas, 1991. Proceedings. Campinas: Unicamp, 1991. p. $138-139$.

ALBI, T; LANZÓN, A.; GUINDA, A.; PÉREZ-CAMINO, M.C.; LEÓN, M. Microwave energy and conventional oven heating effects on edible fats: an study of some physical and chemical parameters. Journal Agricultural and Food Chemistry, v. 45, n.8, p.3000 - 3003, 1997.

ALMEIDA, J.R. Elaiotecnia. Piracicaba: Tip. Journal de Piracicaba, 1950. 451p.

ANTUNES, A.J.; CANHOS, V.P. Antioxidantes. In: ANTUNES, A.J.; CANHOS, V.P. Aditivos em alimentos. São Paulo: Secretaria da Indústria, Ciência e Tecnologia., 1988. cap.5, p.87- 124.

AMERICAN OIL CHEMISTS' SOCIETY. Official and tentative methods. $3^{\text {a }}$ ed. Champaign, AOCS, 1983.

BARRERA-ARELLANO, D. Estabilidade em óleos e gorduras. Óleos e Grãos, n.6, p. $10-13,1993$.

BEKBÖLET, M. Lights effects in food. Journal of Food Protection, v.53, n. 5, p. 430 $-440,1990$. 
BOBBIO, F.O.; BOBBIO, P.A. Pigmentos naturais. In: BOBBIO, F.O.; BOBBIO, P.A. Introdução à química de alimentos. São Paulo: Cargill, 1989. cap. 6, p. $259-305$.

BORGHI, A. B. M. P.; BARRERA-ARELLANO, D. Remoção de clorofila por argilas ativadas. Espuma, n. 71, p. 49 - 52, 1994.

BRASIL. Ministério da Saúde. Comissão Nacional de Normas e Padrões para Alimentos. Resolução $\mathrm{n}^{\circ}$ 22/77 do decreto lei $\mathrm{n}^{\circ} 986$ de 21 de abril de 1969. In: ASSOCIAÇÃO BRASILEIRA DAS INDÚSTRIAS DE ALIMENTAÇÃO. Compêndio da Legislação de Alimentos. São Paulo: ABIA, 1991. v.1A.

BURTON, G. W. Antioxidant action of carotenoids. Journal of Nutrition, v. 119, p. $109-111,1989$.

BURTON, G.W.; INGOLD, K.V. $\quad \beta$-carotene: An usual type of lipid antioxidant. Science, v. 224, n. 5, p. $569-573,1984$.

CABRAL, A.C.D.; MADI,L.F.C.; SOLER, R.G.; ORTIZ, S.A. Embalagens de produtos alimentícios. São Paulo: Secretaria da Indústria, Comércio e Tecnologia, 1982. 338p.

CARLSSON, D. J.; SUPRUNCHUK, T.; WILES, D.M. Photoxidation of unsaturated oils: effects of singlet oxygen quenchers. Journal of the American Oil Chemists' Society, v. 53, n. 10, p. $656-660,1976$.

CHAN, H. W. Photosensitized oxidation of unsaturated fatty acid methyl esters: identification of different pathways. Journal of the American Oil Chemists' Society, v. 54, n. 3, p. $100-103,1977$.

CHEFTEL, J.C. Antioxidants. In: CHEFTEL, J.C Introducion a la bioquimica y tecnologia de los alimentos. Zaragoza: Acriba, 1989. p. 45 - 50. 
CHIPAULT, J.R.. Antioxidants for use in foods. In: CHIPAULT, J.R. Autoxidation and Antioxidants. Minnesota: Lindbergh, 1962. cap. 10, p.477 -542 .

CLEMENTS, A. H.; VAN DEN ENGH, R. H.; FROST, D. J.; HOOGENHOUT, K. Participation of singlet oxygen in photosensitized oxidation of 1,4 - dienoic systems and photooxidation of soybean oil. Journal American Oil Chemists' Society, v. 50, n. 7, p. 325 - 330, 1973.

DAS, N.P.; PEREIRA, T.A. Effects of flavonoids on thermal autooxidation of palm oil: structure-activity relationships. Journal American Oil Chemists' Society, v. 67, n. 4, p. $255-258,1990$.

DORKO, C. Antioxidants used in foods. In: LATIN AMERICAN CONGRESS AND EXHIBIT ON FATS AND OILS PROCESSINGS, 6º , Campinas, 1995. Proceedings. Campinas: Brazilian Society of Oils and Fats, 1995. p.1 - 9.

DZIEZAC, J.D. Preservatives: Antioxidants - the ultimate answer to oxidation. Food Technology, v. 43, n. 7, p. 66 - 74, 1986.

ESPINOZA-ATENCIA, E.J. ; FARIA, J.A.F. Fotoxidação de óleos comestíveis em embalagens plásticas transparentes. Óleos e Grãos, n. 19, p. 44 - 51, 1994.

FAKOURELIS, N.; LEE, E.C.; MIN, D.B. Effects of chlorophyll and $\beta$-carotene on the oxidation stability of olive oil. Journal of Food Science, v. 50, n. 1, p.234 $235,1987$.

FAO. Grasas y aceites comestibles. In: __. Codex Alimentarius. Roma, 1995. cap. 11, p. $1-43$. 
FARAG, R. S.; BADEL, A. Z. M. A.; HEWEDL, F. M. ; EL BAROTY, G. S. A. Antioxidant activity of some spice essential oils on linoleic acid oxidation in aqueous media. Journal American Oil Chemists' Society, v. 66, n. 6, p. 792 $799,1989$.

FARIA, J.A.F. Antioxidantes e estabilidade de óleos comestiveis. Óleos e Grãos, n.20, p $32-34,1994$.

FARIA, J.A.F.; ESPINOZA-ATENCIA, E.J. Efeito da cor das garrafas de policloreto de vinila (PVC) na fotoxidação de óleos de soja. Óleos e Grãos, $n$. 11, p. $40-44,1993$.

FERRARI, R. A. Óleo de milho: composição, processamento e utilização. Espuma, n. 26, p. 41 - 45, 1994.

FRANKEL, E. N.; NEFF, W. E.; SELKE, E.; WEISLEDER, D. Photosensitized oxidation of methyl linoleate: secondary and volatile thermal decomposition products. Lipids, v. 17, n. 1, p. 11 - 18, 1982.

FOOTE, C.S.; DENNY, R.W. Chemistry of singlet oxygen quenching by $\beta$ carotene. Journal American Chemical Society, v. 90, n. 22, p. 6233 - 6235, 1968.

GAVA, A.J. Métodos de conservação de alimentos - Antioxidantes. In: GAVA, A.J. Princípios de tecnologia de alimentos. Rio de Janeiro, 1978. cap.5., p. $54-63$.

GOMES, F. P. Curso de estatística experimental. São Paulo: NOBEL, 1960. $229 \mathrm{p}$. 
GOODWIN, T. W. Carotenoids in land plants. In: GOODWIN, T. W. Carotenoids their comparative biochemistry, New York: Chemical Publishing, 1954. cap. 2, p. $6-62$.

GRAEF, G.L., FEHR, W.R. , HAMMOND, E.G. Inheritance of three stearic acid mutants of soybean. Crop Science, n. 25, p. $1076-$ 1077, 1985.

GRAY, J.L. Mensurement of lipid oxidation: A review. Journal American Oil Chemists' Society, v. 55, n.6, p. 539 - 546, 1978.

GUINONES, J. P. Antioxidantes usados em alimentos. Óleos e Grãos, n. 22, p. 39 $-42,1995$

GUNSTONE , F.D.; NORRIS, F.A. Lipids in food chemistry, biochemistry and technology. Oxford: Pergamon Press, 1983. 170p.

GUNSTONE, F. D. Reaction of oxygen and unsaturated fatty acids. Journal American Oil Chemists' Society, v. 61, n. 2, p. 441 - 447, 1984.

GUNSTONE, F. D. Chemical properties In: GUNSTONE, F. D.; HARWOOD, J. L.; PADLEY, F. B.(Ed) The lipid handbook. London: Chapman \& Hall, 1994. cap. 10 , p. $561-603$.

GUTIERREZ, E. M. R.; REGITANO - D'ARCE, M. A. B.; RAUEN-MIGUEL, A. M. O. Estabilidade oxidativa de óleo bruto de castanha-do-Pará. Ciência e Tecnologia de Alimentos, v. 17, n.1, p. 22 - 27, 1997.

HAWRYSH, Z. J.; SHAND, P.J.; TOKARSKA, B.; LIN, C. Effects of tertiary butylhidroquinone on storage stability of canola oil. II. Pratical Storage. Canadian Institute of Food Science and Technology Journal, v. 22, n. 1, p. $40-45,1989$. 
INTERNATIONAL UNION OF PURE AND APPLIED CHEMISTRY. Standard methods for the analysis of oils, fats and derivatives. $6^{\text {a }}$ ed. Oxford, IUPAC, 1979.p. 71.

JNG, M.Y.; CHOE, E.; MIN, D.B. $\alpha$-, $\gamma$ - and $\delta$-tocopherol effects on chlorophyll photosensitized oxidation of soybean oil. Journal of Food Science, v. 56, n. 3 , p. $807-815,1991$.

JUNG, M.Y.; MIN,D.B. Effects of $\alpha-, \gamma-$, and $\delta$ - tocopherols on oxidative stability of soybean oil. Journal of Food Science, v. 55, n. 5, p. 1464 - 1465, 1990.

JUNG, M.Y.; MIN,D.B. Effects of quenching mechanisms of carotenoids on the photosensitized oxidation of soybean oil. Journal American Oil Chemists' Society, Champaign, v. 68, n. 9, p. $653-657,1991$.

KAYA, A.; TEKIN, A. R.; ONER, M. D. Oxidative stability of sunflower and olive oils: comparison between a modified active oxygen method a long term storage. Lebensmittel - Wissenschaft \& Technologie, v. 26, n.5, p.464 - 468, 1993

KIRITSAKIS, A.; DUGAN, L.R. Studies in photooxidation of olive oil. Journal American Oil Chemists' Society, v. 62, n. 5, p. 892 - 896, 1985.

KORICKA-DAHL, M. B.; RICHARDSON, T. Activated oxygen species and oxidation of food constituents. Critical Reviews in Food Science and Nutrition, v. 10, n. 3, p. $209-238,1978$.

KRINSKY, N. I. Antioxidant functions of carotenoids - A Review. Free Radical Biology \& Medicine, v. 7, n.6, p.617 - 635, 1989.

KURECHI, T.; KATO, T. Studies on the antioxidants: XI. Oxidation products of concomitantly used butylated hidroxyanisole and butylated hidroxytoluene Journal American Oil Chemists' Society, v. 57, n. 7 , p. 220 - 223, 1980. 
LEE, E.C.; MIN, D.B. Quenching mechanism of $\beta$-carotene on the chlorophyll sensitized photooxidation of soybean oil. Journal of Food Science, v. 53, n. 6, p. $1894-1895,1988$.

LEIBOVITZ, Z.; RUCKENSTEIN, H.L.S. Our experiences in processing maize (corn) germ oil. Journal American Oil Chemists' Society, v. 60, n. 2, p. 395 399,1983

LUGASI, A.; HOVÁRI, J.; DWORSCHÁK, E.; NESSZLÉNYI, K.; LEBOVICS,V.; ZSINKA, Á.J.N. Effect of UV irradiation on lipid peroxidation in edible fats. Acta Alimentaria, v. 24, n. 3, p. 269 - 276, 1995.

MAG, T.K. Canola oil processing in Canada. Journal American Oil Chemists' Society, v. 60, n. 2, p. $380-384,1983$.

MERCADO DE EMBALAGENS PARA ÓLEOS COMESTÍVEIS. Óleos e Grãos, n. 29, p. $18-25,1996$.

MOZER, A.H.; EVANS, C.D.; COWAN, J.C.; KWOLEK, W.F. A light test to measure stability of edible oils. Journal American Oil Chemists' Society, v. 42, n. 1, p. $30-33,1965$.

MORRISON, W. H.; LYON, B. G.; ROBERTSON, J. A. Correlation of gas liquid chromatographic volatiles with flavor intensity scores of stored sunflower oils. Journal American Oil Chemists' Society, v. 58, n. 1, p. 23 - 33, 1981.

MULLER-MULOT, W. Rapid method for the quantitative determination of individual tocopherols in oils and fats Journal American Oil Chemists' Society, v. 53, n. 12, p.732 - 736, 1976.

NAWAR, W. W. Lipids. In: FENNEMA, O. R. Food Chemistry. 2 ed. New York, Marcel Dekker, 1985. p.139 - 244. 
NEUMANN, M.M.; FUSERO, S.N.; GARCIA, N.A. A comparative study on the susceptibilities of soybean, sunflower and peanut oils to singlet molecular oxygen photooxidation. Journal of the American Oil Chemists' Society, v. 68, n. 9, p. $662-665,1991$.

OMURA, K. Antioxidant synergism between butylated hydrxyanisole and butylated hydroxytoluene. Journal American Oil Chemists' Society, v. 72, n. 12, p. $1565-1570,1995$.

PADLEY, F. B.; GUNSTONE, F. D.; HARWOOD, J. L. Occurrence and characteristics of oils and fats. In: GUNSTONE, F. D.; HARWOOD, J. L.; PADLEY, F. B.(Ed) The lipid handbook. London: Chapman \& Hall, 1994. cap. 3, p. $47-223$.

PATTERSON, H. B. W. Safeguarding quality and yield. In: PATTERSON, H. B. W. Handling and storage of oilseeds, oils, fats and meal. New York, Elsevier Science Publishing, 1989. cap1, p. 1 - 86.

PRITCHEET, W. C.; TAYLOR, W. G.; CARRAOL, D. M. Chorophyll removal during earth bleaching of soybean oil. Journal American Oil Chemists' Society, v. 24, n. 6, p. $225-227,1947$.

RAWL, H. R.; VANSANTEN, P. J. Apossible role for singlet oxidation in the iniciation of fatty acid autoxidation. Journal American Oil Chemists' Society, v. 47, n.3, p. $121-124,1970$.

ROBARDS, K.; KERR, A. F.; PATSALIDES, E. Rancidity and its mensurement in edible oils and snack foods: A review. Analyst, v. 2, n. 113, p. 216 - 224, 1988.

RODGERS, M.A.J.; BATES, A.L. Kinetic and spectroscopic features of some carotenoid triplet states: sensitization by singlet oxygen. Photochemistry Photobiology, v. 31, p. 533 - 537, 1980. 
SATTAR, A.; DEMAN, J.M. Photooxidation of milk and milk products: A review. Critical Reviews in Food Science and Nutrition, v. 8, n. 13, p. 13 - 37, 1975.

SATTAR, A.; DEMAN, J.M Stability of edible oils and fats to fluorescent light irradiation. Journal American Oil Chemists' Society, v. 53, n. 7, p. 473 - 477, 1976.

SCHAICH, K. M. Free radical initiation in proteins and amino acids by ionizing and ultraviolet raditions and lipid oxidation - Part III: Free radical transfer from oxidizing lipids. Critical Reviews in Food Science and Nutrition, v. 13, n. 3 , p. $189-244,1980$.

SHAHIDI, F.; WANASUNDARA, P.K.J.P.D. Phenolic antioxidants. Critical Reviews in Food Science and Nutrition, v. 32, n. 1, p. 67 - 103, 1992.

SHAHIDI, F. Stability of fats and oils. In: LATIN AMERICAN CONGRESS AND EXHIBIT ON FATS AND OILS PROCESSING, 6oㅜ Campinas, 1995. Proceedings. Campinas: Brazilian Society of Oils and Fats, 1995. p.47 - 54.

SHAUM, D.; VAN DER WERVW, C. Optica. In: SHAUM, D.; VAN DER WERVW, C Física Geral. Editora Mac-Graw- Hill do Brasil, 1973. p.322 357.

SHERWIN, E. R. Antioxidants for food fats and oils. Journal American Oil Chemists' Society, v. 49, n. 8, p. $468-472,1972$.

SHERWIN, E.R. Oxidation and antioxidants in fat and oil processing Journal American Oil Chemists' Society, v. 55, n. 11, p. 809 - 814, 1978.

SHERWIN, E. R.; THOMPSON, J. W. Tertiary-butylhydroquinone - An antioxidant for fats and oils and fat-containing foods. Food Technology, v. 21, n. 6, p. 106 - 110, 1967. 
SIMIC, M. G; JOVANOVIC, S. V.; NIKI, E. Mechanisms of lipid oxidative processes and their inhibition. In: ST. ANGELO, A. J. Lipid oxidation in food. New York, 1992.

SOLER, R. M.; FARIA, E. V.; GUEDES, L. B.; ANJOS, V. D. A.; DANTAS, S. T.; PADULA, M.; TANGO, J. S.; CAMPOS, S. D. S. Embalagens alternativas para óleo de soja. Coletânea do Instituto de Tecnologia de Alimentos, Campinas, v. 16, p. $202-227,1986$.

ST. ANGELO, A. J. Lipid oxidation in foods. Critical Reviews in Food Science and Nutrition, v. 36, n. 3, p. 175 - 224, 1996.

STUCKEY, B., N. Antioxidants as food stabilizers. In: FURIA, T., E. Handbook of food additives. Flórida: Boca Raton, 1983. cap. , p. 185 - 224.

TERAO, J. Antioxidant activity of $\beta$-carotene - Related carotenoids in solution. Lipids, v. 24, n. 7, p. 659 - 661, 1989.

TKACHUK, R., MELLISH, V. J.; DAUN, J. K.; MACRI, L. J. Determination of chlorophyll in ground rapeseed using a modified near infrared reflectance spectrophotometer. Journal American Oil Chemists' Society, v. 65, n. 3, p. $381-385,1988$.

USUKI, R.; ENDO, Y.; KANEDA, T. Prooxidant activities of chlorophylls and pheophytins on the photooxidation of edible oils. Agricultural and Biological Chemistry, v. 48, n. 4, p. 991 - 994, 1984a.

USUKI, R.; SUZUKI, T.; ENDO, Y.; KANEDA, T. Residual amounts of chlorophylls and pheophytins in refined edible oils. Journal American Oil Chemists' Society, v. 61, n. 4, p. 785 - 788, 1984b. 
WARNER, K.; FRANKEL, E.N. Effects of $\beta$-carotene on light stability of soybean oil. Journal American Oil Chemists' Society, v. 64, n. , p. 213 - 218, 1987.

WEIGEL, R.G. Luminotecnia sus principios y aplicaciones. Editora Gustavo Gili S.A., Barcelona, 1952.

ZONTA, E. P.; MACHADO, A. A. SANEST 2: Sistema de Análise Estatística para Conputadores. Piracicaba: SEI, 1992 (softer). 